


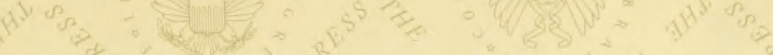

100

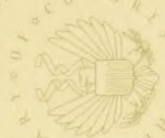

$0^{\prime}$

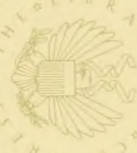

to
100

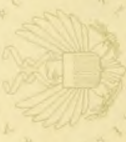

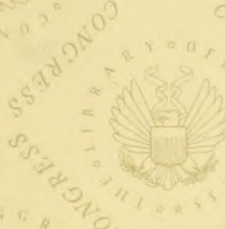
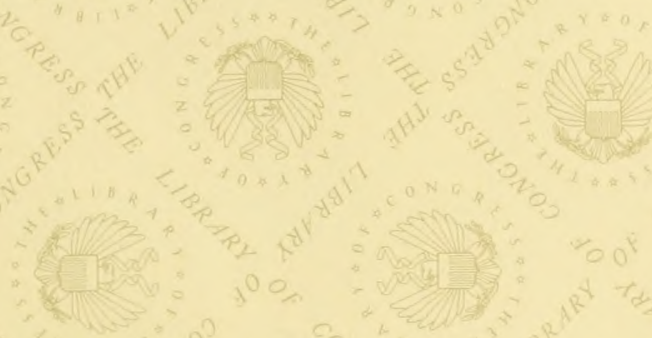

100

100

(2) 12

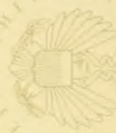

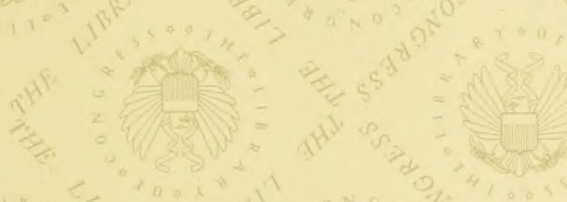

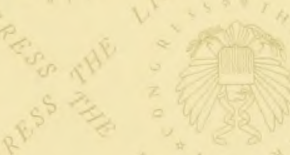

and 20

(3)
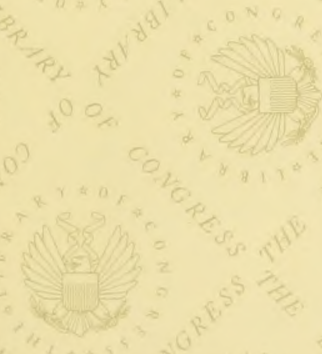

100

से ${ }^{7} d$

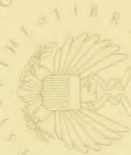

T, 10

\section{$x^{2}=0$}

$\frac{3}{4} 5^{5} 5^{4}$

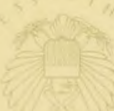

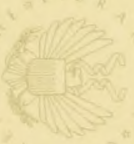

3
30
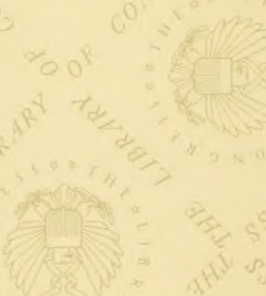

\&it $\&$

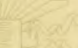

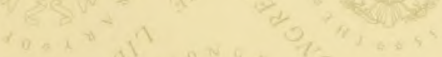

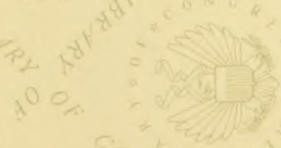

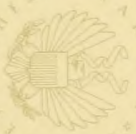

.00 




\title{
ANIMAL PARASITES
}

\author{
AND
}

\section{PARASITIC DISEASES}

\author{
SECOND EDITION. REVISED
}

BY

B. F. KAUPP, M. S., D. V. S.

PROFESSOR OF PATHOLOGY AND PARASITOLOGY, VETERINARY

DEPARTMENT. COLORADO AGRICULTURAL COLLEGE.

LATE PROFESSOR OF PARASITOLOGY, KANSA S CITY VETERINARY COLLEGE.

LATE VETERINARY INSPECTOR, BUREAU OF ANIMAL INDUSTRY, UNITED STATES DEPARTMENT OF AGRICULTURE.

SECRETARY OF THE MISSOURI VALLEY VETERINARY ASSOCIATION. LATE PRESIDENT OF THE MISSOURI (STATE) VETERINARY MEDICAL ASSOCIATION.

MEMBER OF THE AMERICAN VETERINARY MEDICAL ASSOCIATION. ETC., ETG,

\section{CHICAGO \\ ALEXANDER EGER}

1910 


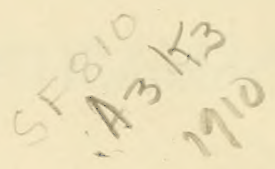

Copyrighted at Washington D, C, by ALEXANDER EGER

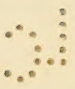

C Cl.4256380 


\section{PREFACE TO SECOND EDITION.}

The first edition of Animal Parasites and Parasitic Diseases has been exhausted in twelve months. The demand for this little concise work has far exceeded the expectations of the author and publisher. The illustrations, which have been so useful, have been doubled in number in this edition. Acknowledgment should be made to my laboratory assistant Mr. E. H. Aicher for the production of the additional pen drawings made from specimens in my collection.

The work is divided into four chapters, treating on the following subjects, viz.; External Parasites, Internal Parasites, Protozoa, Preparation of Specimens. An addenda, on the present status of our knowledge of the chemistry of animal parasites, has been added.

The names of the parasites are arranged in tabular form at the beginning of each of the first three chapters. In the first column of the table will be found the Branch; in the second the Class; in the third the Order; in the fourth the Family; and in the last the Genus and Species, names by which we know the parasites. By reference to this table one can trace each species at a glance down through the classification to the starting point,-the Branch. 
Each parasite is dealt with in the order of the tabulation.

The facts about each are noted under the headings: Synonym, Distribution, Life Cycle, Animals Infested, Parts Infested, Conditions Produced and Treatment. (The latter when treatment is of any avail.)

The photomicrographs are made by myself with an ordinary kodak placed over the occular lense of the microscope and given time exposure. By gaslight the exposure was from three to five minutes.

The Author.

Veterinary Department, Colo. Agri. College, 1910. 


\section{CONTENTS.}

PAGE

INTRODUCTORY

CHAP'TER I.

EctozoA (Classification of the Common External

Parasites-Ectozoa) ……................................... 12

Branch Arthropoda

Class Insecta (Insect Parasites) …………...........12-15

Order Diptera …………........................................ 16

Order Siphonaptera.......................................... 31

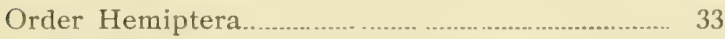

Class ARACHNIDA .................................................. 41

Order Acarina $\ldots \ldots \ldots \ldots$

Order Linguatulida _....... 71

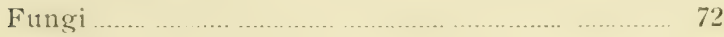

CHAP'TER II.

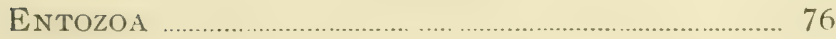

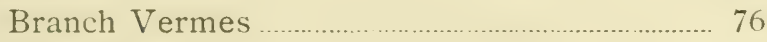

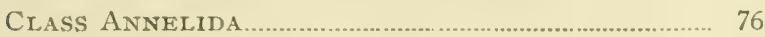

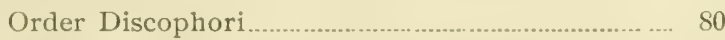

Class NeMATHELMINTHA ……............................. 81

Order Nematoda …. ...................................... 81

Order Acanthocephala _..._........................................ 136

Class Plathelmintia ….................................. $77-79$

Order Trematoda

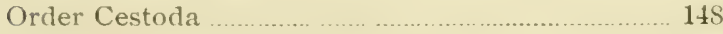

CHAPTER III.

ProtozoA (Classification of the More Common

Parasitic Protozoa) ……...................................174

Branch Protozoa ................................................. 174 
Ci.iSS FLAGELLA. $174-175$

Order Monadida 175

('I.ASS SPOROZOA $17 t-181$

Order Coccidia 181

Order Sarcosporidia 181-186

Order Hemasporidia $181-187$

Ciniss Amoeba 193

CHAP'TER IV.

To Preserve Insect Parasites 195

To Mount EctozoA........................................................... 195

To Preserve EntozoA ............................................. 195

To Stain AND Mount ExtozoA ................................... 196

Preservation of Museum Specrarens....................... 197

To Prepare Specimens to be Sent to the LaboRATORY

Technigue of Staining the Protozoa in Blood CELLS 198

TO STAIN THE TRYPANOSOMA 198

To Stain Coccidia Sarcosporidia or Amoeba MeLEAGRIDIS IN TISSUES

A LIST OF THE ILLUSTRATIONS.

FIGURE

1-Cayor Fly, Larva. 21

2-Melophagus Ovinus, Adult. 26

3-Melophagus Ovinus, Pupa. 26

4-Gastrophilus Equi, Larva 27

5-Oestrus Ovis, Larva. 28

6-Hypoderma Lineata, Larva ….................................. 30

7-Hematopinus Suis........................................................ 37

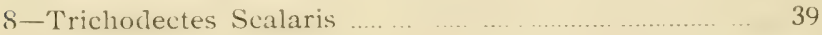

9 -Trichodectes Scalaris, Ovum ........................................ 40 
10-Psoroptes Communis, Variety Ovis, Male..................... 51

11-Psoroptes Communis, Variety Bovis, Females................. 52

12--Psoroptes Communis, Variety Ovis, Head.......................... 53

13-Psoroptes Communis, Variety Bovis, Head …............... 53

14-Demodex Folliculorum, Variety Canis, Stages of Devel-

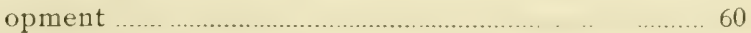

15-Demodex Folliculorum, Variety Canis, Adult Male..... 60

16-Red Mange. Photograph of two pups............................ 62

17-Argas Miniatus, Larva …....................................... 63

18-Ornithodoros Megnini, Larva........................................... 64

19-Boophilus Annulatus, Larva ............................... 64

20-Dermacentor Electus, Larva …...................................... 64

21-Amblyomma Americanum, Larva ........................................ 70

22-Spiroptera Scutata.................................................... 82

23-Spiroptera Megastoma ................

24-Spiroptera Microstoma ................................................. 83

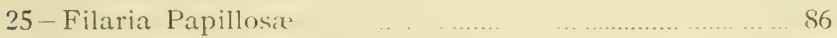

26-Ascaris Megalocephala.............................................. 90

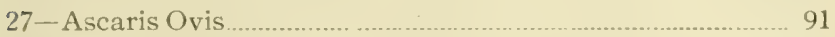

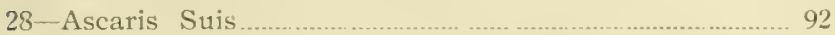

29-Ascaria Marginata ....................................................... 94

30 -Oxyuris Curvula, Female …................. 96

31 -Strongylus Arnfieldi, Caudal Extremity of the Male . 102

32 Strongylus Arnfieldi, Ova in Process of Segmentation .. 103

33-Strongylus Arnfieldi, Head Part....................................... 103

31-Strongylus Arnfieldi, Caudal Extremity of Female 101

35-Strongylus Arnfieldi, Male and Female........................103

36-Strongylus Contortus, Male and Female....................... 107

37-Strongylus Armatus, Male and Female ..........................109

38-Strongylus Armatus, Caudal Extremity of Male _.........110

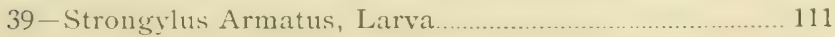

40 -Sclerostoma Tetracanthum, Arale and Female..............113

41--Stephanurus Dentatus, Male and Female.......................115 
42 - ()esophagostoma Inflatum, Nale and Female.

43 ()esophagostoma Inflatum, Cephalic Extremity.

44 -Oesophagostoma Inflatum, Caudal Extremity of Male..119

45-Oesophagostoma Inflatum, Caudal Extremity of Female

46-Oesophagostoma Columbianum, Male and Female .... 121

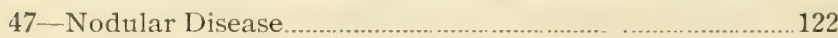

48-Oesophagostoma Dentatum, Male and Female _.............124

49-Uncinaria Radiata, Male and Female ............................. 124

50-Uncinaria Canina, Male and Female _............................127

51-Uncinaria Canina, Caudal Extremity of Male ….......... 127

52-Uncinaria Canina, Cephalic Extremity _...……........... 128

53-Uncinaria Canina, Section of Body of Female.................128

51-Uncinaria Canina, Caudal Extremity of Female _...........128

55-Trichocephalus Depressiusculus, Male and Female .... 130

56--Trichocephalus Affinis, Male and Female_.....................132

57-Echinorhynchus Gigas, Female ………….......................136

58-Echinorhynchus Gigas, Cephalic Extremity …................ 137

59-Distoma Hepaticum ........................................................ 140

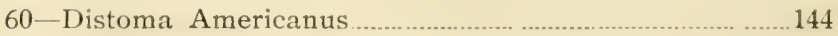

61 -Cysticercus Cellulosæ................................................. 152

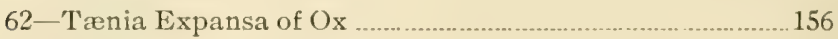

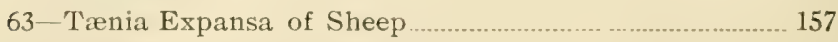

64-Trenia Alba of Sheep …….................................. 158

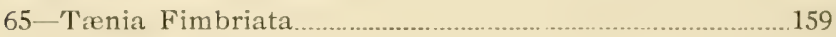

66-Tænia Marginata _._........ 160

67-Cysticercus Tenuicollis............ 161

68-Tænia Canina.................................................. 170

69-Surra ; Photograph of Horse .. . . ..................... 177

70-_rypanosoma Evansi ....................................... 176

71-Sarcocystis Miescheri, Longitudinal Section _.................. 184

72 - Sarcocystis Miescheri, Cross Section ……................ 185

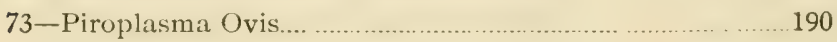




\section{LIST OF PLATES.}

\section{PLATE 1.}

Fig. I-Tabanus Atratus.

" 2-Tabanus Atratus, cephalic extremity.

"3-Tabanus Lineola, dorsal view.

" 4-Tabanus Lineola, side view.

" 5-Sarcophaga Carnaria.

"6-Hematobia Serrata.

“ 7-I-Musca Vomitoria. II-Musca Domestica.

" 8-Stomoxys Calcitrans.

" 9-Gastrophilus Equi.

" ro-Hematobia Serrata, egg shell.

\section{PLATE 2.}

Fig. I-Suctorial apparatus, Musca Domestica.

" 2-Piercing apparatus, Stomoxys Calcitrans.

" 3-Pulex Serraticeps.

" 4-Trombidium Holosericium.

“ 5-Dermanyssus Gallinae.

“6-Cytodites Nudus.

\section{PLATE 3a.}

Fig. I-Symbiotes Communis var. Caprae, male. 2 -Symbiotes Communis var. Caprae, female.

\section{PLATE 3b.}

Fig. 3-Sarcoptes Scabei var. Canis male.

4-Sarcoptes Scabei var. Canis, ovigerous female. 


\section{PLATE 4a.}

Fig. I-Boophilus Annulatus, a-Ventral view, b Dorsal view.

. 2-Amblyomma Americanum, a-Dorsal view. b-Ventral view.

"3-Ornithodoros Megnini, a-Ventral view. b.-Dorsal view.

\section{PLATE 4b.}

" 4-Argas Miniatus, a-Dorsal view, b-Ventral view.

“ 5-Dermacentor Electus.

"6-Boophilus Annulatus, male.

" 7-Ornithodoros Megnini. Section of skin showing spines.

“ 8-Leg, Boophilus Annulatus.

Inserted between pages 66 and 67

\section{PLATE 5.}

Fig. I-Stigmen, Boophilus Annulatus larvae, Drawing from moult.

. 2-Leg, Boophilus Australis, Sideview.

“ 3-Leg, Ornithodoros Megnini.

“ 4-Stigmen, Boophilus Annulatus.

“ 5-Stigmen, Dermacentor Ret:culatus.

“ 6-Capitulum, Boophilus Annulatus.

Inserted between pages 68 and 69

\section{PLATE 6.}

Fig. I-Amblyomma Americanum, ovipositing.

“ 2-Boophilus Arnulatus, ovipositing.

"3-Boophilus Annulatus on skin of cow.

". 4 -Sarcoptic scabies, cat. 


\section{PLATE 7.}

Fig. I-Spiroptera Scutata, a-male, b-female.

" 2-Spiroptera Strongylina, cephalic extremity.

“ 3-Spiroptera Strongylina, candal extremity of male.

“ 4-Spiroptera Strongylina, caudal extremity of female.

" 5-Ascaris Mystax.

“6-Oxyuris mastigodes, female.

" 7-Ascaris Suis, front view of cephalic extremity.

\section{PLATE 8a.}

Fig. I-Spiroptera Microstoma, cephalic extremity.

2-Spiroptera Microstoma, caudal extremity of male.

" 3-Spiroptera Megastoma, cephalic extremity.

" 4-Filaria Cervina, female.

\section{PLATE 8b.}

Fig. 5-Filaria Papillosa, cephalic extremity.

“ 6-Filaria Papillosa, caudal extremity of male.

" 7-Heterakis Papillosa.

“ 8-Filaria Immitis, male. 


\section{PLATE 9.}

Fig. I-Heifer infested with flukes and lung worms.

“ 2-Oesophagostoma Columbianum, cephalic extremity.

" 3-Oesophagostoma Columbianum, caudal extremity male.

" 4-Oesophagostoma Columbianum, caudal extremity female.

\section{PLATE 10.}

Fig. I-Stephanurus Dentatus, cephalic extremity.

“ 2-Syngamus Trachealis, male and female.

" 3-Trichocephalus Crenatus, I female. 2 male.

" 4-Echinorhynchus Canis.

* 5-Echinorhynclus Canis, Section of uterus filled with eggs.

" 7-Trichina Spiralis, encysted larva.

. 8-Paragonimus Westermanii.

\section{PLATE 11.}

Fig. I-Taenia Marginata, cephalic extremity.

- 2-Cysticercus Tenuicollis.

" 3-Taenia Fimbriata, cephalic extremity.

. +-Cysticercus Echinococcus, cyst.

" 5-Cysticercus Echinococcus, larvae. 


\section{PARASITOLOGI:}

INTRODUCTORY.

The study of parasites is called PARASITOLOGS.

The study of worms is called HELMrNTHOLOGY.

The condition of an animal infested with parasites is called PARASITISH.

Organisms that live upon different hosts are called FACULTATIVE PARASITES.

Organisms that pass their entire life upon a single host cause CONSTANT PARASITISM.

Parasites that visit their host for nourishment only, as is the habit of blood-sucking flies, are INTERMITTENT PARASITES.

Parasites that pass part of their life external to their host, as species of the bot-fly family, are TRANSITORY PARASITES.

Parasites that can live only upon one species of animals are called OBLIGATORY PARASITES.

Animal parasites are separated into two divisions, viz.: Ectozoa, or external parasites, and Entozoa, or internal parasites.

Ectozoa (ektos-without, zoa-animal) are those parasites that live outside the body.

Entozoa (entos-within, zoa-animai) are those parasites that live within the budy.

A Parasite is an organism, animal or vegetable, that lives upon another organism, animal or vegetable.

Parasites are placed in three branches, viz.: Arthropoda, Vermes, and Protozoa. 
The Arthropoda are those parasites that are provided with jointed legs. This branch is divided into two classes, viz.: Insecta and Arachnida.

Under the class Insecta are placed the orders: Diptera, Siphonaptera and Hemiptera.

The order Diptera includes the following families, viz.:

Culicidae, which include the gnats and mosquitoes. Simuliidae, which include the buffalo gnat. Tabanidae, which include the horse and ox flies. Muscidae, which include the horn=fly, the horse= fly, etc.

Hippoboscidae, which include the sheep-tick.

Oestridae, which include the bot-flies.

The order Siphonaptera includes the fleas.

Under the order Hemiptera are placed the following families, viz.:

Pediculidae, which include the blood-sucking lice. Philopteridae, which include biting lice.

Liotheidae, which include lice of birds.

The first two families live upon mammals.

The class Arachnida includes the orders Acarina and Linguatulida.

The order Acarina includes the families Ixodidae, Argasidae, Gamasidae, Trombididae, Acaridae.

The family Acaridae is divided into sub families, Sarcoptidae and Demodecidae.

The families Ixodidae and Argasidae include the ticks.

The family Gamasidae includes minute parasites of birds and small animals.

The family Trombidiidae includes the chiggers. 
The sub-family Sarcoptidae includes the scab or mange parasites.

The sub-family Demodecidae includes the follicu= lar or red mange parasite.

The order Linguatulidae includes a parasite which in the adilt state infests the nasal chambers of the dog, etc. 


\section{CHAPTER I.}

\section{CLASSIFICATION OF THE COMMON EXTERNAI PARASITES.}

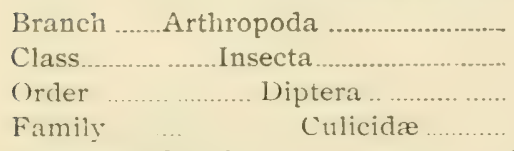
Genus and Species................................... Culex Pipiens.
Culex Pungens.
Anopheles Punctipennis.
Stegomia Fasciata.

Family

Simuliidæ

Genus and Species.

Simulium Pecuarum.

Family

Genus and Species Tabanidæ

Tabanus Atratus.

Tabanus Lineola.

Family

Muscida

Genus and Species

Musca Domestica.

Musca Vomitoria.

Lucilia Macellaria.

Sarcophaga Carnaria.

Glossina Morsitans.

Hematobia Serrata.

Stomoxys Calcitrans.

Family Hippoboscidæ..

Genus and Species.

Melophagus Ovinus.

Family

Oestrida

Genus and Species

Gastrophilus Equi.

Gastrophilus Hemorrhoidalis.

Oestrus Ovis.

Hypoderma Lineata.

Order

Siphonaptera (Siphon-tube; a-without; pteron-wing.)

Family Pulicidie 
Genus and Species

Order

Family

Genus and Species
Hemiptera

Pediculicla

Hematopinus Asini.

Hematopinus Eurysternus.

Hematopinus Vituli.

Hematopinus Suis.

Hematopinus Piliferus.

Hematopinus Stenopsis.

Family Philopteridae

Genus and Species

Trichodectes Pilosus.
Trichodectes Scalaris.

Trichodectes Spherocephalus.

Trichodectes Latus.

Trichodectes Subrostratus.

Family

Genus and Species

Liotheida

Menopon Pallidum.

Menopon Biseriatum.

Class

Arachnida

Order Acarina

Family

Gamasidae

Genus and Species. Family Trombidida

Genus and Species

Leptus Irritans.

Family

Acarida

Sub-Family Sarcoptidæ. Trombi
cium.

Dermanyssus Gallinae.

Trombidium Holoseri-

-

Pulex Serraticeps.

Pulex Avium. 
Genus and Species-Continued ... ...Sarcoptes Scabei Var. Ovis.

Sarcoptes Scabei Var. Caprae.

Sarcoptes Mutans. Var. Gallinae.

Psoroptes Communis Var. Equi.

Psoroptes Communis Var. Bovis.

Psoroptes Commun is Var. Ovis.

Psoroptes Communis Var. Caprae.

Symbiotes Communis Var. Equi.

Symbiotes Communis Var. Bovis.

Symbiotes Communis Var. Ovis.

Symbiotes Communis Var. Caprae.

Svmbiotes Auricularum

Var, Canis.

Cytodites Nudus.

Family

Sub-Family

Genus and Species
Acariclae Demodecidas

Demodes Folliculorum Var. Equi.

Demodex Folliculorum Var. Bovis.

Demodex Folliculorum Var. Ovis.

Demodex Folliculorum Var. Suis.

Demodex Folliculorum Var. Canis.

Demodex Folliculorum Var. Cati.

Family Argasidae 
Genus and Species

Family Ixodidate
Argas Miniatus.

Ornithodoros Megnini.

Rhipicephalus Sanguineus.

Ixodes Ricinus.

Boophilus Annulatus.

Boophilus Australis.

Dermacentor Electus.

Amblyomma Americanum.

Order Linguatulicla......

Gents and Species

Linguatula Rhinaria.

Fungi.

Trichophyton Tonsurans.

Achorion Schoenleinii.

Achorion Keratophagus. Saccharomyces Albicans. Actinomyces Bovis.

\section{INSECT PARASITES.}

The life cycle of most insect parasites is divicled into four stages, riz.: oval, larval, pupal and adult.

The oval stage is the first stage-the egg.

The larval stage is the second stage-the stage in which the insect is a worm.

The pupal stage is the third stage-that metamorphosis passed through in a dirt or membranous sac; the cocoon.

The adult is the fourth stage-the mature state.

Some insect parasites do not pass throngh the oval stage.

Those parasites belonging to the class insecta, anatomically speaking may be divided into three parts, viz.: The head, the thorax and the abdomen.

The head is provided with two eyes, two antennae (feelers) and the mouth parts. 
The antennae are composed of segments (joints or articles) which vary in number according to the species.

The mouth parts are provided with a proboscis for piercing the skin and sucking blood, or with an apparatus for sucking up liquid substances.

The thorax of those belonging to the order Diptera is provided with three pair of legs and one pair of wings. Those we study under the orders Hemiptera and Siphonaptera are provided with three pair of legs only.

With regard to reproduction, the female may lay the ova, larva, or ova containing the larva fully developed.

The insect laying the ova is called oviparous (ova-egg, parous-to bring forth).

The insect producing the larva is called vivipar= ous (vivo-living, parous - to bring forth).

The parasite producing the egg with the larva fully developed within is called ovoviviparous

\section{THE FLIES.}

Mosquitoes-(Musca-fly, ito--small.)

History.-Mosquitoes are found in all parts of the world, from the cold countries of the north to the hot countries of the south. One hundred and fifty species have been described. More than thirty species are found in the United States. Among the common species may be named the Culex Pungens, Culex Pipiens, Culex Equinus, Stegomia Fasciata, and Anopheles Punctipennis.

Description.-Mouth parts provided with lancet-like piercing mandibles; long, slender body; delicate, 
gauzy wings; antennae composed of fourteen segments; three pair of long and slender legs; one pair of eyes.

Life $C_{y}$ cle. - The ova are laid in boat-shaped masses on the surface of the water. The larvae are small, black, worm-like bodies, with forked tails in which are placed the breathing tubes. They are noted to come with this end to the surface of the water for the purpose of obtaining oxygen. They are found in cisterns, ponds and pools of water everywhere, and are commonly called wigglers. They pass this stage in seven days, if conditions are favorable. The pupal stage is passed in twenty-four hours.

The ova hatch in from sixteen to twenty-four hours.

Animals. Attacked.-Among the species that attack man and beast are the Culex Pipiens. The Culex Equinus especially attacks the horse. The genera Anopheles and Stegomia furnish species which attack man and communicate the protozoa producing malaria and yellow fever.

Parts Infested. - The attack is made upon the skin, principally in the evening and at night, by means of the stylet of its rostrum. In piercing the skin it instills a poison which produces inflammation, itching and swelling.

Prophylactic Treatment.-It has been suggested to put fish in the ponds and large bodies of water, to consume the larvae. Kerosene, one ounce to each fifteen square feet of water, will prevent deposit of ova. Cisterns and wells should be kept screened. No tin cans or cther means of providing pools of water should be allowed, in which mosquitoes might 
propagate. Houses should be screened. Sleeping rooms may be smoked with pyrethrum. The pyrethrum should be molded into cones and dried. These cones, when lighted, will smoulder for a long time, and give off a pungent odor which does not kill the mosquitoes, but stupefies them, rendering them harmless.

Simulium Pecuarum (Pecus-cattle, simulo-to simulate.)

Synonym.-Buffalo gnat.

History.-Found in the South, along the Mississ. ippi river and its tributaries. Their destructive effect upon animals dates back as far as 1850 .

Description. - A small black fly; abdomen broad and thick; thorax short, thick and provided with a hump from which it gets its common name, resembling the hump of a buffalo. The antennae are composed of eleven segments. Its wings are wide and short, and its three pair of legs are thick and short.

Life Cycle.-The adult flies are found from April until after June. They lay from 5,000 to 10,000 eggs in a compact mass on some object directly over the water's edge. Upon hatching, the larva falls into the water. The larva is composed of twelve joints. It fastens itself to rocks and other objects in the river bed, often loosening its hold and floating in the current till another favorable place is found. The larva is carnivorous. The pupal stage is passed in a tough brown cocoon with the upper part open. This cocoon is fastened to sticks and other objects in the water.

Animals Infested. - They attack the animals, as horses and cattle, in swarms. By means of their 


\section{Plate I.}

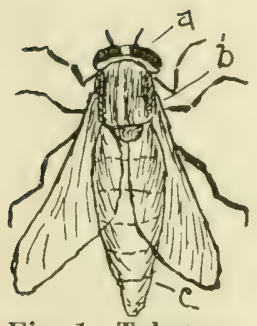

Fiร. 1-Tabnaus

\section{Atratus.}

a, Head showing antennae and compound eyes.

b, Thorax with 3 pair legs and 1 pair tvings.

c, Abdomen.

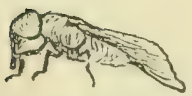

Figs. 4-Tabanus Lineola.

Slde vlew, showing proboscis.

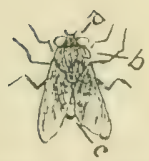

Fig. :-I-Musen Vomitoria.
a. Head.
b, Thorax.
c, Globular shaped abilomeu.

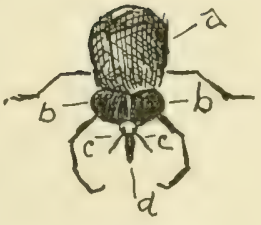

1ำ. 2-Tabanus Atratus.

(Cephalic extremity) a, Thorax.

b, Compound eyes.

c, Autennae.

d, Rcstrum.

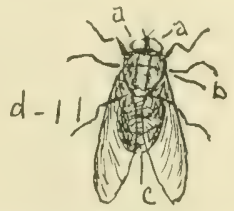

Fig. 5-Snreophagn Fig. 6-Hemntobla Carnaria.

a. Compound eyes.

b, Thorax.

c) Abdomen.

d, Young larvae.

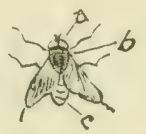

Fin. 7-II-MIuser domestica.

a, b, c, same as I

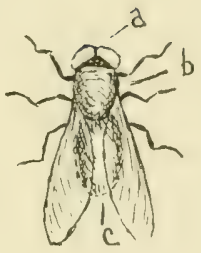

Fig. 3-Tabรกแะ Lincola.

8. Head.

b) Thorax.

c, Ablowen

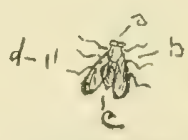

Serrata.

a, Head.

b, Thorax.

c, Abdomen.

d, Eggs.

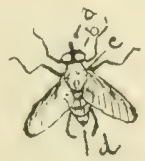

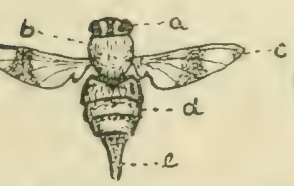

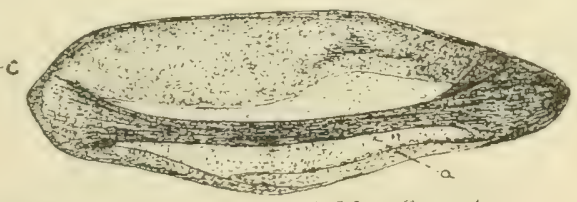

Flis. y-Gostrophilus Equi. Fis. 10-ITematobia Serrata (Female)
a. Head.
b, Thorax.
c, Wing.
d, Abromen,
$\theta$, Ovipositor.

Calcitrans,

a, Stilet.

1), Eyos.

c. Thorax

d, Abdomen. 

rostrum they pierce the skin, suck the blood and instill a poison into the wound which produces inflammation and pain. The animals may inhale the small insects in numbers, and in this way they produce irritation which results in mechanical injury, causing bronchitis and pneumonia. Many animals die. The greatest loss among live stock has been reported in the lower Mississippi Valley.

Treatment.-Rub parts affected with five percent ammonia water. In weak animals give stimulants, as carbonate of ammonia, one dram to one pint of whiskey, three times a day. Keep animal in cool, dark stable. Solutions of quassia, tobacco and oil of tar are often applied externally as a preventive.

'Tabanus Atratus (Ater-black). Horse-fly.

Synonyms.-Nourning horse-fly ; large black horsefly; black gad-fly; breeze-fly.

History.- - Widely distributed throughout the United States.

Description. - The largest fly of the family Tabanidae. It measures about one inch in length. Entire fly is black. The wings are large, and set almost at right angles with the body. Its head is provided with a powerful proboscis.

Life Cycle.-The adult fly lays her eggs in moist places; they hatch into larvae composed of twelve segments each. The pupal stage is passed in the ground, and lasts only a few days. The pupae are nearly an inch and a quarter in length. The adult emerges from the pupa by splitting the case lengthwise.

Animals.Attacked.-Horses and cattle are attacked 
during the warmer parts of the day. By means of its powerful proboscis it pierces the skin and sucks the blood. Often a drop of blood oozes from the point of puncture after the insect has left the animal. They do not attack the animal in swarms, as does the buffalo gnat, nor is the bite so poisonous. Horses and cattle will flee from the buzzing sound of the fly.

Tabanus lineola (Linea-line).

Synonym.-Green-head horse-fly.

History.-Found in all parts of the United States. Most abundant in the prairie districts.

Description. - This fly is about the size of the honey bee. Its head is provided with a powerful proboscis for sucking blood, and is a brilliant green. Its abdomen is elongated and brownish in color.

Life Cycle.-The life cycle is similar to that of the Tabanus Atratus, passing its oval, larval and pupal stages in moist places.

Animals Attacked.-They attack horses and cattle during the warm part of the day. They do not fly in cold or damp weather, and die with the frosts of autumn. They do not make their attack in large numbers.

Musca Domestica (Domus-a house, Musca-fly).

Synonym.-House-fly.

History.-Found in all parts of the world.

Discription.-Medium size; grayish in color. Its head is provided with a trumpet-shaped suctorial apparatus for sucking up liquid substances.

Life Cycle.-Oviparous. The eggs are oval in shape and white in color. They breed in manure and door-yard filth. 
Animals fltacked. - They produce irritation by their numbers upon the skin or wounds of any animal, and by imbibing the exudate and perspiration. They carry germs from the wounds or excreta of one animal to another.

Musca Vomitoria (Vomitoria-causes vomiting, musca-fly.)

Synonyms.-Blow-fly; bluebottle fly; calliphora vomitoria.

History.--Found widely distributed.

Discription. - The fly is about four times the size of a house-fly. Its eyes are brownish in color; thorax and abdomen bluish green.

Life $C^{\prime}{ }^{\prime} l e$. - The eggs are oval in shape and white in color. They are deposited on decomposing animal and vegetable matter, in the wounds of animals and in fresh manure and garbage. When the weather is hot the eggs hatch in a very few hours. The larvae are called maggots, and develop rapidy. On reaching maturity the maggots, if in a wound, drop to the ground and pass through the pupal stage in a short time.

Lucilia Macellaria.

Synonyms. - Screw-worm fly; compsomyia macellaria; cayor fly.

History.-Found throughout the world. Its great-

a

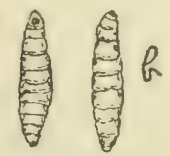

Fig. 1-CAYOR FLY LARVA. a, Ventral View; b, Side View. est damage is done in hot climates.

Description. - The fly is about one-half inch in length and of a bluish green color. It has three longitudinal black stripes on the dorsal surface of the thorax. 
The head is yellowish or reddish in color. The thorax and abdomen are covered with short, stiff black hairs.

Life Cycle. - The time at which the fiy appears depends upon the latitude. In Texas and Louisiana they appear in June and last till autumn. The female is oviparous, and lays as many as 200 eggs at one laying. The larvae invade the wounds of animals. and also decaying matter. The eggs hatch in about nine hours, and the larvae develop rapidly. The head part of the larva is provided with two teat-like projections, and two hooklets. The segments are also provided with hooklets. Its general appearance is like that of a screw, from which it gets its name (screw-worm). In the wound they are found burrowing into adjacent tissue, with the posterior extremity upright. While these are developing other eggs are laid in the wound. The pupae are brown in color, and about two-fifths of an inch in length. The pupal stage is passed in the ground, in ten days.

Treatment.-Chloroform injected into the wound will clestroy them; also creolin or carbolic acid solutions. Curet or forceps may be used in remov. ing them. The wound can then be treated with the zinc and lead solution, made as follows:

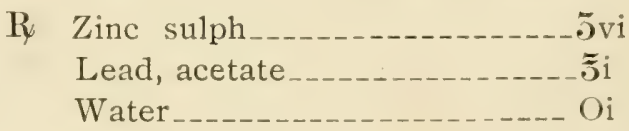

Sarcophaga Carnaria (Sarcophagous-flesh-eating). (Carnivora-dead meat).

Synonyms.-Flesh-fly; gray carnivorous fly; carnivorous sarcophagus. 
History.-Distributed throughout the world. It was first described in 1761 by Linnæus.

Description. - The fly is about the size of the musca vomitoria, and is grayish in color. Its markings are similar to those of the house-fly.

Life Cycle.-The female is viviparous; lays the larvae on fresh meat or in the wounds of animals. The fully developed larvae seek a secluded place and in a few days pass through the pupal stage.

Glossina Morsitans (Glossus-tongrue: Morsitans-biting.)

Synonym.-Tse' Tse' fly.

History. - It is found in swamps and river-bottoms in Central Africa.

Description.-It is a little larger than the common house-fly. The piercing stylet of its proboscis is barbed, and is twice as long as its head. The thorax is orange colored, with four black lines on the dorsal side. The abdomen is yellowish white and the wings are cark in color.

Animals Httacked.-All animals except the elephant, zebra and hen are attacked. It pierces the skin instantly, clrawing blood. It inoculates the animal with the Trypanosoma Brucii, the protozoa producing Nagana.

Condition Produced. - The protozoön lives in the blood; high elevation of temperature $-104^{\circ}$ to $106.5^{\circ}$; anemia; oedema in region of the head, neck and abdomen; nasal catarrh, conjunctivitis, etc.

Post Nortem Findings.-Enlargement of lymph glands and liver; spleen dark colored and friable; petechia and hemorrhages in the serous membranes; atrophy of fat tissue and muscular structure. 
Hematobia Serrata (Hema-blood; bios-life; serra-saw.)

Synonyms.-Horn-fly; saw-fly.

Mistory.-It was introduced into this country in 1887 by an importation of cattle from Europe. It first appeared around Philadelphia, and in a few years was found in all parts of the country.

Description.-A small black fly, about one-third the size of the common house-fly. When at rest the wings are nearly parallel with the body. The head is provided with a proboscis for sucking blood.

Life Cycle. - The flies appear with warm weather, and die with the frosts of autumn. The eggs are oval in shape and brown in color, and are laid in the fresh feces. The eggs are nearly straight along one side and the larva emerges from the shell by raising a long, ribbon-shaped strip at this side. The ovum hatches in about twenty-four hours. The larvae reach their fully developed stage in about five days. They then burrow into the ground about half an inch, where they pass the pupal stage, which lasts about eight days.

Alimals -1ttacked. - Cattle are most often attacked, the flies attacking them in large swarms, burying themselves in the hair and sucking the blood. In rainy weather they are found to attack the animal under the belly. At night they may be found in clusters around the horns.

Conditions Produced.-The constant harassing of the animal by large numbers of the flies causes milch cows to fall off in the yield of milk. Fattening and other animals do not thrive.

Treatment.-Fish-oil and tar, eculal parts, will keep 
the flies away. Coal-tar solutions, such as creolin and kreso, keep the flies away for only a short time.

Stomoxys Calcitrans (Stoma-mouth, calcitro-sting).

Sy'nonyms. - Stomoxys stabulans; stable-fly; stinging fly.

History.-Widely distributed, they appear in the latter part of summer. They were first described in 1761.

Description. - It is about the size of the house-fly. When at rest the wings are nearly at right angles. The head is provided with a solid, elongated styletshaped proboscis, bent near its base.

Life Cycle. - The ova are laid in the fresh feces, where the larval stage is passed. The pupal stage is passed in the ground.

- Animals Attackid.-It enters stables and attacks horses and cattle. Its bite is severe, causing vesicles, which rupture and produce scab; the hair becomes erect and the legs become sore. This fly has been thought to carry the germs of anthrax and of glanders, by attacking healthy animals soon after diseased ones have been feasted upon.

Melophagus Ovinus (Mallos-wool, phagein-to eat).

Synonyms-Sheep-tick; louse-fly.

Description. - The head is small and sunken in the thorax. It is provided with a tubular-shaped proboscis adapted for piercing the skin and sucking the blood. The thorax is distinctly separated from the abdomen, and is provided with three stout pair of legs, which are covered with hair. The last seg- 
ment of each leg is provided with a bi-dentated claw. The abdomen is large, and globular in shape.

Life Cycle.-The female lays eight to ten young in the form of pupae. The pupal case is ovoid in shape and brown in color, and is cemented to a few fibres of wool. These hatch in about four weeks.

Animals Infested.-They are found most abundant on long-wooled sheep. After shearing they have a tendency to leave the sheared sheep for the lambs.

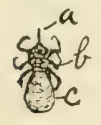

Fig. 2-Melophagus Ovinus.

a, Head with Piercing Rostrum

b, Thorax, with 3 Pair of Legs.

c, The Large, Globular Abdomen.

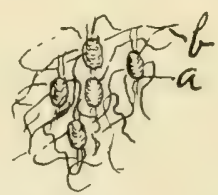

Fig. 3-Melophagus Ovinus PUPA.

a, Pupa.

b, IVool Fibers.

They live upon blood of the host, and grease or yolk of the wool. At point of puncture there is injected a small quantity of poison, which causes irritation and swelling.

Symptoms. - The infested sheep rubs, scratches and bites itself. When present in large numbers these parasites cause unthriftiness and debility.

Treatment.-The sheep dip or kerosene emulsion will kill them.

$$
\begin{aligned}
& \text { (Gaster-stomach) } \\
\text { Gastrophilus Equi } & \text { (Equi-horse) } \\
& \text { (Phileo-to love). }
\end{aligned}
$$

Sy'nony'ms.-Horse bot-fly; oestrus equi; gad-fly.

History.-They were clescribed by the earliest writers and are universally found.

Description.-A fly about the size of a honey-bee; 
body heavy, and covered with soft, yellowish hair. The eyes are small. The female is provided with a long ovipositor. The posterior of the male is rounded.

Life Cycle.-The eggs are oval in shape, light yellow in color, and are cemented to the hair of the animal attacked, principally in the region of the jaws and fore limbs. The fly hovers over the region on which the egg is to be deposited, then darts down, cements it to the hair in an instant, retreats a few feet, hovers again, then deposits another egg. The cap or operculum is pushed off the large end, through which the young grub escapes when the egg is hatched. The eggs hatch in three weeks. The animal, by licking, gets the larva into its mouth; the larva finds its way to the stomach, attaches itself to the pyloric portion by means of two hooklets

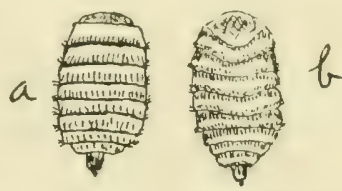

Fig, 4-GastrophILUS EQUi LARVA.

a, Dorsal View.

b, Ventral View,

(small hooks) and remains there ten months. Upon reaching the fully developed larval state it loosens its hold, passes out to the ground with the feces, burrows into the ground one inch and there passes through the pupal stage, which lasts from four to six weeks.

Animal Attacked.-The horse.

Part Infested. - The stomach.

Injury to Host.-Seldom if ever any injury.

$$
\begin{array}{r}
\text { Gastrophilus Hemorrhoidalis (Gaster-stomach) } \\
\text { (Phileo-to love). }
\end{array}
$$

Synonyms.-Oestrus hemorrhoidalis; red-tailed bot-fly; bot-fly of horse. 
History.-Found in common with the Gastrophilus Equi in North America and Europe.

Discription.-Not so large as the Gastrophilus Equi. The thorax is covered with olive-gray hair; a black band is found in the middle. The abdomen is white in front, black in its median part, and orange red at the posterior end.

Life Cycle.-The eggs are oval in shape and black in color. The larvae are taken into the mouth and swallowed, and then, by means of two hooklets, attach themselves to the mucous membrane of the digestive tract. They are found mostly in the right and left sacks of the stomach. They may loosen their hold and become attached at another point. They often become attached to the rectum, causing itching, and rubbing of the tail. The pupal stage lasts from four to six weeks, and is passed in the ground.

Animal Attacked.-The horse.

Parts Infested.-Stomach and intestines.

Oestrus Ovis (Oestrus-gad-fly; ovis-sheep).

Synonyms. - Cephalemyia ovis (cephalo-head, myia-fly); sheep-bot; grub; head-maggot; sheep gad-fly.

History.-Found in America, Europe, Asia, Africa and Australia.

Description. - Small, yellowish gray fly, slightly larger than the house-fly. Body covered with short fine hair. The abdomen is ornamented with five rings; under side of head is white.

Fig. 5-Oestrus Ovis Larva. a, Side View.

b, Posterior view.

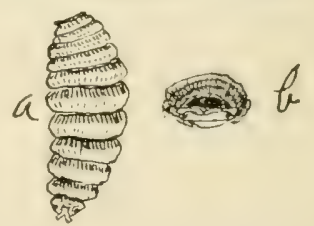


Life Cycle.-The fly is viviparous, and attacks the sheep and goats from June to October, but only in the warmer part of the day. It deposits its larvae in the anterior nares. The larva is provided with two hooklets, by means of which it gradually works its way to the frontal sinuses, where it passes the larval stage, which requires ten months. It then passes sut to the ground, burrows into the ground and there passes through the pupal stage, which lasts from four to six weeks.

Animals Attacked.-Sheep and goats.

Parts Infested.-Frontal sinuses and turbinated bones of the head.

Condition Producud.-The sheep, hearing the noise of the fly, runs, thrusts its nose into the ground or amongst other sheep, and strikes at its nose with its feet in an effort to rid itself of the pest, which, sluggish at other times, now flies at the nostrils with great rapidity. The larvae work their way to the frontal sinuses by means of hooklets and contractility of the body. In the frontal sinuses they attach themselves, by means of two hooklets, to the mucous membrane. If only three or four are present in the sinuses they do not produce much disturbance,a slight catarrhal discharge of a muco-purulent nature. When many are present there is noted a profuse muco-purulent discharge from the nostrils, loss of appetite, frequent coughing and sneezing, slow, weak gait, and tossing of the head. The animal becomes too weak to rise, and finally dies.

Tratment.-Trephine and remove larvae with forceps.

Prophylactic Treatment.-The nose may be smeared 
with tar. It is advocated to make troughs with holes bored in sides large enough for a sheep to lick salt from. Tar, smeared around these holes, is lodged on the nose in the sheep's efforts to get the salt.

$$
\begin{aligned}
& \text { (Hypo-under) } \\
& \text { Hypoderma Lineata } \text { (derma-skin) } \\
& \text { (linea-line). }
\end{aligned}
$$

Synonyms.-Oestrus lineata. Ox gad-fly; warblefly; grub-fly; striped hypoderma; heel-fly.

History.-A species found in America; most common in southern states.

Description.-About the size of a honey-bee. Its body is black, covered with fine hair. The thorax is ornamented with longitudinal gray bands. The female is provided with a cone-shapef ovipositor, with which she deposits her eggs, cementing them to the hair.

Life Cycle.-The fly deposits its eggs upon the hair in the vicinity of the heel. From this point the larvae are taken into the mouth and become lodged in the mucous membrane of the oesophagus. The eggs are laid in summer and the larvae are found in their most fully developed

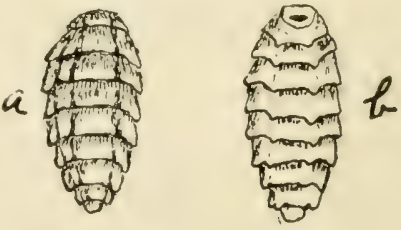

Fig. 6-HypoderMA LiNeATA LARVA.

a, Dorsal View

b, Ventral View.

stage in the oesophagus about November. At this time they are about five-eighths of an inch long. They now leave this locality and wander through the connective tissue to a position underneath the skin in the region of the back. Here 
tumors are formed, with holes at their summits. The holes become larger as the tumors and larvae develop. The larval stage lasts ten months. In this stage they are called grubs, or warbles. By spring they have developed into full-grown larvae, and leave the tumors through the holes in the summits. At this time they are three-fourths to seven eighths of an inch long, and nearly one-half inch thick. It has been observed that they leave behind a tough brown or black skin. They burrow into the ground and pass through the pupal stage in from four to six weeks.

Animal Attacked.-The ox.

Parts Infested.-Oesophagus and sub-dermal tumors in region of back.

Injury to Host. - Some irritation. If attacked by large numbers the animal does not thrive. In those cattle that are slaughtered during the grubby season there is a great commercial loss to hides, on account of the holes in the skin. The percentage of cattle infested varies from practicaliy none in the northern states to seventy-five or eighty percent in the southern states.

\section{THE FLEAS.}

Pulex Irritans (Pulex-flea, irrito-to excite),

Synonym.-Human flea.

History.-Common in dwellings in Europe. Not very common in the United States.

Description.-Body flattened from side to side; head small and rounded; stylet arranged for piercing the skin and sucking the blood; two eyes and two antennae. The abdomen is provided with nine rings. 
The legs are thick and strong, terminating in two hooklets or claws. The posterior pair are the longest, giving them great power to jump.

Life Cycle.-The eggs are ovoid in shape and brown in color; they hatch in from six to twelve days, depending upon the temperature. The larvae are worm-like and are composed of thirteen segments. The mouth parts are arranged for mastication. The larval stage lasts about eleren days; they then pass their pupal stage in tough brown cocoons. The cocoon stage lasts about fourteen days.

Fleas breed in filth, carpets, rugs, kennels and barns.

Animal Infested.-Man.

Injury to Host. - In the adult state they attack the skin. The puncture causes itching and inflammation.

Treatment.-Cleanliness; pyrethrum or tobacco dust sprinkled in the infested quarters.

\section{Pulex Serraticeps (Seco-to cut).}

Synonym.-Dog and cat flea (Fleon-to flee.)

History.-Universally found.

Description.-Similar in appearance to the Pulex Irritans, with the exception that it is provided with fifteen to eighteen spines on the posterior margin of the pro-thorax. In the preceding species the thorax is entirely nude.

Life Cycle.-Eighteen to twenty eggs are laid in some dirty or dusty corner, which pass through the same stages as the preceding species.

Animals Infested.-They attack the cuticular surface of dogs, cats and men.

Trcatment.-Dogs can be dipped in a five per-cent 


\section{Plate II.}

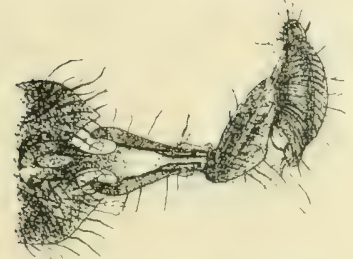

Fig. 1-Suctorial apparatus. (Musen Domestiea).

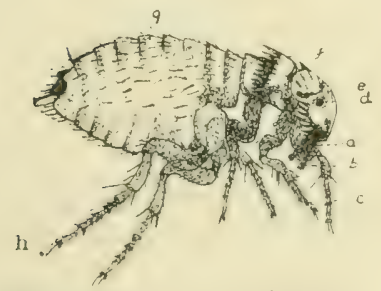

Fig. 3-Pulex Serraticeps a, Mandihles.

i), Palpi.

c, Anterior pair of legs

d, Ocelli.

e, Antennae.

f, Thorax.

g, Abdomen.

h. Hooklets on terminal tarsus.

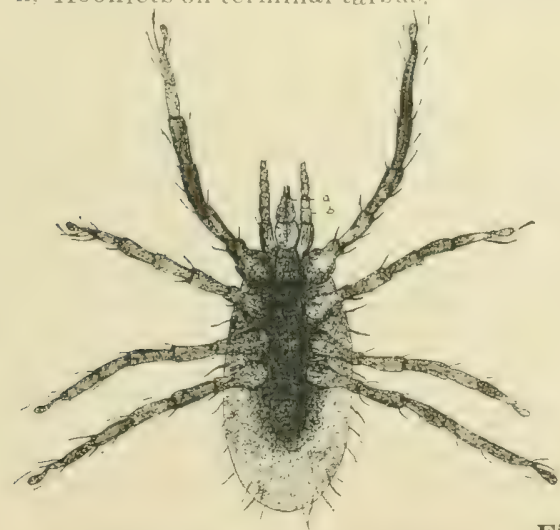

Fig. 5-Dermanysus Galliuac. a, Rostrum.

b, Palpus.

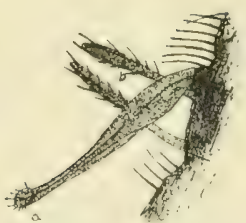

Fig. 2- Miercing npparatu. (stomoxys Cnlcitrans). a, Proboscis.

b) Palpi.

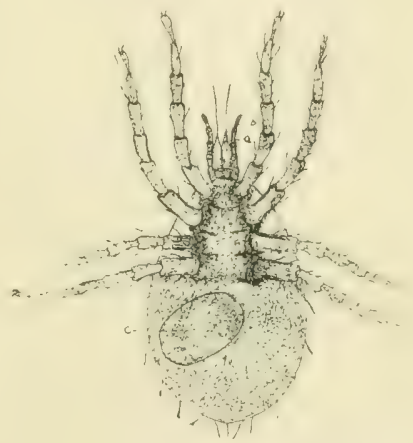

Fig. 4-Trombitium Holosericium.

a, P'iercing mandibles.

b, Palpi.

c, Uterus.

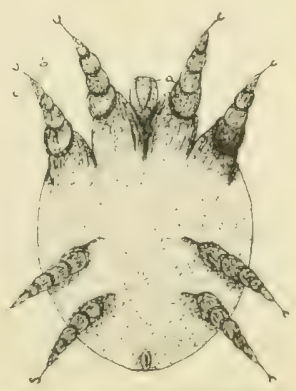

Fig. 6-Cytodites Nudus.

a, Rostrum.

b) Ambulacrum.

c, Pedicle to same. 

solution of creolin. Creolin may prove fatal to cats. Tobacco dust or pyrethrum may be dusted in infested quarters.

Pulex Avium (Avis-bird).

Synonym.-Bird flea.

Description. - The head is rounded, and is not provided with spines on the lower border, but a row of minute bristles is found on the side. The mandibles are short.

Animals Infested.-The attack is made principally upon small birds.

\section{THE LICE.}

Phthiriasis (Lousiness)-(Louse).

Phthiriasis is the condition of an animal or bird infested with lice. The lice infesting the domestic animals are divided into three families, viz.: Pedicu= lidae, Philopteridae and Liotheidae.

Under the first is placed the genus Hematopinus. Under the second is placed the genus Trichodectes.

Those species of lice belonging to the genus Hematopinus are provided with a piercing apparatus which projects anteriorly from the head. They live upon the blood of the host.

Those species belonging to the genus Trichodec= tes are provided with mouth parts arranged on the under part of the head. They live by mastication from epidermis and hair of the host.

The lice are oviparous; the eggs are called nits and are cemented to the hair. The eggs are oval in shape and white in color.

Symptoms. - Infested horses and cattle are noted to rub against fences and posts, corners of buildings, 
in an effort to relieve themselves of the itching sensation produced by the lice. Cattle are noted to lick themselves. The hair has a rough, stairy, matted appearance. Dogs scratch and bite themselves, showing evidence of great pruritus. The hair becomes matted or scratched off and emaciation follows. Sheep and goats show much the same symptoms. In hogs, the animals rub and scratch. Upon close examination the lice and nits can be found. In hogs a favorite place for the lice to deposit their eggs is in the folds of skin posterior to the ears. In later stages the animals may become emaciated.

Lousiness is noted to be more prevalent in winter and spring, on account of close association of animals during these seasons, and the long hair, which forms a protection for them.

Treatment.-All quarters, stalls, mangers, harness, blankets, curry-combs, rub-rags, etc., should be disinfected. If in the spring of the year, the horse may be clipped.

The animals may be sponged or dipped in any of the following, or in a five-percent solution of creolin or kreso :

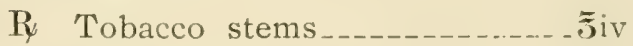

Water _..._............... gal. i

M. Sig.-Boil for thirty minutes.

R Stavesacre seeds_.........

Water._._.

M. Sig.-Boil for thirty minutes.

R Quassia chips_......... E

Water _...................... i

M. Sig.-Boil for thirty minutes.

For hogs, the kerosene emulsion, sprayed on the 
herd by means of a sprinkling can or spray-gun will be found to be very effective treatment. The emulsion is made as follows:

R Kerosene_._._._.......gal. ii

Common soap__._._._._.

Water______________._. gal. i

M. Sig.-Dissolve the soap in boiling water; add this solution boiling hot to the kerosene, stirring the mixture for ten minutes.

When used this emulsion is usually diluted as follows: One part emulsion to nine parts water:

Hematopinus (Hema-blood, pinein, to drink).

The species belonging to this genus are bloodsuckers, and are much larger than the biting lice. They are bluish in color. The head, thorax and abdomen are distinct. The head is provided with a rostrum which projects anteriorly. It is arranged for piercing the skin and sucking blood. There are two simple eyes and two antennae (feelers). Each antennae is composed of four or five articles, or segments. The thorax is wider than the head, and is provicled with three pair of legs. The legs are short and strong, and the terminal segments are provided with one or two hooklets. By means of these hooklets the louse is enabled to creep, and to hold on to its host. The abdomen is large and is usually composed of nine segments. The female is larger than the male.

The following are the common species of bloodsucking lice :

Hematopinus Asini (Asinus-ass).

Synonym.-Hematopinus Macrocephalus. 
Animal Infested.-The horse.

Description.-The head is long and narrow. A deep notch is noted just back of the attachment of the antennae. In this notch are located the eyes. The abdomen is oval. A few hairs or bristles are found on the head, legs and body. The legs are composed of four articles each, and the antennae of five.

Hematopinus Eurysternus (Euros-broad).

Synonym.-The broad-nosed ox-louse.

Animal Infested.-Cattle.

Description. - The head is short and broad; the thorax is wider than long, and widest at the posterior border. The abdom $2 n$ is large and oval and a broad stripe is noted on the dorsal side of the abdomen of the male; on the female two black blotches are found on the terminal segment. This louse, like the preceding one, is about one-eighth of an inch long.

\section{Hematopinus Vituli (Vitulus-calf).}

Synonyms.-Hematopinus Tenuirostris; the longnosed ox-louse.

Animals Infested-Cattle.

Description.-The head is long and slender and somewhat sunken in the thorax. The thorax is longer than broad. The abdomen is also long and slender and the entire louse has a long and slender appearance.

Hematopinus Suis (Suis-hog).

Synonyms.-Hematopinus Urius; Hematopinus Irritans.

Animal Infested.-The hog.

Description.-Largest species of the genus. Five 
hairs are noted on each side of its piercing stylet. Two protuberances are noted just posterior to the attachment of the antennae, forming deep notches. The legs are marked by dark bands at the joint. The terminal end of the last segment is provided with one large and one small claw, and between them is found a disk that is provided with small

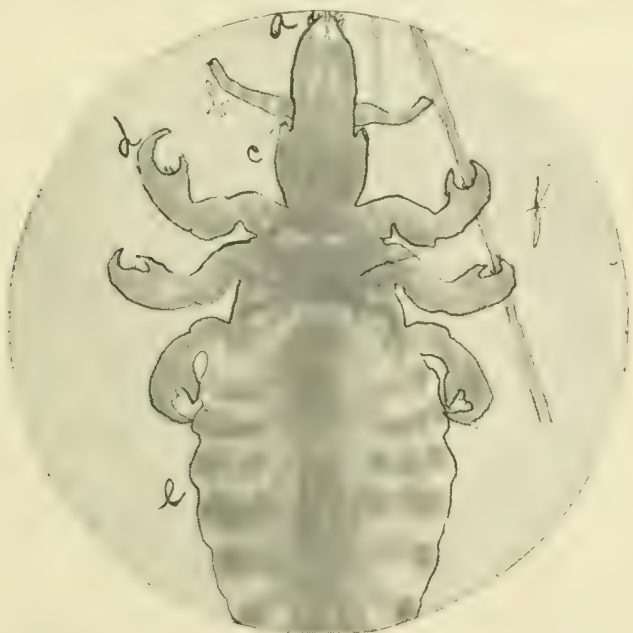

Fig. 7-Henatopinus Suis. Photomicrograph, $\mathbf{i x} 2 / 3$ inch.
a, Head with piercing stylet.
b, Antennae -5 segments.
c, Deep notch in which the eyes are implanted.
d, Claws on end of terminal segment.
e, Abdomen.
f, Thorax, bearing 3 pair of legs.

spikelets, thus giring it a great power to hold on. It is about one-fifth of an inch long.

While this louse is found on all parts of the body, a favorite place is in the folds of skin just back of the ears, where the nits or eggs may be found in abundance. 
Hematopinus Piliferus (Pilus-a hair).

Animal Infested.-This is the blood-sucking louse of the dog.

Description. - Its head is short, almost as long as broad. The antennae and legs are short and the abdomen is large and oval in shape.

Hematopinus Stenopsis (Stenos-narrow).

Animals Infested.-Goats and sheep.

Description.- The head is long and narrow; thorax short; abdomen long.

Trichodectes (Trix-a hair; dectos-biter).

The species of this genus are small and light in color. The mouth parts are located on the under side of the head. The mandibles are strong and are arranged for mastication. The head is provided with two simple eyes and two short antennae. The head is as wide as long, and wider than the thorax. The abclomen is globular in shape and divided into nine segments. Its food consists principally of epidermis.

Trichodectes Pilosus (Pilos-a hair).

Animals Infested.-The horse, the ass and the mule.

Description. - The head is rounded in front; the antennae are inserted well back and are composed of three articles each. The abdomen is oval and tapers posteriorly.

Trichodectes Scalaris (Scalaris-to climb-a ladder).

Animals Infested.-Cattle.

Description.-This species is very common. Its 
head is crescent-shaped and scarcely as wide as long. The abdomen is narrow and rather ovoid in form, and is comprised of nine segments. The legs are short and are equipped with claws which aid it in

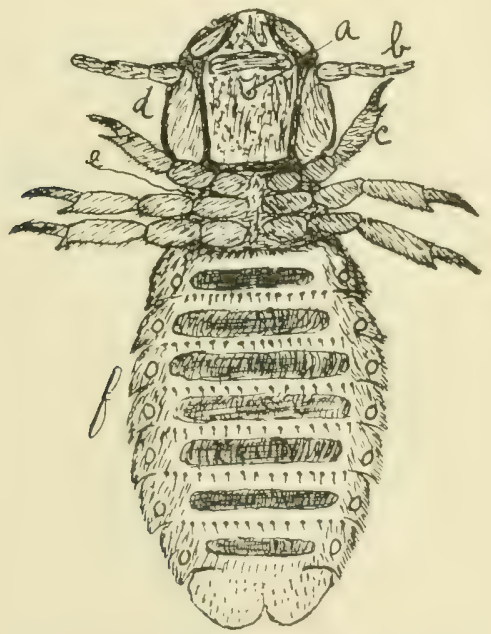

Fig. 8-TRICHODECTES SCALARIS-magnified.
a, Mouth Parts.
c, Legs.
e, Thorax.
b, Antennae.
d, Head.
f, Abdomen.

holding on to its host. A few scattering hairs are noted over the head, legs and abdomen.

$$
\begin{array}{r}
\text { Trichodectes Spherocephalus (Spher-a sphere) } \\
\text { (Cephala-a head). }
\end{array}
$$

Animal Infested.-This louse infests sheep.

Description.-The head is nearly as wide as long, the anterior part being crescent shaped. The thorax is narrower than the head; the abdomen is oval in shape and the legs are short. It is common. 
TRICHODEC'TES LATUS (Latus-broad).

Animal Infested.-The dog.

Discription.-The head is wider than long; the antennae and legs are short and each is composed of three articles or segments; the abdomen is globular

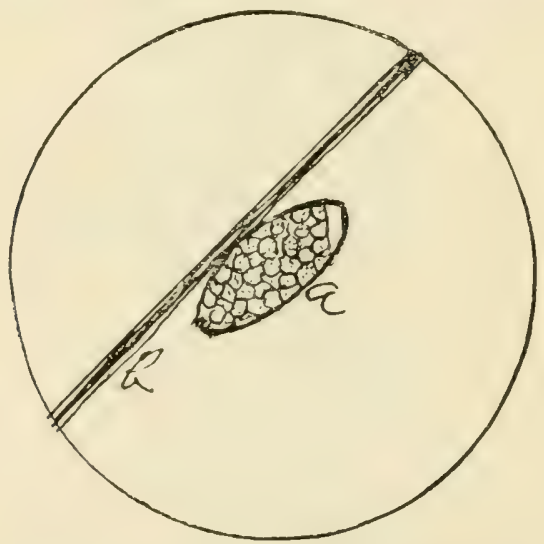

Fig. 9-Trichodectes Scalaris-Ovum.

a, Ovum in Process of Segmentation, b, Hair.

$1 \mathrm{x}^{2} / 3$ inch, magnified.

in shape. It is the host of the Cryptocyst, which is the larvae of the Taenia Canina.

Trichodectes Subrostratus.

Animal Infested.-The cat.

Description. - The head is slightly longer than broad, and pointed in front; the abdomen is elliptical in shape; the legs and antennae are short, and are composed of three articles each.

\section{LIOTHEIDAE.}

The lice of chickens belong to the family Liotheidae. The lice from birds roosting in the barn, or 
whose quarters are separated only by a partition, may get upon horses and cattle and cause temporary parasitism. Each parasite has its own host or hosts and will not live permanently upon another.

\section{Menopon Palliduit.}

This is the most common louse of the chicken. The head is crescent shaped and slightly angular in front; the thorax is wider than long, but narrower than the head; the abdomen is an elongated oval. Fine hairs are found over the body and legs.

\section{MENOPON BISERIATUM.}

A louse infesting the chicken. The head is crescent shaped in front; the antennae are very short; the thorax is narrower than the head; the body is long and oval. Fine hairs are found distributed over the body and legs. This species is larger than the preceding. It may be found on the head of the young chick.

\section{ARACHNIDA.}

The parasites belonging to this class are not insects, - the head, thorax and abdomen are not distinct, and the head is not provided with antennae.

\section{ACARINA.}

Under this order we study the following families, and sub-families, viz:

Gamasidae and Trombidiidae, to which belong species of parasites infesting birds and small animals. The chigger belongs to the latter family.

Sarcoptidae (Sarco-flesh; kopto-to cut). This sub-family is divided into three important genera, 
producing scabies in all animals. It includes the airsac mite.

Demodecidae include the parasites that produce follicular or red mange.

Argasidae and Ixodidae include the ticks.

In these parasites the divisions of head, thorax and abdomen are not distinctly marked, macroscopically. They are all blood-suckers. The head is provided with a stylet for piercing the skin and sucking the blood. The piercing mandibles are surrounded by two palpi. The eyes are small or wanting. The larva is provicled with three pair of legs, the adult with four. The free extremity of the last segment is provided with a hooklet, ambulacrum or pulvillum, which aids the parasite in holding on to its host.

\section{ACARIASIS.}

This is a condition of an animal being infested with some species of parasites belonging to the order Acarina. There are two kinds of Acariasis, viz: Psoric and non-psoric.

Psoric Acariasis is a condition in which the parasites produce scab; infested by species of the subfamilies Sarcoptidae and Demodecidae.

Non-Psoric Acariasis is a condition in which the parasite does not produce scab; infested by species of the families Gamasidae, Trombididae, Argasidae and Ixodidae.

\section{THE ACARI.}

Dermanyssus Gallinae (Derma-skin; gallus-a cock).

Synonym.-Chicken mite.

History.-Universally found in hen-houses.

Description.-They are very smail, as the word 
"mite" indicates. The body is ovi-pyriform in snape and broadest through the posterior third. The piercing stylet is cone shaped, and on either side is a rounded palpus. The color of the body is yellowish red, depending on the amount of blood contained in the digestive tract. The legs are arranged on the anterior half of the body.

Animals Infested.-Birds.

Condition Produced.-They attack the birds in large numbers, piercing the skin and sucking the blood, and produce great irritation (pruritus). They may even cause death of the host. Infested setting hens may leave their nests. The parasites hide in the nests, and cracks and crevices of the building. If the nests are in the same building with horses or cattle, or if the birds so infested roost in the stable with larger animals, the mites may become temporary parasites of the larger animals, causing pruritus and scratching, rubbing, rough coat, etc.

Treatment.-Roosts, nests and buildings should be whitewashed with limewater to which has been added creolin or kreso. The roosts should be drenched with kerosene. Pyrethrum and sulphur, equal parts, may he sprinkled in the nests two or three times a week.

'T'ROMBIDIUM Holosericeum (Trombos-harvest) (holo-whole.)

Synonyms.-Chigger; mite; harvest bug. History.-Found in Europe and America.

Desription. - This parasite is just visible to the unaided eye. The body is oval in shape and reddish in color; the legs are provided with six articles each, the terminal end of the last segment being fur- 
nished with two hooklets and a hair; the piercing apparatus is conical in shape and on either side is found a palpus; the legs are located on the anterior half of the body.

Life Cycle.-The eggs are laid in the cracks and crevices and in the filth of hen houses, where they hatch, the egg first hatching into the six-legged mite, which moults and develops into the eight-legged state.

Animal Infested. - They infest the cuticular surface of birds and small animals, and pierce the skin and suck the blood, producing great irritation, which may cause death. They may become parasites of large animals if the infested birds roost in quarters adjarent to or within the stable.

Treatment.-Same as for Dermanyssus.

LEPTUS IRRITANS (Leptus-thin, small ; irrito-to irritate.)

Synonym.-Chigger.

History.-Found in the grass and timber during the hot part of summer.

Description.-Always in the larval form; the body is nearly round; the head is broad and is provided with piercing mandibles. It is bright red in color.

Animals Infested.-The parasite is brushed from the leaves of vegetation by man or animal, when it buries itself in the skin and produces intense itching.

Treatment.-If the affected part be touched with a one-percent solution of formalin it will kill the paraasites and stop the itching; or, the parts may be touched with a two-percent solution of aqua ammonia. 


\section{SARCOPTIDAE.}

The three principal genera of the sub-family Sarcoptidae are:

Sarcoptes (Sarco-flesh; kopto-to cut).

Psoroptes (Psora-itch).

Symbiotes (Sym-togather; bios-life).

The Sarcoptes live on the body where the hair is short, - in horses and dogs on the body; in sheep, on the facial regions.

The Psoroptes live on the body where the hair is long, - in horses and cattle in the mane and down the back; in sheep, on the body.

The Symbiotes live on the extremities,-legs.

GENERAL DESCRIPTION OF THE FAMILY.

Minute in size; the body is oval and obtuse at both ends, convex above and flat below; the mouth parts are provided with a single lancet-shaped piece, surrounded by palpi ; the legs are divided into five articles each, the free extremity of the last segment is provided with an ambulacrum or one or two hairs.

The genus Sarcoptes, species Scabei, is provided with a head as broad as it is long; the rostrum is short, and is margined by two cheeks.

Male.-The first, second and fourth pair of legs are provided with ambulacrum and the third pair with one bristle at each terminal extremity.

Female. -The first two pair are provided with ambulacrum and the last two pair with one bristle at each terminal extremity.

The genus Psoroptes, species Communis, is provicled with a head that is longer than broad; the 
rostrum is conical in shape and elongated, and not margined by cheeks.

Male. - The first three pair of legs are provided with ambulacrum, the fourth pair with two bristles.

Female.-The first two and fourth pair of legs are provided with ambulacrum. The third pair with two long bristles.

The genus Symbiotes, species Communis and Auricularum,- - rostrum as wide as long, and destitute of cheeks.

Malc.-All legs are provided with ambulacrum.

Female.-The first, second and fourth pair are provided with ambulacrum and the third pair with two bristles.

\section{LIFE HISTORY OF THE FAMILY SARCOPTIDAE.}

The life history is divided into five stages, viz.: The oval, larval, pupal, adult and ovigerous female.

First Stage.-Ova.-Under favorable conditions the eggs hatch in five to ten days.

Second Stage.-Larval Stage.-Six-legged and asexual; it passes through two or three moults.

Thin Stage. Nympha.-The last moulting in the lirval stage adds a fourth pair of legs; no sexual organs; the males and females are distinguished by the difference in size, the females being larger.

Fourth Stage-Mature Male and Female.-The last moulting in the nympha stage develops the distinct sexes.

Fifth Stage. - The Ovigerous Female. - The impregnated female moults, which causes changes in the genital apparatus.

It is estimated that each ovigerous female Sarcopt 
lays fifteen eggs, of which ten may be females and five males. Under favorable conditions it will pass its life cycle in fifteen days. At this rate, one ovigerous female would cause the production of $1,500,000$ scab parasites in 90 days.

\section{THE SCAB PARASITES.}

Sarcoptes Scaber, variety Equi (Equus-horse.)

Synonym.--Itch mite; mange mite.

History.- In the United States it is found among horses in the Northwest, especially upon the range.

Animals Infested.-This is the common scab parasite of the horse.

Life Cycle.-The following may be added to what has been given as to the stages acari pass through: The ovigerous female burrows into the skin, forming galleries. In these galleries may be found females, ova and larvae. As soon as the eggs are hatched the larvae leave the gallery. In the serum under the scab may be found the larvae, nymphae, adult males and females.

Condition Produced. - The parasite is equipped with a piercing stylet with which it pierces the skin, the puncture causing a minute red spot, followed by a small vesicle, which ruptures. The serum drics and forms a minute scab. In this way the myriads of parasites cause a piling up of scabs, thus producing a scabby condition. As the disease progresses the scabby patches enlarge and the scabs pile up, until they are often half an inch in thickness, unless the parts have been rubbed.

Symptoms.-Pruritus; will rub against any post, fence, stall or other object. Itching is more intense 
at night than during the day, and worse in warm weather than in cold; when clothed than when not clothed. The parasite first makes its attack in the region of the withers and back, and gradually spreads over the body. Hairless scabby patches appear in later stages.

Mode of Infestation.-The horse may come in contact with infested animals, or be placed in quarters in which infested animals have recently been kept; or, contact with curry-comb, rub-rag, brush, harness, blanket or saddle recently used on infested animals.

Sarcoptes Scabei; variety canis (Canis-dog).

Synonym.-Mange mite ; itch mite.

History.-This species is widely distributed.

Animal Infested.-The dog.

Condition Produced; Symptoms. - It begins first on the facial region and ears; then on the breast, feet and abdomen, and last on the body. It is not uncommon to find cases with the entire cuticular surface affected. The scabs are not allowed to pile up as we see on the backs and withers of cattle and other large animals, for because of the intense itching the animal constantly rubs and scratches itself so that we find only thin scabs. The skin becomes partially denuded of hair, and in later stages the animal becomes thin, even emaciated, and is a dejected looking creature. If a scraping be made from a fresh scab by aid of the knife (care being taken to secure the serum from between the scab and the skin) and this scraping be examined under the microscope, the parasites may be observed. If this scraping be placed in a bottle and the bottle placed in the 


\section{Plate IIIa.}
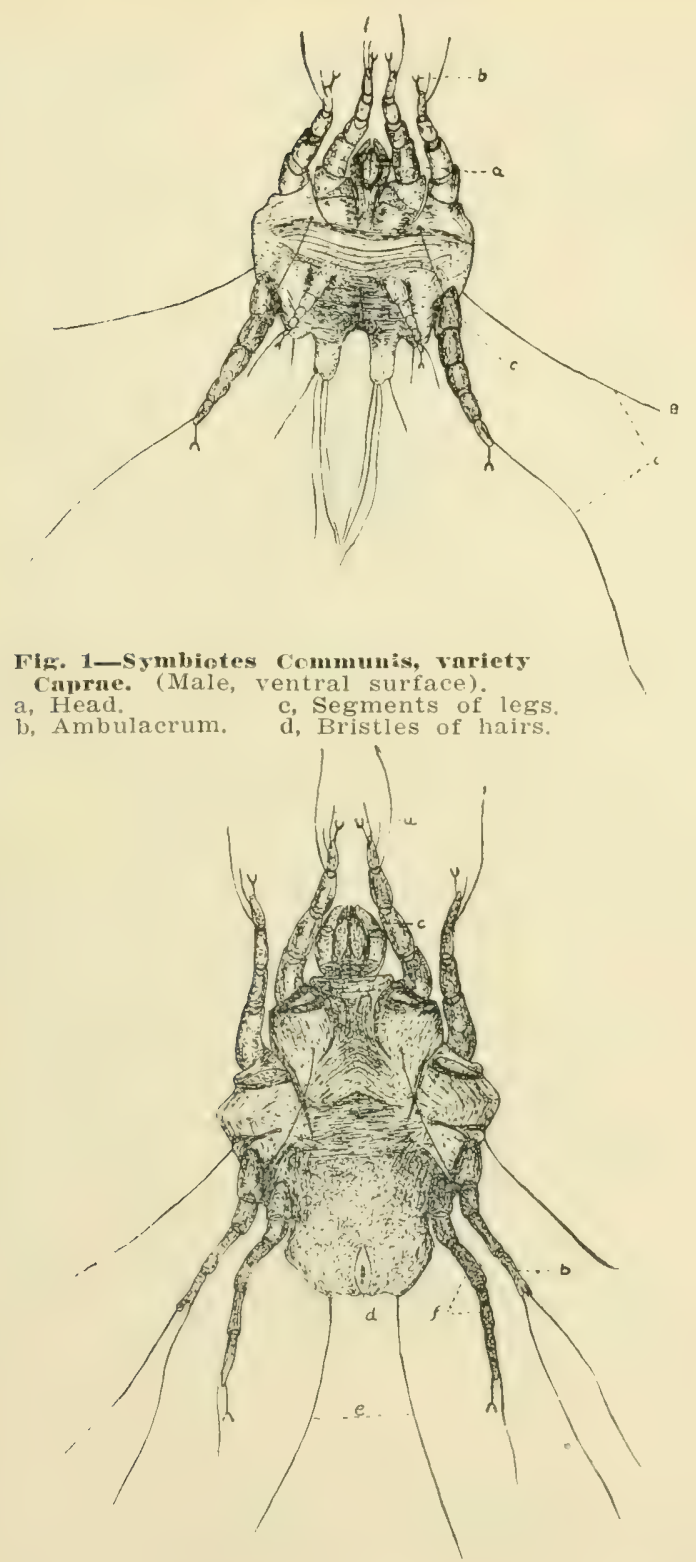

Fig. 2-Symbiotes Communis, variety Caprae. (Ovigerous female).

a, Ambulacrum.

b, 3d pair of legs with 2 bristles. d, Vüiva.

f, Segments of legs. b-e, Bristles of hairs. 


\section{Plate IIIb.}

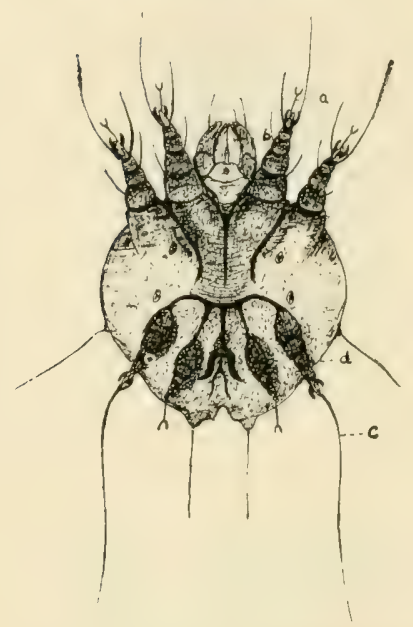

Fin. 3-Sareoptes Seabei, variety Canis.

(Male. Ventral view).

a, Ambulacrum.

b, Head yarts.

c, Bristles.

d, Segments of legs.

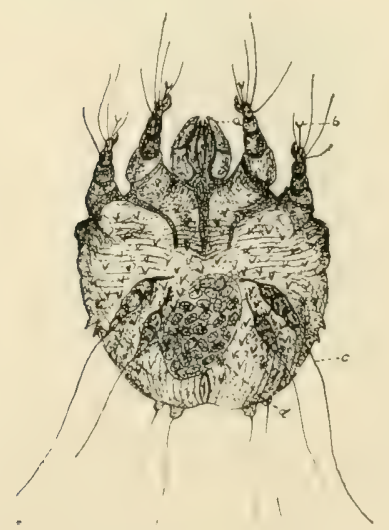

Fis. 4-Sarcontes Serbei, variety Canis.

(Ventral view of ovigerous female).
a. Rostrum.
b, Ambulacrum.
c, Bristle.
d, Uterus. 
sun or other warm place, the parasites will leave the scab and will be seen as minute white specks upon the walls of the bottle.

Sarcoptes ScabeI ; variety Suis (Suis-hog).

Synonym.-Itch-mite.

History. - Not common in the United States.

Animal Infested. - It is the only species of the subfamily Sarcoptidae that infests the hog.

Condition Produced; Symptoms. - The scab parasites may begin their propagation primarily at any point on the body, though usually they begin near the ears, around the eyes, on the inner side of the thighs, or between the forelegs. The parasites cause iutense itching, the animal rubs and scratches, scabs appear, the skin becomes thickened, and the hair stands erect; in later stages the hair falls out. This parasite has been transmitted to man and dog, where it produced temporary parasitism, causing intense itching for a few days.

SARCOPTES ScabeI; variety ovis (Ovis--sheep).

Synonym.-Face-scab parasite of sheep.

History.-Rare in America.

Condition Produced.-A scabby condition of the head, resembling other forms of scabies.

Sarcoptes ScabeI, variety Caprae (Capra-goat).

History. - The sarcoptic form of scabies in goats has been reported at different times; rare in this country.

Animal Infested.-The goat.

Condition Produced: Symptoms. - It usually attacks the head and neck first, then spreadis to the body, 
and finally, if not treated, the whole body and limbs will be affected, as in the dog. It causes intense itching, scabs pile up, and the hair falls out, revealing the scabby patches.

Sarcoptes Mutans; variety Gallinae (Gallus-a cock).

History.-Widely distributed.

Animals Infested.-Fowls, on the legs.

Description. - The acarus is much smaller than the species producing scabies in the large animals. It is round in shape and its legs are short, giving it a stubby appearance.

Condition Produced. - The condition produced by these parasites is called scaly leg. They live under the scales, especially on the anterior part of the tarsi. The irritation produced by its punctures results in a scabby or scaly condition of the legs by much the same process as in scabies of the large animals. The minute scabs accumulate under the scales, displacing them and producing a lumpy, scaly condition, the crust becoming porous and honey combed. The parasites can be found in the serum between the scab and the leg, appearing as minute white specks.

Psoroptes Communis; variety Equi (Equus-horse).

Synonyms.-Long-nosed Psoropt; Psoroptes Longirostris.

Description.-About the same size as the Sarcoptes. Its rostrum is more than twice as long as wide.

Vitality.-It will live for thirty days off of the host, if in a moist atmosphere, and temperature not too low.

Animal Infested.-The cuticular surface of the horse. 
Condition Producd.-It produces scabies in the same manner as the Sarcoptes, the parasites living in colonies under the scab. The scab parasites usually implant themselves on the animals where the hair is long, as the mane, back and rump. Its spread is slow, though it may later spread over the body. The maxillary space, and where the hair is thinnest. as the groin, and the axillary region, are favorite

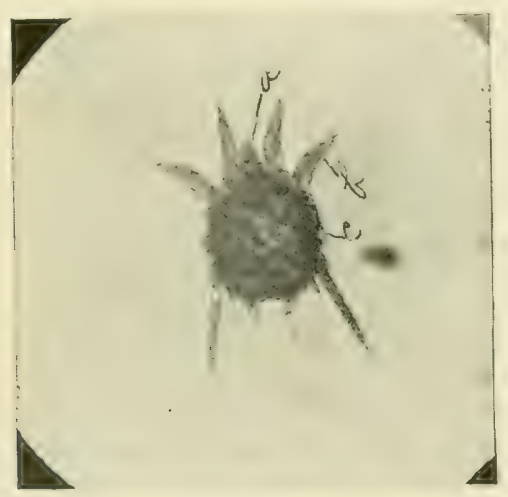

Fig. 10-Male Psoroptes Conmunis, variety Ovis. Photomicrograph $1 \mathrm{x}^{2} / 3$ inch.
a, Head parts.
b, Legs.

c, Body. (Thorax and abdomen are not distinctly marked macroscopically.)

locations in later stages. The biting and rubbing, a result of the intense irritation produced by the parasites, cause the hair to become matted and present a stairy appearance. Later the hair falls out and reveals scabby hairless patches. The mode of spread of the contagion, and the treatment, are the same as in scabies produced by other parasites. If the disease is not treated the animal becomes thin in flesh, anemic, and finally dies. 
Psoroptes Communis, variety Bovis (Bovis-ox).

History. - Widely distributed in the United States; found in the middle West and South.

Animal Infested.-This is the common scab parasite of the ox.

Condition Produced.-The back, loins and croup are the first parts to become infested. On account of the difficulty in scratching these parts the scabs

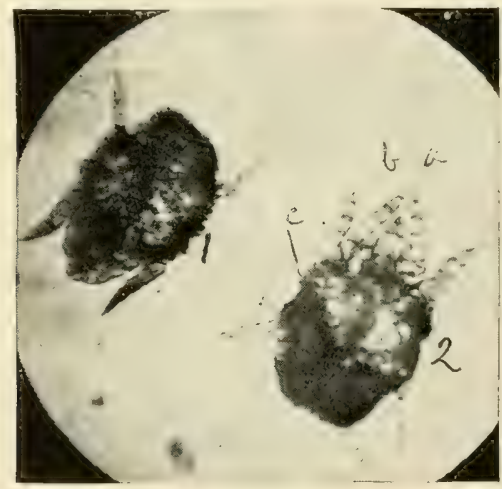

Fig. 11-Psoroptes Communis, variety Bovis. Photomicrograph.

1 and 2, Females.

b, Legs. a, Head parts.

c, body.

pile up, often an inch in thickness. The animal rubs and licks himself as a result of the pruritus, gradually becoming thin in flesh, and later emaciated.

Psoroptes Communis, variety Ovis (Ovis-sheep).

History.- Widely distributed. Found in western and southwestern parts of the United States; also in France, Germany, Asia, Australia and Mexico.

Animal Infested. - This is the common scab parasite of the sheep. 
Condition Produced; Symptoms. - In watching a bunch of sheep that have recently become infested, it will be noted that they are restless; that they will bite themselves; that bunches of wool will become

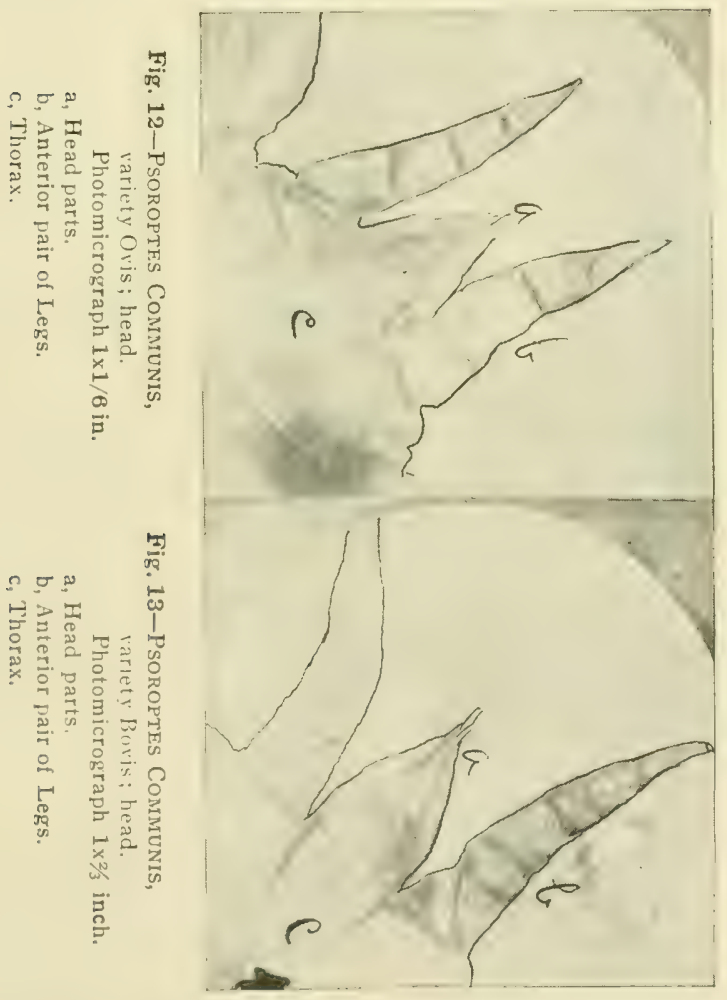

loosened; possibly some saliva will be noted at this point. If the skin be examined with the aid of a hand lens, or if a scraping be made with a knife (care must be taken to get close to the skin), the 
parasite will be found. Or, if the scraping be placed in a clear glass bottle and the bottle set in the sunshine or a warm place, the parasites will soon be found crawling over the walls of the bottle. In the later stages the scabs will appear on the back and rump. The scabs continue to pile up and the wool falls out, revealing large scabby woolless patches. The animal becomes emaciated, and finally dies. This parasite causes great loss in the wool crop.

Mode of Infestation.-By being placed in quarters where infested sheep have recently been kept; by being shipped in cars not disinfected after using for transportation of infester sheep; through shipping centers, unless such centers are controlled by proper quarantine regulations; by the introduction of an infested sheep into a bunch not infested; or, by being driven over a trail recently followed by scabby sheep.

Psoroptes Communis, variety Capræ (Capra-a goat).

Produces scabies in goats in the same manner as the Psoropt in sheep.

Symbiotes Communis, variety Equi (Equus-horse).

Synonym.-Foot-scab parasite.

History.-Symbiotic scabies is not common. It has been found in some parts of the old world, and is more prevalent among coarse horses and those that are poorly cared for.

Description.-This mite is a trifle smaller than the species of the two previous genera. The rostrum is nearly as wide as long.

Animal Infested.-The horse. 
Condition Produced.-It produces scabies of the legs, usually in the region of the fetlock and pastern of the posterior extremity. In later stages the scabby condition extends up the leg, possibly as high as the body. The skin becomes thickened and rigid and the legs swollen. Cracks may be formed in the pastern region from which may be found a secretion of a fetid nature. The parasites live in colonies under the scab.

Treatment. - Thoroughly scrub the affected parts with soap and warm water. After thoroughly soaking the parts with water and soap the scabs may be easily removed. Then apply any of the dip prepations.

Symbiotes Communis, variety Bovis.

History.-Not common.

Animals Infested.-Cattle.

Condition Produced.-Symbiotic scabies in the ox begins around the base of the tail and rump. It is slow to spread from this locality and has been known to affect the animal for years, with a slow tendency to spread toward the body. It is said that it does not cause such intense pruritus as the sarcoptic form.

Symbiotes Communis, variety Ovis.

Synonym.-Foot-scab parasite.

Animals Infested.-Sheep.

Condition Producel.-It produces scabies of the feet and legs. It is slow to spread, showing a tendency to recovery in summer, but spreading more from sheep to sheep in winter. Like other scabies it produces itching and the animal stamps and rubs the affected parts. Symbiotic scabies most often 
attacks the hind legs, but may spread to the fore limbs.

$$
\text { Srmbiotes Communis, variety Caprae. }
$$

Animal Infested.-The goat.

Condition Producid.-Attacks by preference the neck and back. Yellowish, thick, hard crusts form. The skin underneath the scab becomes thickened and cracks are often observed. Tumefaction of the lymph glands that receive the lymph from these parts has been noted. The hair becomes matted and falls out, exposing the scabby area.

Symbiotes Auricularum, variety Canis (Auris-ear)

Animal Infested.-The dog.

(Canis-dog).

Numes of Discase.-Otacariasis, auricular scabies, parasitic otitis, epileptiform disease of dogs.

Condition Produced; Symptoms. - The parasites produce an inflammation of the external ear, and in some cases ulcers are observed. In the scrapings from these ulcers the Acari can be found. Evidence of itching is manifested; the dog shakes his head from side to side and scratches his ears with his paw. The hunting dog, after vigorous exercise, shows symptoms like those of epilepsy. Later the dog is attacked more frequently with these fits, and becomes sullen, with a tendency to be cross.

Treatment.-Disinfect kennels with five-percent kreso, or sediment from the lime and sulphur dip, etc.

Thoroughly cleanse the ear and apply the following :

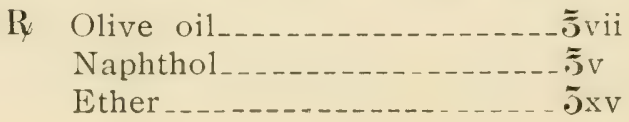


M. Sig.-Inject a small quantity of this mixture into external auditory canal once a day.

A saturated solution of alcohol with boracic acid can be used.

Cytodites Nudus (Cyto-cell; Nudus-nude).

Synonym.-Air-sac mite.

History.-Rare in this country; found in Europe.

Description.-Scarcely visible macroscopically. The body is rounded in shape and whitish in color. The rostrum is conical. The legs are strong, conical in shape and composed of five articles each. The free extremity of the last segment of each leg is provided with an ambulacrum. (An ambulacrum is a cup-shaped sucker attached to the extremity of the leg by a pedicle.) The adult is provided with four pair of legs; the two anterior pair are located on the anterior third, and point forward; the two posterior pair are located on the posterior half, and point backward.

Animals Infested. - They infest the air-sacs of fowls and pheasants. They are white in color and can be seen macroscopically as small bodies, very minute in size. They even reach the air cells of the bones.

Condition Produced. - Their irritation causes inflammation and results in death of the host.

\section{TREATMENT OF SCABIES.}

Large bunches of cattle and sheep which become infested with scab parasites must of necessity be dipped. For this purpose the dip which has proved the most successful is the lime and sulphur dip. 
The lime acts as a solvent for the sulphur. The sulphur is a parasiticide. This dip is made in the following proportion:

Unslaked lime

8 pounds.

Sulphur._._._._._._._._._. 24 pounds.

Water 100 gallons.

Boil for two hours. Use at a temperature of 100 degrees to 110 degrees Fahr. Keep the animal in the dip two or three minutes by the watch. Clean the sheds or barns and yards. Disinfect the fences, stalls, racks, and feed troughs with the sediment of the dip. Another dip is the arsenical dip, made as follows :

Arsenious acid (white arsenic) _- 10 pounds.

Sulphur 1 ounce.

Soda ash____._- 10 pounds.

Soft soap _._._._._._._._. 2 pounds.

Boiling water..._._._._._. 2 gallons.

After cooling add enough water to make twenty. five gallons. It is estimated that this quantity of dip is sufficient for twenty-five sheep.

The tobacco-sulphur dip is made as follows:

Tobacco leaves 1 pound.

Sulphur 1 pound. Water 6 gallons.

Place the tobacco in a vessel of warm water, cover and let steep for twenty-four hours. Bring to a boil, let cool and strain. Press all the juice out of the leaves. Mix enough water to the sulphur to make a paste, then mix with the tobacco infusion, thoroughly stir and heat to a temperature of 110 and sponge or dip the animal. 
Coal tar products are used to some extent. Some are reliable and some are not. The kreso dip put up by P. D. Co. is said to contain some dissolved sulphur, therefore has a double combined parasiticide effect. Scaby sheep should be clipped. After one week dip. At the end of ten days dip the second time and remove to non-infested quarters. In case of scabies in horses clip the animal. Thoroughly scrub with a dip. Repeat in ten days. For dipping devices for cattle there are used the plunge dip, the cage dip and the spray dip.

\section{DEMODECIDAE.}

The sub-family Demodecidae includes a group of parasites that live in the hair and sebaceous follicles of the skin and produce cuticular pustules. They are placed under one genus,-Demodex (worm-like) and one species,-Folliculorum (follicle).

Gencral Description.-Under a low-power microscope the parasite has a general outline similar in shape to an oat grain. The head part is broad and is provided with a stylet or lancet-piece arranged at the anterior extremity. The thorax is not distinctly separated from the abdomen. The larva is provided with three pair of legs, the adult with four. Each leg is made up of three short segments, the last one being very short and provided with two hooklets or claws.

Life History. - The life history is similar to that of the sub-family Sarcoptidae. The ova are laid in the pustule. The newly hatched larvae are asexual and are provided with three pair of legs which are mere tubercles. After moulting the larvae are observed 
to have four pair of legs. Another moulting brings the larvae to the pupal stage, with legs fully devel. oped, and after still another moult they are sexually mature.

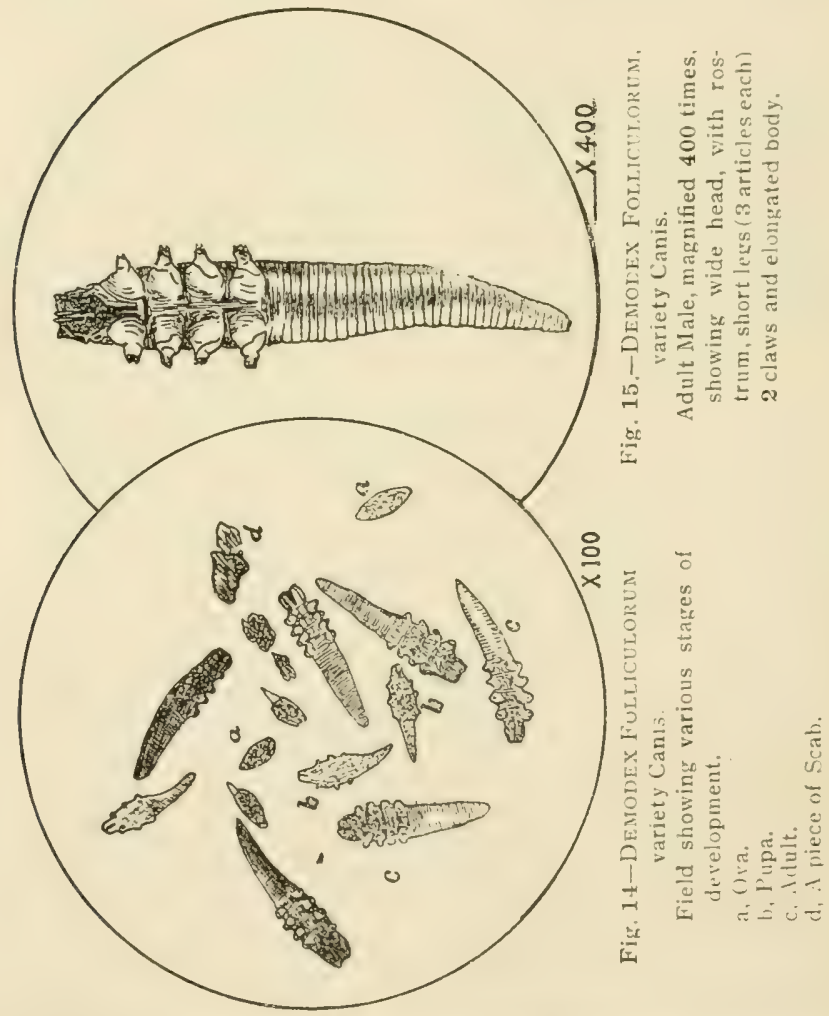

Of the varieties of Demodex Folliculorum eriumer. ated only two are common in the United States.

Demodex Folliculorum, variety Canis.

History.-First studied in Europe. It is common in many localities of the United States. 
Animal Infested.-The dog.

Parts Infested; Symptoms.-The parasite burrows into the hair or sebaceous fullicles, occluding the ducts and producing pustules. These pustules are prominent, and give the skin a rough appearance. The animal is ustually first attacked by the parasite in the region of the breast, legs, axillary ancl facial regions. The skin becomes red, and hence it is called red mange. Considerable irritation accompanies the malady. The dog scratches and bites the warts, the hair falls out and the skin becomes thickened. In later stages the entire cuticular surface becomes affected.

Treatment.- Successful treatment of this malady is difficult because of the difficulty of getting the solution to the interior of the pustules. A mixture of gasoline, oil of tar and oil of cade has been used with more or less good results. Also

Oleo-resin aspidii_.......... 8 parts

Creolin

Alcohol ...... _... 50 parts

Demodex Folliculorum, variety Suis.

History.-Frequently fuund in America and in Europe.

Animal Infested.-The pig.

Condition Produced.-The parasites attack the cuticular surface in the axillary reginn and flanks; then the disease spreads over the entire surface of the body and legs. The skin becomes thickened and rough. The pustules push up, giving the skin a papillated appearance.

Mode of Infistation. - The animal may be infested 
through coming in contact with infested animals, by being placed in quarters in which infested animals

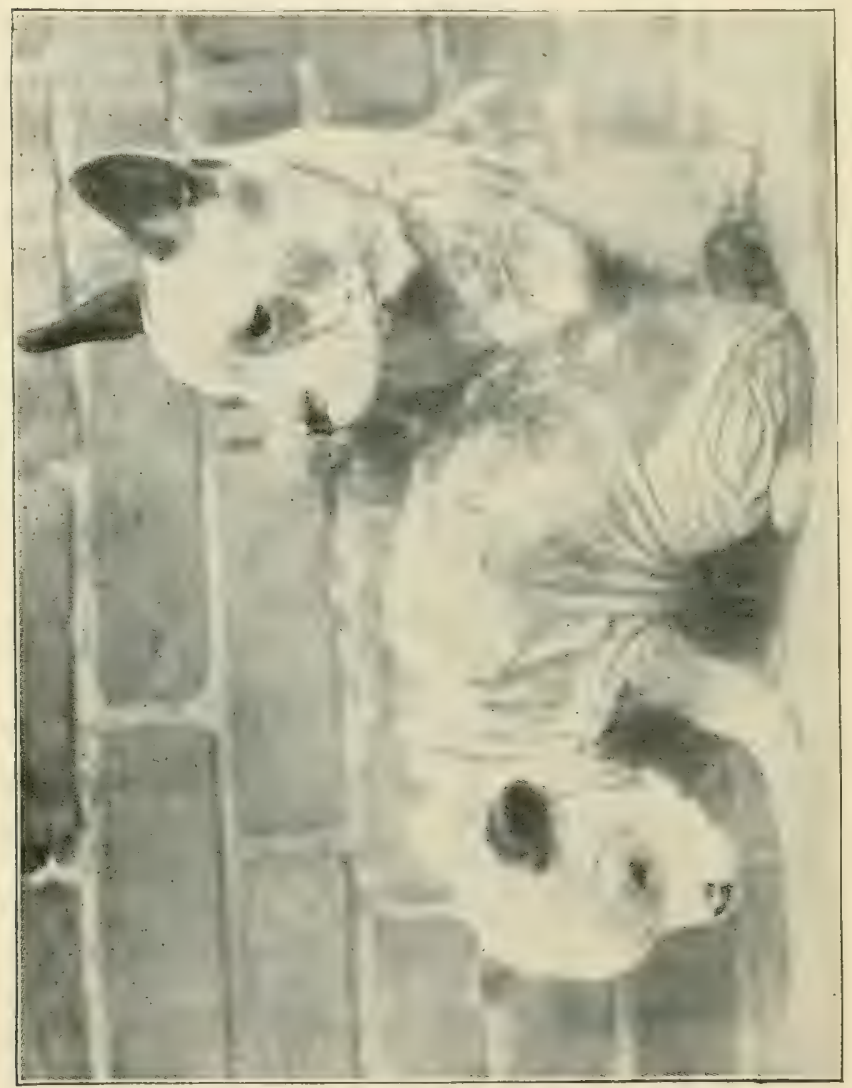

Fig. 16-Two pups affected with Demodecic SCABIES or Red Mange. (Photograph).

have been kept, or shipped in cars or other vehicles in which infested animals have been transported. 


\section{THE TICKS.}

\section{ARGASIDAE.}

The family Argasidae includes the ticks. They are provided with flat, oval bodies. The piercing mandibles and hypostome are located beneath an overreaching cephalo-thorax, or anterior part of the dorsal

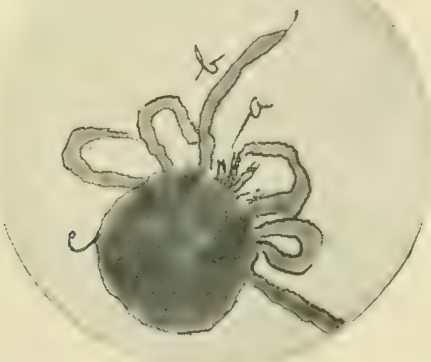

Fig. 17-ARgas Miniatus, Larva.

a, Mandibles and Palpi.

b, Legs.

c, Body.

surface. The dorsal shield is absent. The life history is similar to that of the common ticks.

\section{Argas Miniatus.}

Synonyms.-Argas Americanus; Chicken tick.

History.-Found in Mexico and the Southern part of the United States.

Description. - The parasite is flat like a bedbug, and ovoid in shape. It is provided with an overreaching dorsal surface, the top of which is pitted. The head parts consist of two mandibles provided with teeth at the terminal end. Beneath these is a 
spatula-shaped hypostome divided into two symmetrical halves, and on each half there are arranged three
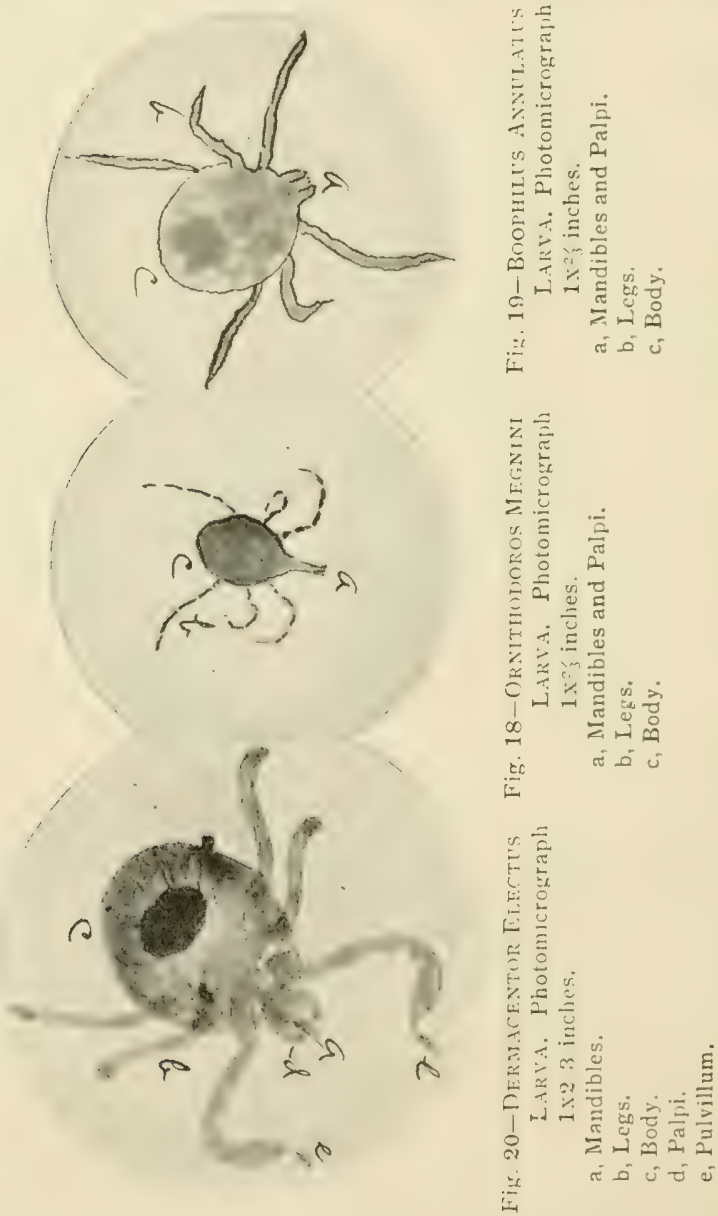

rows of irregular shaped denticles. The mandibles are surrounded by palpi. 
Animals Infested.-The tick is found in the hens' nests and in the litter. They attack the birds mostly at night. They drive the hens from their nests and cause death of the host. They may be found on larger animals.

\section{Ornithodoros Megnini (Megnin).}

Synonyms.-Spinose tick; ear tick; spider tick; Rhyncoprium Spinosum.

History.-Found in the South and middle West.

Description.-The female, when engorged with blood, is about the size of a castor bean. The body is oval in shape, with the transverse diameter of the anterior third greater than that of the posterior third. Its cuticular surface is covered with spines, from which it gets its name,- "spinose tick." The head parts are prominent; the hypostome not provided with denticles in the larval stage. The palpi are round in shape, and long. Its color varies from brown to violet. A specimen, two-thirds engorged with blood, taken from a steer, moulted once, and lived from Feb. 10, 1906, to July 8, 1907.

Animals Infested.-It infests the ears of horses, cattle and other animals.

Condition Produced. - They attach themselves to the skin lining the conchi, and also invade the auditory meatus. This causes much irritation; the animal shakes his head and shows other signs of nervous disorder. It is reported to have caused death.

Treatment.-Oil, or any antiseptic solution of sufficient strength to be a parasiticicle. Oil coats over. closing the breathing tubes, and asphyxiates the tick. 


\section{IXODIDAE.}

This family includes a group of ticks, the head parts of which are slightly longer than broad. The palpi are short. The head is provided with mandibles and hypostome as in the preceding family.

Rhipicephalus Sanguineus (Sanguis-blood.)

Distribution.-Has been reported in Southern states.

Description.-Resembles the Boöphilus Annulatus in size and shape, though the head is more prominent and the palpi are short and broad, but longer than the hypostome. The base of the capitulum (or head parts) is broader than long, forming a projecting angle at each side. In the male the dorsal shield is red and covers nearly all of the dorsal surface.

Animals Infested.-Cattle and other animals.

IxoDes Ricrnus (Ricinus-castor oil plant; eidos-like.)

Synonym.-Castor bean tick.

History.-Found in America, Europe and Africa.

Description.-In shape it resembles the castor bean. Its color is variegated like that of the castor bean, the dorsal shield being a deep chestnut brown. The mandibles are armed with teeth; the hypostome is lanceolate in shape, each half being provided with six rows of denticles. The body of the male is flat, oval and of a deep reddish brown, the dorsal shield covering almost all of the dorsal surface.

Animals Infested.-It attacks the cuticular surface of the horse, ox, dog, etc. 


\section{Plate IVa.}
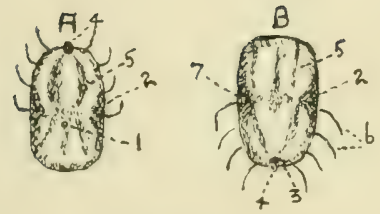

Fig. 1-Boophilus Annulatus. (Engorged females).

A-Ventral view.

$\mathrm{B}$-Dorsal view of same.

1. Anus.

2, Lateral constrictions.

3 , Rudimentary dorsal shield.

4, Short rostrum.

5, Longitudinal dorsal depressions.

6. I,egs.

7, Stigmen.

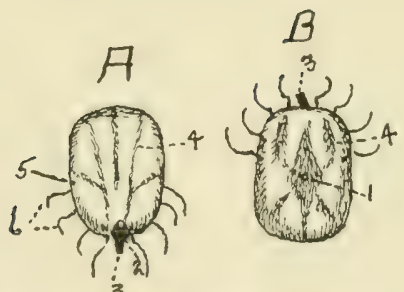

Fis. 2-Amblyomma Aneriยภกแm.

(Engorged female).

A-Dorsal view.

B-Ventral view.

1. Anus.

2, Well developed dorsal shield, showing white spot.

3 , Rostrum.

4, Longitudinal Jepressions.

5, Stigmen.

6, Legs.

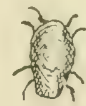

A

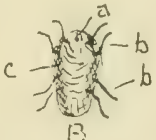

B

Fig. 3-0rnithodoros Megnini.

(Engorged females).

A-Dorsal view.

$B$-Ventral view.

a, Rostrum.

b, Legs.

c, Body tapering posteriorly. 


\section{Plate IVb.}

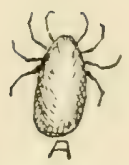

Fig. 4-Argas Miniatus. (Engorged females).

A-Dorsal view.

B-Ventral yiew.

a, Rostrum.

b. Legs.

c, Body.

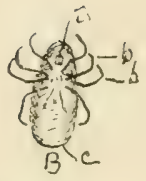

Fig. f-Boophilus Annulatus. (Mature, male).

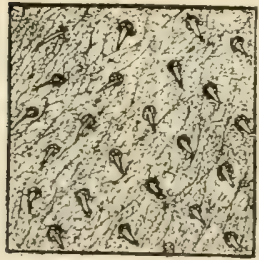

Fig. 7-Ornithodoros Megnini. (Section of skin, showing spines). (Engorged female).

a. Prominent rostrum. b, Large white shield.

c, Legs.

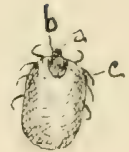

Fig. "-Dermacentor Electus.

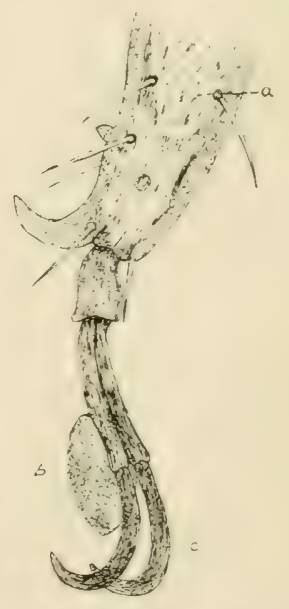

Figr. S-Yeg Boophilus Annulatus.

a, Tarsus.

b, Pulvillum.

c, Hooklets. 
Boophilus Annulatus (Annulus-a ring).

Synonyms.-Boöphilus Bovis; Margarapus Annulatus; fever tick; Texas fever tick; Ixodes Bovis.

History.-Found in southern part of United States and in southern Europe.

Animal Infested.-The ox.

Discription.-The engorged female is about the size of the castor bean, has a constriction in the mid. dle of the lateral sides, with two longitudinal depressions anterior to, and three posterior to this constriction, on both dorsal and ventral surfaces. The legs are not.strong, and are located on the anterior half of the body. The head is not prominent; it is provided with mandibles, palpi and hypostome, and the latter is furnished with eight rows of denticles. The dorsal shield is sma!l and brownish red in color. The surface of the parasite is often marked with delicate yellowish white wavy lines. The extremity of each leg is provided with a pulvillum, two hooklets and a globe shaped apparatus. Breathing is by means of a trachea located on either side posterior to the last pair of legs, and covered by a perfurated scale called a Stigmen. The male does not become engorged with blood, but remains flat. Its dorsal surface is a brownish red color.

Life History. - The engrorged female drops to the ground, seeks a secluded place, as under some object, and begins ovulation (laying eggs) in from three to five days. This period lasts about two weeks. During the period of ovulation the female scarcely moves. The eggs are ovoid in shape and brown in color, and are covered with a varnish-like substance. The eggs are pushed out from the ante- 
rior extremity of the body, forming a mass numbering, usually, 4,000 to 5,000. These eggs hatch in about three weeks, if the temperature is favorable. The larvae are small, six-legged asexual parasites. In this stage they have lived in a bottle for six months without food. They crawl over the ground or upon the blades of grass or weeds, and thus are brushed off by animals passing along. Once on the animal they attach themselves usually in the region of the thigh, between the hind legs. After one week they moult (passing through a change in the anatomical structure, during which time they shed the skin.) They are now provided with four pair of legs and at the end of another week they moult again, and become sexually mature. The males seek the females and place themselves in apposition, in which position the male can be found still alive after the female is fully engorged. But its life is short after being removed from the host; it dies within a few hours. The female draws blood slowly for the first two weeks, then rapidly for the third week, becoming fully engorged in three weeks, drops off, and is ready to begin ovulation; gradually shrinks during ovulation until she is only about one third of her original size, then dies.

Condition Produced.- The tick carries the proto= zoa (Piroplasma Bigeminum) causing Texas or Splenic Fever. The larva, as soon as it gets onto the host, attaches itself to the skin and begins to draw blood. At this time it inoculates the host with the protozoa. The single celled parasites enter the red blood cells, break them up and liberate the hemoglobin; the protozoa have multiplied in sufficient 


\section{Plate V.}

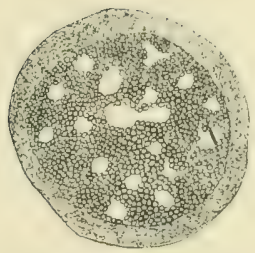

Fig. 1-Stignen, Hoophilux Anumatus lareac. (From moult).

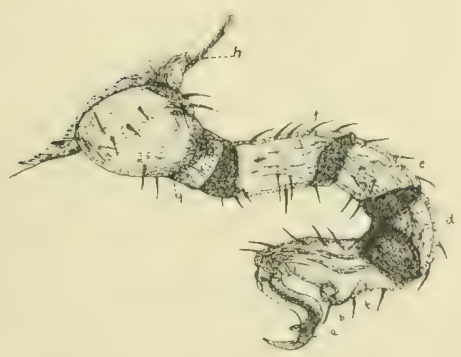

Fiź. 3-Leg of Ornithodoros Meguini.

a, Hooklit.

1), Sense pore.

c, Tarsus.

d. Protarous,

f. Tilia.

f, Femur.

g, 'Trochanter.

h, Portion of body.

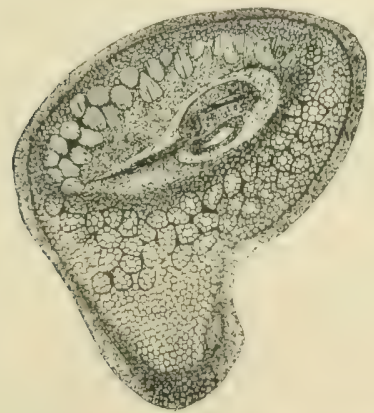

Fig. 5-Stigmen from Dermucentor Reticulatus.

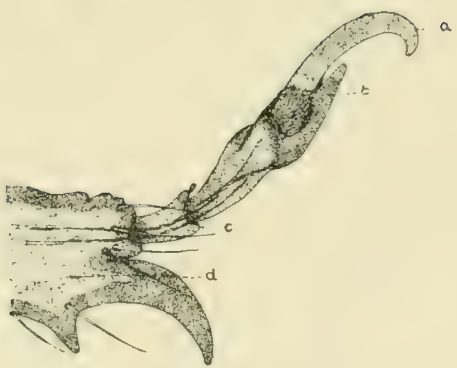

Fig. 2-Booplailus Australis, Lez, side view,

a, Hooklet.

b, Side view of disc.

c, Pedicle.

d, Tarsus.

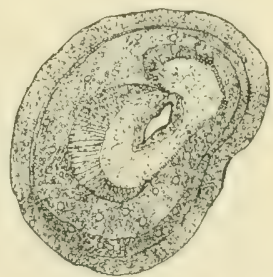

Fiš. 4-Stigmen from adult IPophilus Annulatus.

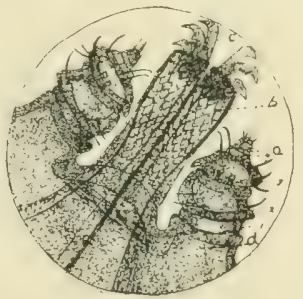

Fig. 6-Ventral view of enpitulum, Booplilus Anmulitus.

a, Palpus.

b, Hypostomo armed with s rows of Denticles.

c. Mandibles showing diglts.

d. Base of capitulum.

a, PALPUS.

1. Basal Article.

2. Ante-penultimate article.

3. Penultimate article.

4. Apical article. 

numbers to produce the acute symptoms of tick fever by the eleventh day. The liver becomes congested, the bile thickened and granular; the spleen becomes greatly enlarged, and the contents is the consistency of blackberry jam. The urine is port wine colored, and the cancellated portion of the bone is black; the fat is lemon colored, due to staining of the cells of the tissue with hematin. During this time the animal slows loss of appetite, stands off by itself, back arched, high elevation of temperature, accelerated respiration and pulse, port wine colored urine.

\section{Boophilus Australis (Australia).}

Synonym.-Australian fever tick.

History.-Found in Australia, South America, Cuba, Porto Rico and India.

Animals Infested. - The ox, the deer and the horse.

Discription. - The female is about the same size as, and has markings similar to, the Boöphilus Annulatus. The dorsal shield is slightly smaller, and is light in color; the palpi are short. In the male the dorsal shield covers the entire dorsal surface. The free extremity of the leg is provided with two hooklets and a fan-shaped organ, instead of the globule shaped apparatus, as in the species Annulatus.

Condition Produccl.- They carry the protozoa producing fever as Boöphilus Annulatus does in the United States.

UERMACENTOR ELECTUS (Derma-skin; kentesis-puncture).

Synonyms.-Dog tick; wood tick; Dermacentor Americanus.

History.-Very commoinin the woyds of the United States. 
Animals Infested.-Dog, horse, ox, etc.

Description.-The engorged female is about the size of the fever tick, though the legs are longer and the head parts more prominent. The dorsal shield is large, somewhat elongated through the anteroposterior diameter, and is white in color. The hypostome is provided with six rows of denticles. The

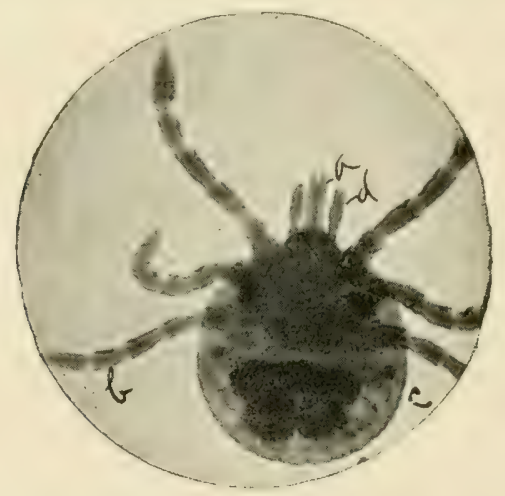

Fig. 21-Amblyoma Americanum Larva. Photomicrograph 1X2/3 inch.
a, Mandibles.
b, Legs.
c, Body.
d, Palpi.

dorsal surface of the male presents a large, white dorsal shield and silvery markings.

\section{Amblyoma Americanum (American).}

Synonym.-Lone Star tick; Amblyomma unapuncta.

Distribution.-Southern United States and South America.

Animal Infested.-The ox.

Description.-About the same size as the preceding described tick. The dorsal shield is triangular in 
shape and reddish brown; it is marked with a white spot in the posterior borcler. The head parts are more prominent than in the Boöphilus Annulatus. The hypostome is furnished with six rows of denticles.

\section{LINGUATULIDA.}

This order includes a group of degraded Acari, the most common of which is the

\section{Linguatula RHINARIA (Lingua-tongue).}

Synonyms. - Pentastoma Taenoides; Linguatula Taenoides.

Distribution.-Common in Europe; not reported in the United States.

Discription. - The body of the adult is white, elongated and lanceolate shaped toward the head. It tapers posteriorly and presents the general appearance of a worm. The ventral surface is flattened; it is rounded dorsally; the body is composed of about ninety rings: the head part is provided with small hooklets which enable it to hold on firmly. The males are much smaller than the females.

Animals Infested.-Adult infests dogs; larva infest cattle, sheep, etc.

Life History.-The adult deposits the ova in the nasal chambers of the dog, and they are afterward expelled by the animal when sneezing; thus the grass of the pastures or other food or water become contaminated with the eggs. These eggs are taken in by the intermediate host, and upon reaching the stomach hatch and liberate the embryos. The embryos are ovoid in shape, flat below and convex above, and thus somewhat resemble the Acari. 
They are provided with two pair of legs. The head extremity is furnished with a stylet-shaped boring apparatus. By means of this boring apparatus they find their way through the stomach or intestinal wall and become located in the mesenteric lymph glands, lungs or liver, where they develop into fully formed larvae. This transformation requires about seven months.

Condition Produced.-The larvae thus encysted are taken in by carnivorous animals, through consumption of the affected part, or the larvae may leave the cyst by migration, and if they reach the bronchi may be expelled with mucus through fits of coughing, and thus soil the feed or water. In the adult state the parasites infest the nasal chamber, and possibly the pharynx and larynx. They hold on to the mucous membrane by means of hooklets and produce an inflammation which is accompanied by a muco-purulent discharge. The animal sneezes, scratches and rubs its nose, etc.

\section{FUNGI.}

The fungi that attack animals are vegetable parasites and are similar to the common moulds in their general appearance and method of reproduction. Reproduction is by spores, which are small round bodies, microscopic in size, resembling small seeds. The filaments, or mycelia, consist of a series of cells arranged end to end. These cells consist of a cell wall and protoplasm. The spores have a greater resistance to unfavorable conditions than the mycelia, and when placed under favorable conditions, or "fertile ground," produce the mycelia. 


\section{Plate VI.}

Fig. 1-Amblyomma Americaกин.

(Oviprsiting).

Note white spot in dorsal shield.

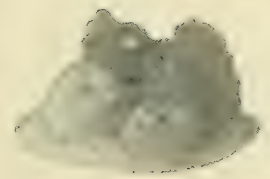

Fig: :- BBopphilus Aunulatu: (Ovipositing).

Note skrinking of the body. posteriorly.

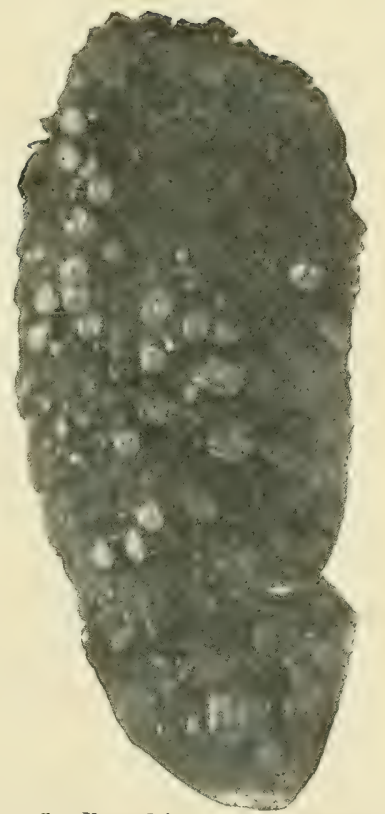

Fig. 3-Donphilus Anumlatus. (In different stages of 10velopment on skin of cow)

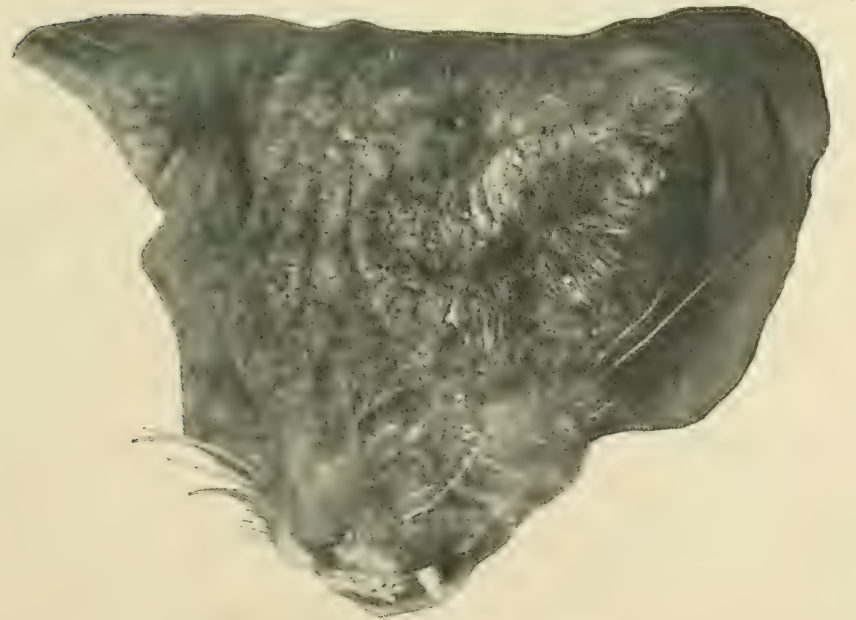

Fig. 1-Sareoptic scabies, ent. 

Trichophyton Tonsurans (Trix-hair; phyton, a plant.) ('Tonsurans-to shear.)

Discase.-Tinea tonsurans: circinate ringworm; ringworm.

Animals Infested.-Man, horse, ox, hog, dog, cat, and bird.

Symptoms. - The affected spot is at first red; it gradually enlarges and is covered with a thin, grayish scale, under which is found serum. The hair is cut off at the surface as a result of the invasion of the skin by the fungi. The circumference is red, while the older inner portion assumes a grayish color. The condition is accompanied by itching; the animal rubs and scratches itself.

Parts Infested.-In man it is noted in the facial region and arms; sometimes contracted by handling infected pets. In horses it infests principally the body, but has been observed on the extremities. In cattle the facial region is a favorite location. In hogs we observe the body as the most usual part attacked; in dogs the body and extremities ; in birds the dependent part of the head, as the comb and wattles.

Moiles of Infection.-Animals may become infected by coming in contact with infected ones, by being shipped in cars or boats in which infected ones have recently been transported, by being placed in other infected quarters, as barns, pastures, etc., or by using blankets, rub-rags, etc., which have recently been used upon infected animals.

Treatmont.-The most effectual remedial agent is iodine, which should be brushed on the affected part once a day; or, four percent nitrate of silver may be used. 
Achorion Schoenleinir (Achor-scurf; Schoenlein.)

Discase.-Tinea favosa; honeycomb ringworm.

Animals Infestcd.-Infests by preference the smaller animals, as the dog, cat, bird, rat, mouse, etc.

Symptoms.-The fungi implants itself in the skin at the opening of the hair follicle; here it forms a cup-shaped mass surrounding the hair or feather. Later the hair falls out, which gives the skin a honeycombed appearance. There is an odor given off which simulates the odor of mice or cat's urine.

Mode of Infection.-Cats and dogs usually become infected from infected prey, as rats and mice. As a result the parts most infected are the fore legs and head.

Treatment.-Same as in the preceding forms, or hyposulphite of soda, one ounce to the pint of water.

Achorion Keratophagus (Kerato-horn; phagean-to eat)

Disease.-Seedy toe.

Animals Infected. - The horse and mule.

Parts Infected.-The mycelium develops along the line of the horny tubes; this results in a degeneration of the horn tissue, and a soft, powder-like substance accumulates between the wall and the sole.

$\begin{aligned} & \text { (Saccharos-sugar) } \\ & \text { Saccha Romyces Albicans } \text { (Myco-mycelium) } \\ & \text { (Alba-white.) }\end{aligned}$

Synonym.-Oidium albicans.

Disease.-Thrush; mycotic stomatitis.

Animals Infected.-Foals and calves.

Parts Infected.-Mucous membrane of the mouth.

Condition Produced. - The infected mucous membrane becomes red, inflamed and tender to the touch. 
In the center of the inflamed area are white ulcerous spots invaded by mycelia and spores.

Treatment.-Wash the mouth with a solution of boracic acid, chlorate of potash or other antiseptics.

$$
\begin{aligned}
& \text { (Bovis-ox) } \\
\text { Actinonyces Bovis } & \text { (Aktis-a ray) } \\
& \text { (Iuke-a mushroom). }
\end{aligned}
$$

Synonym.-Ray fungus,

Disease Produced.-Actinomycosis.

Distribution.- Widely distributed throughout the United States and Europe; especially common in the middle West.

Animals Infected.-Man, horse, ox and hog.

Parts Affected.-Superior and inferior maxilla and soft structures adjacent to them, glands of the head and neck; also lung tissue; rare in other organs. In the sow it has been found involving the mammae. In the ox it has been found in the liver, prescapular and superficial inguinal lymph glands.

Description of Fungus. - The fungi appear in the pus as yellowish granular bodies. A microscopic study of these bodies shows clusters of club-shaped ceils in ray formation; the small ends are directed inward, forming a rosette-like circle. 


\section{ENTOZOA.}

The internal parasites, or entozoa, are placed under the branch Vermes.

Vermes (vermis-a worm) is divided into three classes, viz.: Annelida, Nemathelmintha, and Plathelmintha.

Annelida (annulus-a ring) includes the order Discophori. This order includes the family Gnathobdellidae. This family includes the genus Haemo= pis, which infests the pharynx and mouth.

Nemathelmintha (nema-thread; helminthworm) is divided into two orders, viz.: Nematoda and Acanthocephala.

Nematoda (thread-like) is divided into five families, viz.: Filaridae, Ascaridae, Oxyuridae, Strongylidae and Trichotrachelidae.

Filaridae (filum-a thread) include the genera Spiroptera, Simondsia, and Filaria. They are thread-like worms infesting various parts of the body.

Ascaridae (askarizo-to move briskly) include the genus Ascaris, which infests the small intestines.

Oxyuridae (oxyo-pointed; oura-tail) include the genus $\mathbf{0 x y}$ uris, which infests the posterior bowel.

Strongylidae (strongylos-cylindrical) include the genera Strongylus, Sclerostoma, Stephanurus, Syngamus, 0esophagostoma and Uncinaria, which infest the various parts of the body.

Trichotrachelidae (trix-hair) include the genera Trichocephalus and Trichina, which infest the intestinal tract. 
Acanthocephala (acantha-thorn; cephale-head) includes the genus Echynorhynchus, which infests the intestinal tract.

Plathelmintha (flat-wide) includes the orders Cestoda and Trematoda.

Cestoda (kesto-girdle) includes the family Taenidae and genus Taenia (tape worms) which in the adult state infest the intestines.

The family Bothriocephalidae includes the genus Bothriocephalus, which passes the larval stage in fish.

Trematoda (perforated) includes the families Fasciolidae, Paramphistomidae and Schistosomi= dae.

The family Fasciolidae includes the genera Disto= ma and Paragonimus, which live in the liver and lungs.

The family Paramphistomidae includes the genus Amphistoma, which infests the stomach.

The family Schistosomidae includes the genus Schistosoma, which lives in the blood.

CLASSIFICATION OF THE COMMON INTERNAL PARASITES.

Branch .......Vermes

Class

Annelida

()rder.

Discophori

Family Gnathobdellidae

Genus and Species. Haemopis Sanguisuga.

Class

Nemathelmintha.

Order

Nematoda

Family

Filaridae

Genus and Species

Spiroptera Scutata.

Spiroptera Megastoma.

Spiroptera Microstoma. 
Genus and Species-Continued

Family

Genus and Species

Ascaridae
Spiroptera Strongylina. Spiroptera Sanguinolenta.

Simondsia Paradoxa.

Filaria Papillosa.

Filaria Cervina.

Filaria Immitis.

Ascaris Megalocephala.

Ascaris Vituli.

Ascaris Ovis.

Ascaris Suilla.

Ascaris Marginata.

Ascaris Mystax.

Ascaris Inflexa.

Family

Oxyuridae

Genus and Species

Oxyuris Curvula.

Oxyuris Mastigodes.

Family Strongylidae

Genus and Species.

Strongylus Arnfieldi.

Strongylus Micrurus.

Strongylus Pulmonalis.

Strongylus Filaria.

Strongylus Rufescens.

Strongylus Paradoxus.

Strongylus Pusillus.

Strongylus Contortus.

Strongylus Ostertagi.

Strongylus Armatus.

Strongylus Vasorum.

Sclerostoma Tetracanthum.

Sclerostoma Hypostomum.

Stephanurus Dentatus.

Syngamus Trachealis.

Oesophagostoma Inflatum.

Oesophagostoma Columbianum. 
Genus and Species-Continued

..Oesophagostoma Dentatum.

Uncinaria Radiata.

Uncinaria Cernua.

Uncinaria Canina.

Uncinaria Stenocephala.

Family

Genus and Species Trichotracheliclae.

Trichocephalus Depressiusculus.

Trichocephalus Affinis.

Trichocephalus Crenatus

Trichina Spiralis.

Order. Acan thocephala ...

Genus and Species Echinorhynchus Gigas.

Class Plathelmintha

Order Trematoda

Family Fasciolidae

Genus and Species.

Distoma Hepaticum.

Distoma Americanum.

Distoma Lanceolata.

Paragonimus Westermanii.

Family Paramphistomidae.

Genus and Species Amphistoma Cervi.

Family Schistosomidae

Genus and Species

Orcler

Cestodae.

Family

Taenidae

Gentus and Species

Taenia Solium. Taenia Saginata. Taenia Perfoliata. Taenia Mamillana. Taenia Plicata. Taenia Expansa. Taenia Alba. Taenia Denticulata. Taenia Fimbriata. Taenia Marginata. Taenia Echinococcus. Taenia Coenurus. 
Genus and Species-Continued.

Taenia Serrata.

Taenia Serialis.

Taenia Canina.

'Taenia Crassicollis.

Family Bothriocephalidae.

Genus and Species.

Bothriocephalus Latus.

\section{ANNELIDA.}

HaEmopis Sanguisuga (Sanguis-blood; suger -to suck).

Synonym.-Horse-leech.

Distribution.-Found in Europe, America, Turkey and Africa.

Description. - The leech is black or brownish in color, flattened ventrally and rounded dorsally. The body is composed of ninety-five to ninety-seven rings. It is soft, slimy and capable of great extension and contraction. It is provided with an oral and an anal sucker; the suckers are shaped like the beak of a flute. The mouth is located in the oral sucker; it is arranged in the form of a three-rayed star, each ray forming a slit through which a jaw may pass. By means of this sucker it holds firmly to the mucous membrane, and by means of the teeth in the jaws to wounds it, and thus is enabled to suck the blood. The anal sucker is nearly twice as large as the oral one, and aids in holding on to the host; the anus opens at the upper border. Ten eyes are located on the anterior part of the dorsal surface. The leeches are hermaphrodites; they are two to three inches in length.

Life Cycle-Leeches inhabit the water. The females, at the time of ovulation, leave the water and bury themselves in the mud, where twelve to twenty eggs are laid; the female then crawls out, leaving the eggs buried as in a cocoon. These eggs hatch 
in from three to four weeks. The leeches reach their adult state in about five years, and may live to be fifteen to twenty years old.

Animals Infested.-The horse, the ox and the dog.

Parts Infested. - Mucous membrane of the mouth, pharynx, nasal chambers, eyes and lips.

Symptoms. - When infested by large numbers there is observed loss of appetite, emaciation, anemia, hemorrhage from the nostrils or mouth, depending upon the location of the leeches; pale visible mucous membrane; later weakness and possibly death. A single leech, when engorged, will hold two drams of blood. When thus filled they loosen their hold, fall to the ground, and in this condition can fast a whole year. The buccal apparatus of the leeches secretes a fluid which in a measure prevents coagulation of blood, so that hemorrhage follows after their detachment from the mucous membrane. Animals become infested through drinking water from infested pools or streams.

Tratment.-Leeches may be removed by throwing a strong salt solution upon them, which causes them to loosen their hold. They may be removed with the aid of a dry towel or with forceps.

\section{NEMATODA.}

The order Nematoda includes worms that are round or cylindrical in shape. They are provided with a complete digestive apparatus. There are two sexes-male and female; the females always larger than the males. They infest various parts of the body, as the intestinal tract, vascular system, lungs, abdominal cavity, etc. They may produce abscess, 
hemorrhage, pneumonia, etc., causing unthrifty condition, loss of appetite, emaciation, anemia and death.

\section{FILARIDAE.}

The family Filaridae includes thread-like worms that infest various parts of the body, as the esophagus, stomach, vascular system aud abdominal cavity. They are not blood-suckers.

\section{(Scutem-shield)}

SpIROPtera Scutata (Sp:ira-spiral)

(Pteron-wing).

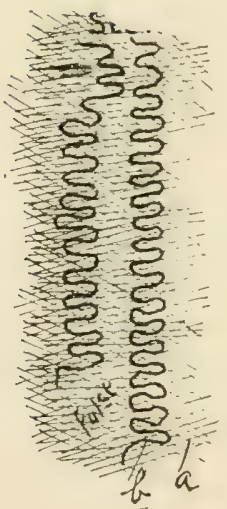

Fig. 22-SPIROPTERA SCUTATA.

a. Esophageal Mucous

Membrane.

b, Worm imbedded in spiral manzer.

Synonym.-Gongylonema scutata.

Distribution.-Common in America and Europe.

Description.-A thread-like worm, yellowish in color and two to four inches in length. The tail of the male is coiled, and is provided with two wings and two spiculae. The tail of the female is straight and the head is nude. It is ovoviviparous.

Animals Infested.-The horse, the ox, the sheep and the pig.

Parts Infested.-They are found coiled in a zig-zag manner in the mucous membrane of the esophagus.

Injury to Host.- No injury has been attributed to their presence.

Spiroptera Miegastoma (Mega-large; stoma-mouth).

Distribution.-Common in America and in Europe. Description. - A thread-like worm, white in color 


\section{Plate VII.}

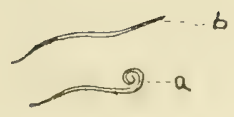

Fig. 1-spiropterat seutata.

i, Male,

b, Female.

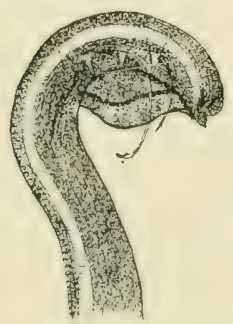

Fig. :-Spiroptern Strongyliแก.

(Caudal extremity of male Showing 2 spiculae and wings, also papillae).

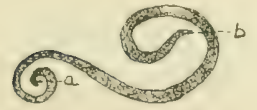

Fig. :- Isenris Mystax.

a, Cephalic extremity.

b, Caudal extremity.

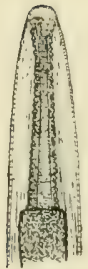

lige: :-Spiroptera strongri11 a.

(Cephalic extremity showing mouth and oesophagus).

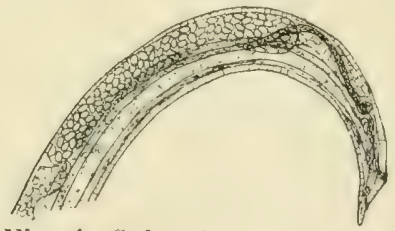

INis. 4-Spiroptera strongyli112.

(Caudal extremity of female showing uterus filled with eggs, vulva and anus).

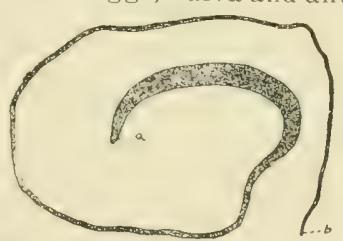

Eig. T-Oxyuris Mastigorles. (Female).

a, Cephalic extremity.

l), Caudal extremity.

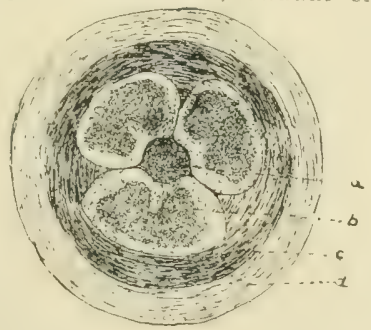

Fin. (i-Cephalic extremity of Iscaris Suis.

(Front view).

¿, Oral opening.

b. Lips.

c, Cuticular surfice surrounding niouth.

d, Portion of body. 

from one-half to three-fourths of an inch in length. The tail of the male is coiled in a spiral manner. This extremity is provided with two unequal spiculae and five anal papillae. The tail of the female is straight and ob- Fig. 23-s tuse; the rulva is situated near the ante- ROPTERA rior third of the body ; the female is ovo- a. Male. viviparous. The head is provided with b, Female. four thick lips!

Animal Infested.-The horse.

Parts Infista-Condition Produced. - The worms are found in the stomach of the horse, where they cause tumors; the larvae find their way into the ducts of the gastric glands, where by their presence they produce sub-mucous tumors; these tumors develop until they are as large as pigeon's eggs and round or oval ins shape, and the cavity of the tumor may contain dozens of the worms; an opening communicates with the interior of the stomach. The color of the mucous membrane orer the tumor does not differ from that of the remaincler of the mucous surface.

I Injury to Host. - When found usually only one or two tumors are present, and no serious disturbance has been noted.

Siproptera MICrostoma (Aicro-smell; stoma-mbith).

Distributiont-Found frequently in the United States and in Europe.

a

Discriftion. - In shape and color this worm resembles the preceding one. The Fit $24-S_{P 1}$ male is about one-half inch long, the feimconstorit. male three-fourths. The tail of the male b, Memale. is coiled in a spiral manner; the tail of 
the female is straight; she is ovoviviparous. The caudal extremety of the male is provided with two spiculate of uneoual length and two aisal papillate. The head is provided with two lateral lips.

Animals Infested.-The horse, the ass and the mule. Parts Infested.-The stomach.

Injury to Host.-The worms may be found in myriads, free in the stomach conterits. Occasionally one will be found with its head lodged in the mouth of a duct of a gastric gland. They may produce ulcers and interfere with the health of the animal.

Treatment.-Benzine or gasoline, in doses of two to four drams, followed by a physic.

Spiroptera Strongylina (Strongylos-round.)

Distribution.-Found in Europe and the middle west of the United States.

Description.-A small white worm, thread-like in calibre. The male is about one-half inch in length; the female three-fourths to four-fifths of an inch. The mouth is round, and is not provided with lips or papillae. The worm may be straight or curved in a half moon shape, it has a narrow lateral wing on one side, just posterior to the head. Tail of male is tightly coiled, one and one-half times and is provided with two broad une(ual membraneous alae, six papillae and two spiculae.

Animal and Parts Infested.-Stomach of the hog.

Injury to Host.-The worms are usually found free although they have been reported to have formed tumors in the wall of the stomach. No harm has been attributed to them.

Spiroptera Sanguinolenta (Sanguis-blood.)

Distribut on.-North and South America, Asia and Europe.

Description.-A thread-like worm, red in color. 
The male measures one to one and one-half inches in length; the female two to two and one-half inches. The tail of the male is curved in a spiral manner and provided with two unequal spiculae; the tail of the female is straight or slightly curved. The vulva is situated about one-fourth of an inch posterior to the head.

Life Cycle.-The cockroach is the intermediate host. The roach finds the eggs of the worm in the feces of the dog. In the digestive tract of the cuckroach the embryo is liberated from the egg; the embryo burrows through the intestinal wall and becomes encysted in the abdominal cavity. The dog in turn eats the cockroach whose abdominal cavity contains these encysted larvae.

Animal Infested.-The dog.

Parts Infested.-The esophagus and stomach.

Condition Produced. - The larva becomes lodged in the walls of the esophagus or stomach and causes a tumor which may reach the size of a pigeon's egg. A cavity in the center of the tumor may contain as many as twenty worms. There is usually an opening at the summit of this tumor. If the tumor is located in the wall of the stomach it may rupture on the peritoneal surface, and may cause a fatal peritonitis. When tumors are located in the wall of the stomach vomiting is sometimes moted; catarrh of the stemach and rapid loss of condition may follow.

Simondsia Paradoxa (Simonds).

Distribution.-Found in Europe; have not been reported in the United States.

History, - Discovered in 1852 by Mr. Simonds in a German pig in the London Zoölogical Garden. 
Description:-The body is thread-like in calibre and tapers toward the head; the cephalic extremity is provided with two lateral membranous wings; the mouth is supplied with two papillae; 'toward the posterior part of the body of the female there is developed a rosette-shaßed organ which is formed by the everted uterus; the tail of the male is coiled in a spiral manner and is provided with two spiculae; the male is one-half inch long, the female three-fifths inch.

Animal Infested.-The pig.

Part Infested:-The stomach.

Condition Produced.-The males are found free in the stomach, while the females are found in small tumors. Large numbers of them may produce indigestion and inflammation.

Filaria Papillosa (Filum-thread; papilla).

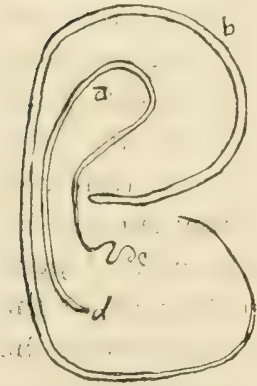

Fig. 25-FILARIA PAPILLOSA.

a, Male.

b, Female.

c, Spiral Tail of Male. d, Cephalic Extremity. long; the female three to four inches; the female is ovoviviparous.

- Animals Infested. - The horse, the ass and the mule. Parts Infested.-Peritoneal cavity, and, by nigra- 


\section{Plate VIIIa.}

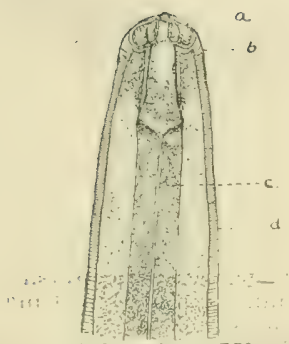

1... 1-Spirolera Microstoma. (Cephalic extremity).
a, Oral cavity.
i), Pharynx.
c, Oesophagus.
d, Cuticular surface.

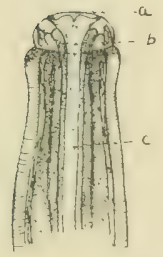

Fig. 3-Spiropterg Mregastoma. (Cephalic extremity).

a, Oral cavity.

b, Pharynx.

e, Oesophagus.

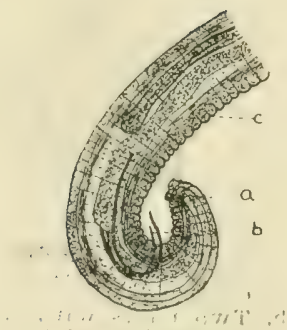

Fig: 2-Spiropter Hicrostomia.

(Caudal extremity of male).

a, Anus.

b, Spiculae.

c, Transverse markings.

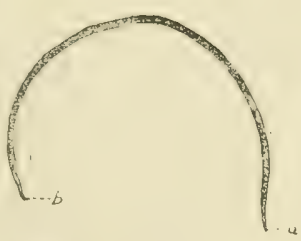

Fig, 4-Filaria Cervint.

a, Cephalic extremity.

b, Caudal extremity. 


\section{Plate VIIIb.}

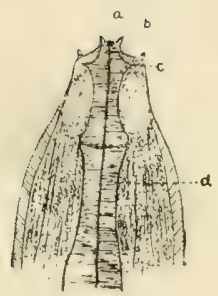

Fiz. T-Filaria Pap:llosa. (Cephalic extremity).

a, Oral cuvity.

b, Two rings with four papillae each, two in situ.

c, Pharynx.

d, Oesophagus.

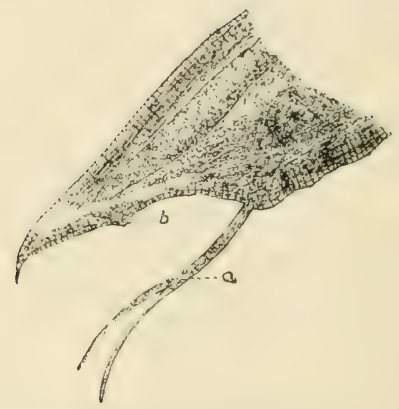

Fig, 6-Filaria Papillona.

(Caudal extremity of male). a, Spiculae.

b, Anus.

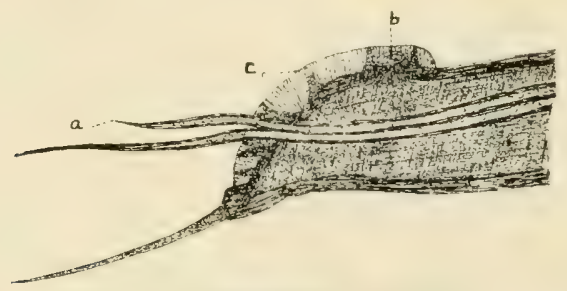

Fig. 7-Heterakis Papillosa.

(Caudal extremity of male).

a, Spiculae unequal length.

b, Preanal sucker.

c, Papillae.

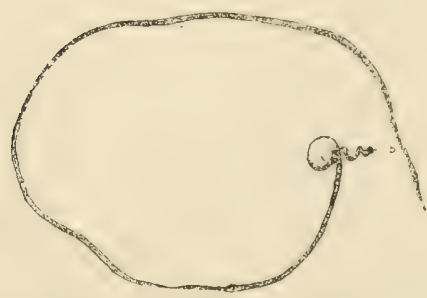

Fig. S-Filaria Immitis.

(Male)

a, Cephalic extremity.

b, Caudal extrenity. 
tion, other parts of the body, as scrotum, pleura, between muscles, etc.

Injury to Host. - The Filaria Papillosa are common in horses in the United States, but are found only in small numbers and do not produce serious results. If found in large numbers they may cause anemia, debility and death. This filaria while in the immature state may find its way to the eye, and the worm can then be seen floating in the aqueous humor. By opening the anterior chamber the worm can be taken from the eye. The name, Filaria $\mathbf{0 c u l i}$, or Filaria 0culi Equina, has been given to this worm when found in this locality. When the worm finds its way to the eye it may cause inflammation, swelling of the eye and closure of the lid. The cornea may become opaque.

\section{Filaria Cervina (Filaria-a hair).}

Synonym.-Filaria Labiato-Papillosa.

Distribution.-Very common in the United States, India, etc.

Description. - In size, shape and color this worm resembles the Filaria Papillosa except that the head is provided with four papillae, the four outer ones being absent. The female is furnished with two lateral caudal papillae. Like the preceding it is ovoviviparous.

Parts Infested.-Peritoneal cavity and by migration other parts of the body. The worms are found free; occasionally one is found imbedded in a roll of fat just under the serous membrane.

Injury to Host.- In the United States it is not found in large numbers, and no serious results are noted. Deaths due to infestation with myriads of 
these worms are reported from India. They have been reported as finding their way to the chambers of the eye:

Filaria ImMitis ( $(\mathrm{m}$-in; mittere--to send).

Distribution.-America, Denmark, Italy, China,' Japan, Brazil and other countries; especially prevalent in low, marshy places.

Description.-A long, thread-like worm, white in color and obtuse at both ends. The mouth is circular and surrounded by six small papillae. The tail of the male is coiled in a spiral manner, making about three and one-half turns, and is provided with twentytwo papillae; the spiculae are of unequal length. The male is six to seven inches long; the female eight to ten; the tail of the female is straight; she is ovoviviparous:

Life Cycle.-The mosquito is known to be an intermediate host; in the intestinal tract of this insect the minute embryo finds its way up the Malpighian tubes and there passes through a non-motile stage into the larva. Later the larva becomes motile and migrates through the tissue to the head and enters the proboscis; thus the dog is inaculated with the larval form at the time the mosquito punctures the skin.

Animal Infested. -The dog.

Parts Infested. - Right side of the heart and the pulmonary artery:

Injury to Host. - Perhaps the first symptom noticed will be dullness, followed by debility and dropsy; the $\operatorname{dog}$ is seized with convulsions, which become more severe as the worms become more nlimerous; 
vomiting has been noted l: the patient usually dies in convulsions:

Post Mortem. Findings.-In some cases hundreds of worms may be found in the right side of the heart and in the pulmonary artery; in other instances a lesser number. Sometimes the worms are found wound in a mass obstructing the passage of blopd and causing an endocarclitis and endarteritis.

\section{ASCARIDAE.}

The family Ascaridae are commonly called Lum= bricoids because they resemble the earth worms in shape and color. They include a group of worms the bodies of which are much larger in calibre than the preceding family. The head parts are provided with three lips, and in most species stand out prominently, being marked by a constriction posteriorly. Species of this family infest the intestines of all animals, principally the young.

Under the family Ascariclae is placed the genus Ascaris. They are not blood suckers.

Ascikis Megalocepirata (Megalo-large; Cephale-head).

Distribution.-Widely distributed; common in the United States.

Discription. - This is the largest species of the family Ascaridae. The body is as large in calibre as a lead pencil; its color is a yellowish white and it is marked with transverse ridges; the head is distinct and is provided with three lips; the tail of the male is straight and it is provided with small lateral membranous wings and 80 to 100 papillae: In the female the rulva is located in the anterior one-fourth of the 
body. The male measures eight to ten inches; the female ten to twelve inches; the female is oviparous

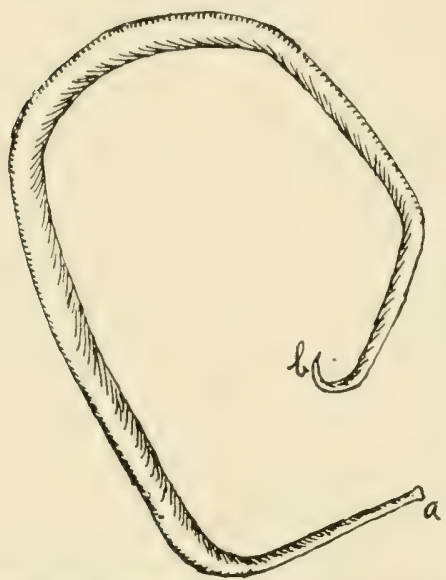

Animals Infested.The horse, the ass and the mule.

Parts Infested. - The small intestines.

Symptoms. - They are found free in the small intestines and consume food taken in by the host and digested; thus they rob the host of its nutrients. By their presence they maycause various troubles of diFig. 26-ASCAR1S MEGALOCEPHALA (a gestion: they may cause young one).

a, Head, Showing Three Lips.

b, Caudal Extremity.

a catarrhal condition of the small intestines, and the irritation may be sufficient to produce diarrhoea, a rough coat and an unthrifty condition. Worms may be passed in the feces.

Treatment.-An aloetic ball made of one ounce Barbadoes aloes, cne dram powdered nux vomica, with is sufficient quantity of linseed meal and glycerine to make a bolus, followed by two drams tartar emetic twice a day; or, two-dram doses of iron sulphate three times a day for three or four days, conjoined with the aloetic ball; or, oil of turpentine two to three ounces, and two to three pints of raw linseed oil. 
ASCARIS Vituli (Vitulus-a calf.)

Synonym.-Ascaris Bovis.

Distribution.-Common in Southern Europe; rare in America.

Description. - In this species the head is small and distinct; the lips are enlarged at the base and stand ( ut prominently: the posterior extremity terminates in a conical point which is reddish white in color; the male is six to eight inches long; the female is eight to ten inches long and oviparous. They have been known to ascend to the abomasum.

Animal Infested.-Principally calves.

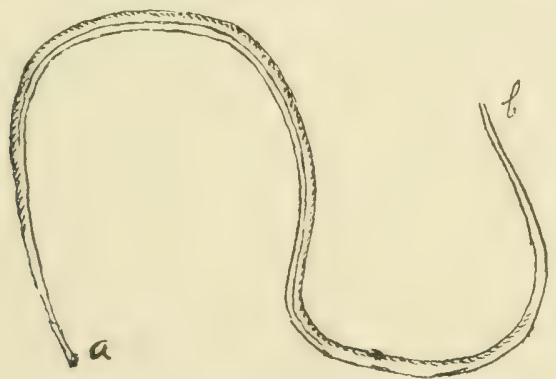

Pig. 27-AsCARIS Ovis. a, Cephalic Extremity.

b Caudal Extremity.

Parts Infested - Small intestines.

Symptoms. - Large numbers cause unthriftiness and are said to produce colic and even inflammation of the mucous membrane of the intestine.

Treatment.-Same as for horse; the dose should vary with the size and age of the animal; the physic should consist of from one-half to two pounds of Epsom salts.

Ascaris Ovis (Ovis-sheep).

Distribution.-Found in Europe ; rare in America. 
Description. - The head is small and provided with three lips with denticulated borders. The upper lip is furnished with two small papillae; the remaining lips have only one papilla each. The parasite is yellowish white in color; is oviparous ; is attenuated at both ends. The male is four to six inches long; the female six to eight inches.

Animal Infested.-Sheep.

Parts Infested:-Small Intestines.

. Symptoms. - Similar to those in calves. . is i

Treatment.-Similar to that for calves.

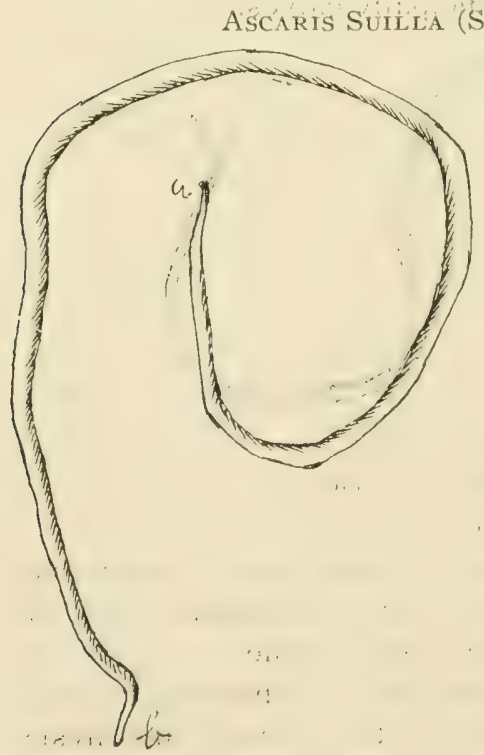

Fig! 28-ASCARIS Suls (a young one).

a, Cephalic Extremity.

b, Caudal Extremity.

Synonyms-Ascaris Suis; Ascaris Lumbricoides.

Distribution.-Very common in the United States; also found in other countries.

Description.-The head is small; the superior lip is provided with two papillae, which are located at the lower angles; the two remaining: lips are provided with one papilla each, 1ocated at the middle, of the base; the caudal extremity of the male is provided with sixty to seventy papillae; the male is seven to ten 
inches 'long; the female ten to twelve inches; it 'is oyiparous; pinkish white in color.

Animal Infested. - The hog.

Parts Infested. - The small intestines:

Symptoms. - Large numbers cause various intestinal "disorders, as indigestion, colic, diarrhoea and obstruction, followed by emaciation. Large numbers always cause an unthrifty condition. If the worms ascend to the stomach they cause nausea and vomiting; if they enter the pancreatic duct they cause obstruction and inflammation of that part, and possibly jaundice. As much as two feet of the small intestines of the pig has been noted to be thoroughly filled with worms, which, upon being removed, were found in a tangled mass.

Treatment. - The matter of medicating hogs is not so easy a task as in other animals; the medicine may be put in milk or other thin fluid which is readily relished by them, then pouring this into a trough where all can share in the food; it will be found that they can thus be satisfactorily medicated. Santonin and powdered areca nut can be given together in the following proportions: The areca nut should be given in from one-half grain to one grain per pound weight, with santonin one to four grains per pig, depending un the size.: The powdered aréca nut, being an irritant, acts as a purgative.

ASCARIS Marginata (Marginatus+marginal).

Synonym.-Maw worm:

Distribution.-Common in the United States; also found in Europe and other countries.

Description. - The body: is pinkish white in color; 
the head is usually slightly curved and is provided with two lateral membranous wings which are broader

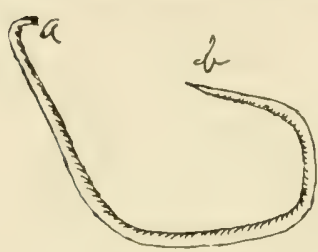

Fig. 29.-ASCARIS MARGINATA.

a. Cephalic Extremity.

b, Caudal Extremity.

behind than in front and make the head resemble an Indian arrow; each lip is provided with a papilla; the male is one and one-half to two inches long; the female two to three inches; the female is oviparous; the vulva is located on the anterior third of the body.

Animal Infested.-The dog.

Parts Infested. - The small intestines.

Symptoms. - The puppy is most often infested, though we find them in older dogs. About forty percent of the dogs are infested. The parasites cause irregularity of digestion, as diarrhøea, colic, nervousness, irregular appetite and unthrifty appearing coat, and later emaciation. If the parasites ascend to the stomach, nausea and vomiting are noted. The bowel may be occupied by large masses of these worms; the passing of the worms is a diagnostic symptom.

Treatment. - The dosage should vary with the age and size of the animal; puppies take one-half grain santonin with five to ten grains areca nut. As the dog grows the dose of santonin may be increased to three or four grains, according to age and size. The dosage of powdered areca nut is one to two grains for each pound weight; the areca nut is an intestinal irritant and acts as a purge.

Ascaris Mystax (Mystax-mustache).

Distribution.-Found common in America and other countries. 
Description.- - In regard to its anatomical structure it is similar to the Ascaris Marginata of the dog, and by some is regarded as a smaller variety of the same species.

Animal Infested.-The cat.

Part Infested.-The small intestine.

Symptoms.--If the worms ascend to the stomach nausea and vomiting are noted. Cats infested by large numbers of them show symptoms of nervousness and loss of appetite with various digestive disorders. The cat sits around and is dull and stupid.

Treatment.-The same as in the dog, with correspondingly smaller doses.

Ascaris InfleXa (Inflexis-to bend).

Synonym.-Heterakis Inflexa.

Description. - The body is yellowish white in color; the male is one and one-half inches long; the female one and one-half to two inches.

Animals Infested.-Fowls.

Parts Infested.-Intestines.

Condition Proluced-Digestive disorders, as indigestion and diarrhoea, which may terminate in death. They have been found so numerous as to obstruct the lumen.

Tratment.-For adult birds, powdered areca nut, twenty to thirty grains, made into pill form. Younger birds should be given doses accordingly. Turpentine in doses of from one to two teaspoonfuls, given before feeding.

\section{OXYURIDAE.}

The worms that belong to the family Oxyuridae are commonly called pin worms. They include a 
group of worms whose heads are provided with three small lips. The body is rather heavy and in the female the tail is long and attenuated. The males are provided with spiculae and two pre-anal papillae, and a rudimentary caudal pouch:

The Oxyuridae are not blood suckers.

Under the family Oxyuridae is placed the genus Oxyuris.

OXvuris Cúvula (Oxys-pointed'; oura tail).

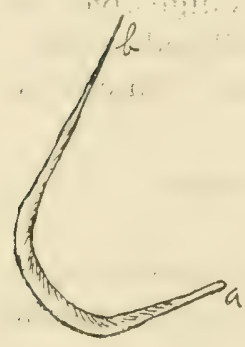

Fig. 30 - (INYURA CUR-

verit (Female).

Synonym-Pin worm; maw worm; curved Oxyuris.

Distribution. - Very common in the United States.

Description. - The body is whitish in color and rather thick; the head is blunt and is provided with three:lips; the tail of the female is long and attenuated; the vulva is located in the anterior third of

a, Cephalic extremity. the body. The male is provided b. Caudal extremity; with a rudimentary caudal pouch and one spicula; the posterior extremity is blunt. The male is from one-half to thee-fourths inch in length; the female is from one to one and one-half inches in length; the female is oviparous.

Animals Infested. - The horse, the ass and the mule. Parts Infestcil - Throughout the length of the large intestine and the rectum.

Condition Produced. - Their presence in large numbers causes considerable irritation, which results in a catarrhal state. After evacuation of the bowels there is noted a small quantity of thick, whitish fluid around the anitis (the product of catarrh) which dries 
in this region and appears as a white deposit. Pruritus may accompany this affection if the worms be lodged in the rectum. The animal rubs the root of the tail; as a result the hair becomes rough, broken, and has a matted appearance. The animal is unthrifty; the coat is rough; worms are passed with the feces, which is a diagnostic symptom.

Treatment.-An aloetic ball containing powdered aloes one ounce and powdered nux vomica two drams, followed by tartar emetic two drams twice a day for three days; or, iron sulphate, two- to three-dram doses twice daily for several days.

Oxyuris Mastigodes (Mastix-whip; eidos-form).

Synonym.-Long-tailed Oxyuris.

Distribution.-Found throughout America and Europe.

Discription.-Similar to the preceding species in size, shape and color; the tail of the female is attenuated; the attenuated portion is three to four times the length of the body; the female measures from three to four inches in length; the male is similar to the male of the Oxyuris Curvula.

- Animals Infestid. - The horse, the ass and the mule. Parts Infested. - The crecum, the colon and the rectum.

Symptoms and Treatment.- Same as with the Oxyuris Curvula.

\section{STRONGYLIDAE.}

The family Strongylidae includes a large group of blood-sucking worms. It includes six genera common to the domesticated animals, viz.: Strongylus, Sclerostoma, Stephanurus, Syngamus, 0esophago= stoma and Uncinaria. 
The condition produced by the genus Strongylus is called Strongylosis.

The condition produced by the genus Sclerostoma is called Sclerostomiasis.

The condition produced by the Stephanurus is called Stephaniasis.

The condition produced by the genus Syngamus is called Syngamosis.

The condition produced by the genus Oesophagostoma is called 0esophagostomiasis.

The condition produced by the Uncinaria is called

\section{Uncinariosis.}

The heads of some are provided with papillae; others are nude, while some have a buccal armature consisting of membranous teeth.

Some infest the stomach and the small or large intestines; others are found in the fat around the kidney and in the lungs, etc. The male is provided with a caudal pouch which may be a single pouch or divided into two (bilobate). The caudal pouch is composed of finger-like projections or ribs ; stretching from rib to rib is a delicate membranous expansion which forms the pouch, the ribs acting as supports. Two spiculae, usually of equal length, are observed. In some species they project beyond the pouch, others scarcely to its posterior border. The caudal pouch is used to clasp the female during th act of copulation.

\section{STRONGYLOSIS.}

Strongylosis is a condition in which the animal is infested by some of the strongle. There are five forms of strongylosis, viz.: 
Bronchial or Pulmonic Strongylosis, -infestation of the bronchi or lungs.

Gastric Strongylosis, -infestation of the stomach.

Intestinal Strongylosis,-infestation of the intestines.

Vascular Strongylosis,-infestation of the blood vessels.

Renal Strongylosis,--infestation of the kidney or fat around the kidney with strongle.

Wet seasons favor the development of the disease, as moisture insures the life of the embryo outside of the body of the animal. The disease is most prevalent on low-lying and swampy lands. It may be spread by the ova or embryos being carried in the stream of water, or by infested animals being introduced into a herd; the animal becomes infested through contaminated food and water. It is probably necessary for these worms to pass out of the host in order to complete a portion of their life history. If the ova or embryos fall into water or moist places they may remain alive for several months, provided there is no putrefaction of organic matter. At the end of one week they have been noted to moult, After a second moulting they apparently become shriveled and remain in the skin. In this state they may resist desiccation, and possibly cold temperature, for a long time. Upon being taken in by the host they become revivified and develop into adult worms. A weakened physical condition lessens the animal's powers of resistance to the invasion of the parasites. 
BRONCHIAL AND PULMONARY STRONGYLOSIS.

This condition is also called Verminous Bronchi= tis, or Verminous Pneumonia.

In Bronchial Strongylosis the worms are found coiled in small balls in the bronchial tubes; their presence causes bronchitis and may occlude the bronchial tube.

In Pulmonary Strongylosis the worms find their way to the air saccules and produce a like condition. Broncho=pneumonia may develop as a result of infestation of both bronchi and air saccules. The bronchial type of the disease is most often found in the young animals, while the pulmonary form is found in the old ones. All animals are infested by their respective species of the genus Strongylus.

Symptoms. - At autopsy, a ferw worms have been found in the lungs of animals that showed no signs of disease during life. The symptoms are slight at the commencement of an attack; there is a loss of appetite and an unthrifty appearance of the animal, and finally emaciation. There is a rise of temperature; accelerated respiration due to the plugging of the bronchi with worms and mucus.

It is accompanied by a cough which becomes more painful as the disease progresses. In later stages the fits of coughing are accompanied with convulsions, and the animal finally dies of suffocation. The animal may expectorate ova or larvae. Upon auscultation mucus rales may be heard; dullness may be noted on percussion.

Treatment.-The problem of medicating large numbers of cattle, sheep or hogsinfested by the lung worms is somewhat difficult. In horses and asses 
the steaming with oil of encalyptus and turpentine, of each one dram in one-half gallon of water, for one-half hour twice daily, will be effective treatment. The can is made cone shape, so that one end of a rubber hose can be attached to the top. The other end of the hose is attached to a hole in a disc-shaped board placed in the bottom of a grain sack; in the top of the sack is a hoop which holds the sack open for the reception of the nose.

\section{THE LUNG WORMS.}

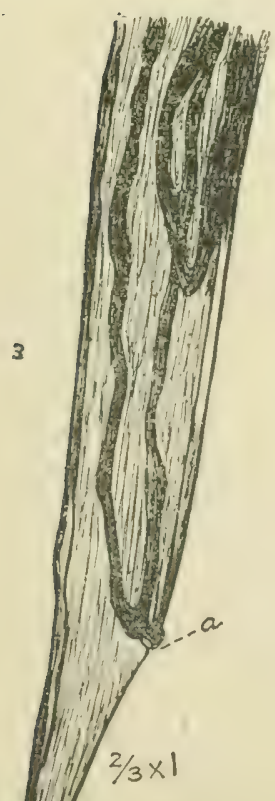

Strongylus Arnfieldi (Arnfield).

Distribution.-Rare in the United States.

Description. - It is a thread-like worm, white in color; the mouth is orbicular and nude; the caudal pouch of the male is short; the spiculae do not project as far as the posterior border of the pouch; the tail of the female ends abtuse$1 y$; the male is from one to one and one-half inches long, the female from two to two and onehalf inches; the female is oviparous.

Animals Infested.-The horse, the ass and the mule.

Parts Infested.-The bronchi and lungs.

Fig. 34-Strongylus ARNFieldi. Caudal Extremity of Female.

a. Anus. 


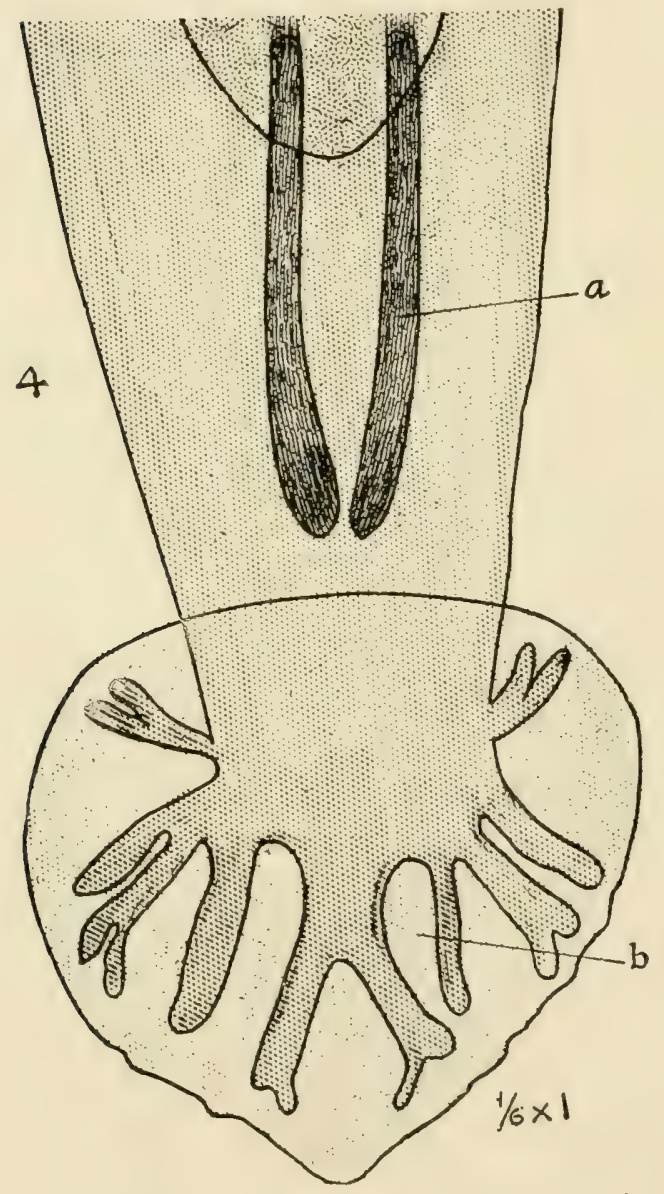

Fig. 31-Strongylus ARnfieldi Caudal Extremity of Male a, Spiculae.

b, Caudal Pouch showing special arrangement of ribs. 


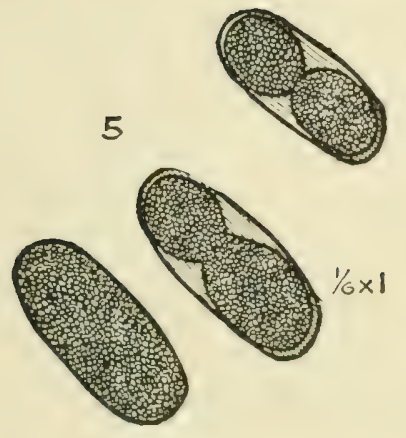

Fig. 32,-STRONGylus ARnField, Ova.

Process of Segmentation.

Drawing made from Ova in Utero stained with eosin and methylin blue.
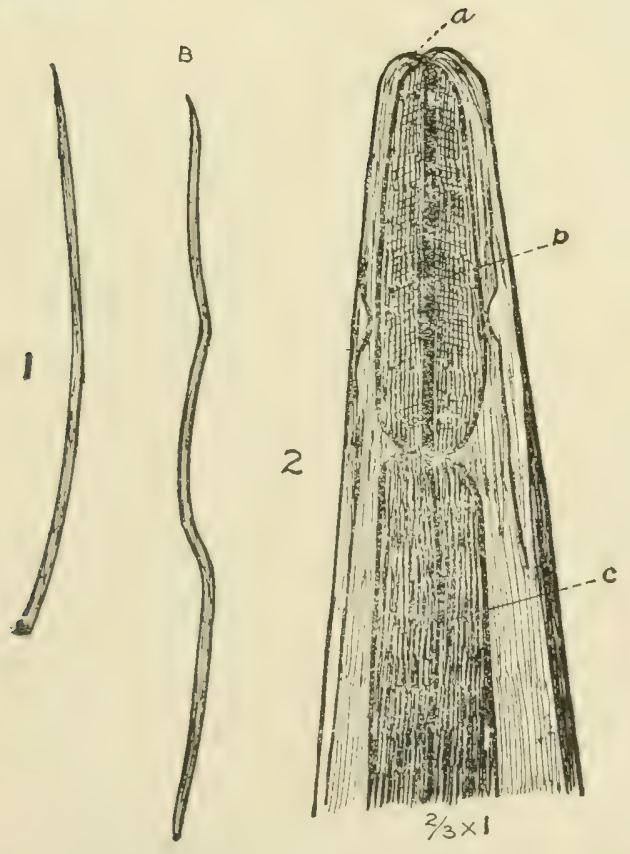

Fig. 35-STRongyluS ARNFiELd Adults about natural size,

Fig. 33-STRONGYLUS ARNFIELDI Cephalic Extremity.

a, Mouth. b, Oesophagus. c, Intestines.

a, Male.

b, Female. 
Strongylus Micrurus (Micros-small; oura-tail).

Distribution.-Common in certain localities of the United States; found in Europe.

Description. - The parasite resembles the preceding one in general appearance; is white in color; the mouth is circular and nude; the spiculae of the male are short and strong, the caudal pouch small; the body of the female tapers to a short, sharp tail; the male is one and one-half to two inches long, the female two to three inches; the female is ovoviviparous.

Animal Infested.-The ox.

Parts Infested.-Bronchi and air cells.

Strongylus Pulmonalis (Pulmo-a lung).

Distribution.-Found in America and Europe.

Description.-The mouth is circular and is surrounded by small papillae; the caudal pouch of the male is bell-shaped and is provided with seven ribs; the tail of the female is attenuated, tapering to a sharp point; the male is one to one and one-quarter inches long, the female one and one-quarter to one and one-half inches.

Animals Infested.-Principally young calves.

Parts Infested.-Principally bronchi.

Condition Produced. - The conditions and symptoms are the same as given in the general description of verminous bronchitis.

The malady is cften called Hoose, Husk, or Paper Skin.

Strongylus Filaria (Strongylos-cylindrical) (filum-a thread).

Distribution.-Found in the United States and other countries. 
Description. - This parasite is filiform, white in color and attennated at both extremities; the mouth is circular and nude; the caudal pouch of the male is well developed; the spiculae do not reach to the outer border; the male is two to three inches long, the female three to four inches; the female is ovoviviparous.

Animals Infested.-The sheep, the goat and the camel.

Parts Infested.-Bronchi and lungs.

Discruse Produced.-The disease is called Hoose, Husk, Paper Skin or Lamb Disease.

Conditions and symptoms are the same as described under general symptoms.

Strongylus Rufescens (Rufescent-reddish).

Synonym.-Strongylus Ovis Pulmonalis.

Distribution.-Found in some localities in United States.

Discription.-Thread-like and reddish brown in color; the mouth is provided with three papilliform lips; the candal pouch is small and has a shallow notch on each side; the tail of the female terminates in a blunt point; the male is one to one and a cuarter inches long, the female one and one-quarter to one and one-half inches.

Animals lnfested.-Sheep and goat.

Parts Infested.-Bronchi and lungs.

Strongylus Paradoxus (Paradoxum-beside).

Synonym.-Strongylus Elongatus.

Distribution.-Common in the United States.

Discription. - The body is thread-like and white or 
brownish white in color; the mouth is surrounded by six papillae; the caudal pouch of the male is fairly well developed; the spiculae are very long; the tail of the female terminates in a blunt point; the male measures about one inch in length, the female one to one and one-half inches.

Animal Infested.-The hog.

Farts Infested.-The bronchi and lungs.

Strongylus Pusillus (Pusillus - very little).

Distribution.-Rare; has been reported in Europe.

Description.-A hair-like worm ; the mouth is nude; the caudal pouch of the male is short; the spiculae are long and slender; the tail of the female terminates in a blunt point; the male is about one-sixth inch long, the female one-half inch; the female is oviparous.

Animal Infested.-The cat.

Parts Infested.-The bronchi and lungs.

Condition Produced.-Small pneumonic areas are produced throughout the lung by the presence of embryo or adult. These granules are yellowish white, and vary in size from a pinhead to a millet seed. The nodules project from beneath the pleura or they may be imbedded in an area of gray hepatization. The symptoms are similar to those manifested in larger animals. The frequent fits of coughing may be followed by vomiting. In later stages they lose condition,-stairy coat, emaciation and death.

Treatment.- Steam inhalation of oil of eucalyptus and turpentine. 
Strongylus Contortus (Contortus-twisted).

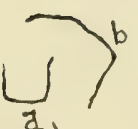

,

Fig. 36-

STRONGYLUS CONTORTUS a, Male.

b, Female.

Synonym.-Haemonchus Contortus.

Distribution.-Common in many states, especially in the South and middle West.

Description.-Hair-like in appearance; body white or pinkish white in color; the mouth is nude; two lateral papillae are noted a short distance from the head; the cuticular surface has fine transverse striations; the caudal pouch is bilobate, i.e., the pouch is divided into two parts; the body of the female terminates in a pointed tail; the male measures four-fifths of an inch in length, the female about one inch.

Life Cycle.-The female is oviparous. The ova are passed from the animal in the feces; the egg thus passed has been found to be undergoing segmentation, and has hatched in from two to three days. The embryo is very small and is provided with a fine-pointed tail. In the development from the embryonic to the fully developed larval stage, it moults at least twice; the embryo becomes shriveled in the last moult, and remains in the skin, in which state it is usually found upon blades of grass or other objects. In this state it can retain its vitality for several weeks, withstanding desiccation and freezing. When taken into the stomach the larva becomes revivified and developes into the adult stage. The worm is a bloodsucker and is often found attached to the mucous membrane, holding on by means of its buccal armature.

Animals Infested.-The ox, the sheep and the goat. Parts Infested.-Abomasum and intestines. 
Symptoms.-This is a serious form of intestinal strongylosis, often causing great loss among cattle and sheep. The first symptoms are those of diarrhoea loss of appetite, followed by gradual loss of condition. The mucous membranes become pale, due to the loss of blood; the hair becomes rough; there is great thirst and langu()r; swellings may be noted about the head and chest; the skin becomes dry, hence the condition has been called paper skin. The animal may die.

Treatment.-Kamala, thymol, benzine, turpentine and gasoline have been given with more or less good results. The best results are probably derived from the following treatment: To cattle that have fasted over night give two to six ounces of gasoline once a day for four or five days. The first day give one to two pounds of Epsom salts. To lambs and sheep give two to eight drams of gasoline, after fasting, and drench with the proper amount of salts, as in cattle. It is recommended to give gasoline in doses sufficient to make the animal show symptoms as though drunk.

\section{Strongylus Ostertagi (Ostertag).}

Synonym.-Strongylus Convolutus.

Distribution.-Found in the middle IVest and in the southern states; also in Europe.

Description.-The anatomical structure resembles that of the Strongylus Contortus. The color of the body is brownish yellow. The male measures onethird of an inch in length, the female one-half inch.

- Animals Infested. - The ox, the sheep and the goat.

Parts Infested.-Abomasum and intestines. 
Condition Producid.-It becomes lodged in the mucous membrane of the abomasum and intestines, more commonly in the former location. Upon examination of the infested tissue small nodules, the size of a pinhead or millet seed, will be observed. These nodules may be slightly depressed in the center. If this membrane be placed in a compressor glass it will be found to contain the larva or adult worm.

Symptoms. - The symptoms are the same as those produced by the Strongylus Contortus.

Treatment.-The same as for the Strongylus Contortus.

Strongylus Armatus (Armatus-armed).

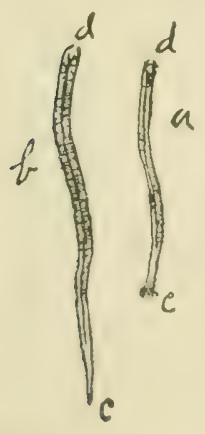

Fig. 37.-

Strongylus AkMitus

a, Male.

b, Female.

c, Caudal extremity.

d, Cephalic extremity.

Synonyms.-Sclerostoma Equinum, Palisade Worm, Armed Sclerostoma. Distribution. - Common in the United States, also found in other parts of the world.

Description.-In calibre the body is the size of a small darning needle. It is whitish-brown shading to red, depending on the quantity of blood contained in its intestinal tract. Its body is marked with transverse striae; the head terminates rather bluntly; its mouth is circular and provided with a buccal armature (membranous teeth) by which means it holds on to the mucous membrane and sucks blood; the male is provided with a well developed caudal pouch which gives the posterior part a "cut off" appearance; the tail of the female 
terminates in a blunt point; the male is from one to one and one-quarter inches in length, the female one and one-half to two inches.

Animals Infistcd.-The horse, the ass and the mule. Parts Infested.-Large intestines.

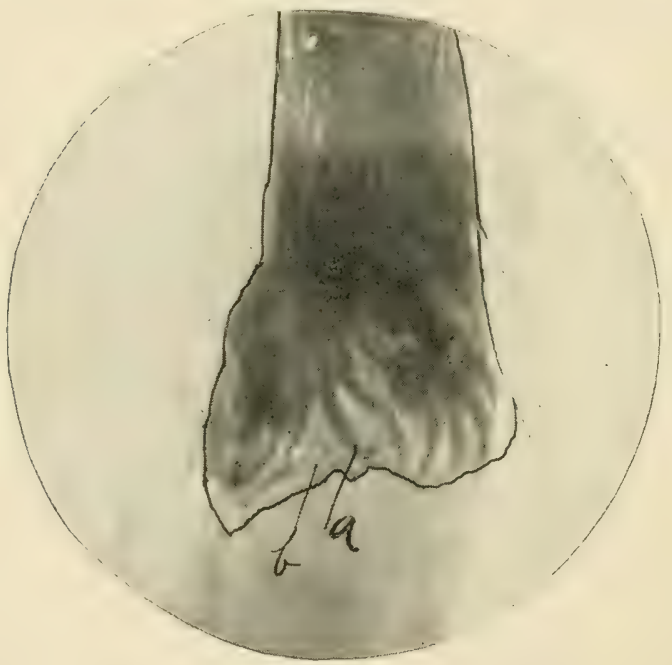

Fig. 38-Strongylus Armatus,-Caudal Extremity, Male. Photomicrograph $1 \mathrm{x} 2 / 3$ inch.

a, Ribs,

b, Web.

Life Cycle.-The female is oviparous ; the ova pass out to the ground with the feces; the embryos are taken in with the food or water which is contaminated with the excrements laden with the ova and embryos; they penetrate the mucous membrane and cause a cyst or tumor varying in size up to a pea; in this tumor thus formed is found the immature worm; the embryos are also found in little pel- 
lets among the intestinal contents; after moulting they leave the cyst and become sexually mature in the intestines; in the embryonic stage they may enter the blood stream, or possibly penetrate the tissues and become located in the trunk of the anterior mesenteric artery, where they produce aneurism. In the old horses used for dissecting purposes at the Kansas City Veterinary College, about sixteen percent are affected by these aneurisms. In some the larva are found penetrating the wall of the vessel, partly within and partly outside; again they are found under the epithelial layer of the vessel, while many are found within the fibrin formed in the aneurism. If the aneurism becomes so serious as to clog the artery, then a condition known as thrombo=em= bolic colic results.

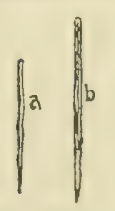

Fir. $39-$

STRUNGYLus ARatTUS, Larva, taken from an aneurism of the great mes. enteric ar-

tery.

a, Partially dereloped Larva.

b; Fully developed Larva.

Symptoms. - Many horses harbor the adult worms in the intestines without showing constitutional effects of such infestation; but if the parasites are in sufficient numbers they cause an unthrifty coat, loss of appetite, anemia, diarrhoea, emaciation and possibly death. It is now believed that the wounds caused by blood-sucking worms in the intestinal tract furnish an avenue for entrance into the system of infective micro-organisms. In thrombo-embolic colic the animal suffers great pain, trembles, paws, lies down frequently, perspires, looks at his abdomen, rolls, and is in constant pain. In later stages the patient has a drawn facial expression and an anxious look. The limbs and ears are cold. The pulse, which is at first 
strong, now becomes gradually weaker, still more accelerated, the breathing is hurried and the animal dies.

Post Mortem Lesions.-Upon autopsy the aneurism is found which has obstructea the artery; or, it may be that an embolus from the aneurism has caused the plugging of one of the mesenteric arteries, and thus cut off the blood supply to a part of the bowel, - this portion of the bowel becomes very dark, in some instances black, due to venous congestion.

Strongylus Vasorum (Vas - a vessel).

Distribution.-Reported in Europe.

Description. - The worm is threacl-like in calibre and white or pink in color ; the mouth is nucle; the male is provided with a short, bilobate caudal pouch and two long spiculae; the male is two-fifths of an inch in length, the female one-half inch.

Animal Infested.-The dog.

Parts Infestal. - The adult infests the blood-vessels, especially of the right side of the heart, and the pulmonary artery ; the larva infests the lungs.

Condition Produced.-The ovum or embryo becomes jodged in the small arteries of the lungs, and it produces thrombosis. Its presence also causes a small granule or tubercle to form in the lung tissue; in the center of the tubercle is found the ovum or embryo, surrounded by epithelial, embryonic and giant cells, as found in the tubercles caused by the bacilius of tuberculosis.

Symptomis. - Sudden dyspnoea, anemia, emaciation and oftentimes cough. Ova or embryos may be expelled by the fits of coughing. 
Sclerostoma Tetracanthum (Sclera-hard; stoma-

mouth)

(Tetra-four ; acanthos-

thorn).

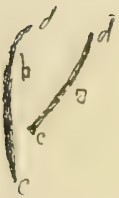

Fig. 40-SCLEROSTONA TETRA-

a, Male. CANTHUI

b, Female.

c, Caudal Ex-

tremity.

d. Cephalic Ex-

tremity.

Distribution.-Common in the United States.

Description.-In calibre the body is the size of an ordinary pin, and white or pinkish in color; it tapers slightiy anteriorly, and in this respect it differs from the Strongylus Armatus that is often found in company with it. The mouth is circular and is provided with six papillae, four of which are much larger than the two remaining ones, and are arranged so as to form a square; the caudal pouch is short; the tail of the female terminates in a blunt point; the male is two-fifths to three-fifths of an inch long, the female three-fourths of an inch.

Life History. - The ova pass out to the ground with the feces; they are taken in by the host through food or water soiled by the excrement of infested animals. The embryos embed themselves in the mucous membrane of the bowel and form cysts. Some are found in small, hard pellets in the bowel. In the adult state they are found free in the intestinal tract

Animals Infested.-The horse, the ass and the mule. Parts Infested.-Caecum and colon.

Condition Produced. - The adult "sclerostomes are blood suckers; by means of their burz- armature they wound the mucous membrane and suck blood; 
these wounds often furnish channels through which infection may take place. When found in large numbers they produce an unthrifty appearance, anemia, emaciation, hemorrhagic diarrhoea and may produce death.

Tratment-The same as for the Strongylus Armatus, viz: Physic and tartar emetic.

Sclerostoma Hypostomuit (hypo-under, stoma-mouth)

Distribution. - Found in the United States and Europe. Not very common.

Description. - The body is thread-like, white in color and rigid; the head is slightly globular; the mouth parts are provided with a double row of membranous teeth; the head is surrounded by six papillae; the caudal pouch is short and gives the male a cut off appearance; the tail of the female terminates in a blunt point. The male is three fifths of an inch in length, the female about one inch.

Life History. Mode of Infestation.-The female is oviparous, the ova pass out to the ground with the feces; the embryos after emerging from the ova go through certain changes and are then taken in by the host through the food and water. Upon reaching the intestinal tract they develop into the mature form.

Animals Infested. - The sheep and goat.

Parts Infested.-Small and large intestines.

Condition Produced.-By means of the buccal armature they hold on to the mucous membrane and suck the blood; punctiform hemorrhages have been noted in the intectinal mucosa; when in large numbers they cause disturbance in digestion, a general un- 
thrifty appearance, diarrhoea, emaciation, anemia and possibly death. These wounds often furnish channels through which infection may take place.

Treatment.-Physic and gasoline are prescribed as in infestation with the Strongylus Contortus.

(Dentos-toothed)

Stephanurus Dentatus (Stephanos-a crown)

(Oura-a tail).

Synonym.-Sclerostoma pinguicola. Kidney worm. Lard worm.

Distribution. - In the United States found especially in southern hogs; not so common in northern ones. Also found in Brazil and Australiz.

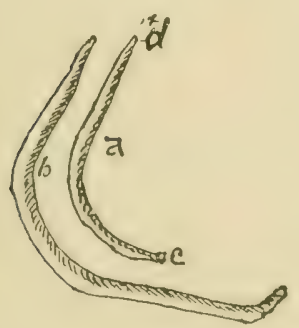

Fig. 41.-

Stephanures Dentatus

a, Male.

b, Female.

c. Caudal extremity

d, Cephalic extremity.

Description. - The body is slightly larger than a knitting needle; the outer integument is transparent; the dark intestinal tract shows through the integument, which gives the worm a mottled appearance. Both caudal and cephalic extremities present a blunt appearance; the head part is provided with six papillae; the tail of the male is provided with a caudal pouch; the male is one to one and onefourth inches long, the female one and orie-fourth to one and one-half inches.

Animal Infested.-The hog.

Parts Infested. - It infests the fat in the sublumbar region.

Condition Produced. - Small abscesses varying in size to a pigeon's egg are found in the fat in the 
sublumbar region; when these abscesses are cut open the center is found to contain a small amount of purulent material and usually a male and female sometimes three or four worms; the worms rarely invade the kidney; occasionally they may be found in the pelvis of that organ. They may invade the psoae muscles and lymph glands in various parts of the abdominal cavity; they have also been observed in the liver; thus multiple abscesses are sometimes observed in advanced cases.

\section{Syngamus Trachearis (Syn-with; Trachea.)}

(Gamus-Marriage).

Synonyms.-Gap worm. Sclerostoma Trachealis. Distribution.-Found widely distributed throughout the United States.

Description. - The head is provided with capsulelike rings in the center of which are placed six lancetlike teeth; the male is small, only one-fourth to onethird of an inch in length, and is provided with a caudal pouch; the female is about one inch in length; the tail teminates in a blunt point; the vulva is located in the anterior third; the male clasps the female firmly during the act of copulation and does not release its hold even after it is removed from the host; this gives the specimen a forked appearance; the small one the male, the large one the female.

Life Cycle.-Upon death and decomposition of the gap worm the ova are liberated in water or moist places, and the embryos develop into minute hair-like worms. The bird becomes infested through the food or water; the larva migrate through the abdominal 
air sacs to the bronchi, where they develop to full size. Animals Infested.-Principally young chickens, turkeys. pea fowls and wild game.

Parts Infested. - The trachea.

Discase Produced.-Gapes, syngamus bronchialis, syngamosis.

Symptoms. - The worms, finding their way to the trachea, attach themselves to the mucous membrane by means of their buccal apparatus, and by means of the six teeth they wound the mucous mcmbrane and suck the blood; the bird is noticed to open its mouth frequently and gasp for air on account of the partial occlusion of the air passage by the worms; wheezing and coughing are also noted. Often the worms may be expelled during a severe fit of coughing; the bird has a loss of appetite, appears dull and stands around with drooping wings; finally when the worms form sufficient bulk to occlude the lumen of the trachea the animal, in its death struggle, is observed to throw its head over the back and, gasping, dies of asphyxiation.

Prophylaxis. - Moisture is necessary for the development of the larva; if birds be kept on a board floor until they are half grown the greatest danger will be eliminated; the floors and runs should be frequently sprinkled with a $1 \%$ solution of creolin or carbolic acid. The drinking and feeding dishes should be cleansed occasionally with antiseptic solution. The dead carcasses should be burned.

Treatment. - A horse-hair doubled several times, forming a loop, is often thrust down the bird's throat, twisted several time and withdrawn; the worms in this way are removed. 
Oesophagostoma Inflatum (Stoma-mouth ; Inflated). Distribution.-Found in the middle west and south.

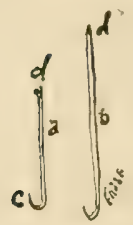

Fig. 42

OESOPHAGOSTOMA

INF LATUM

a, Male.

b, Female.

c, Cephalic extremity.

d, Caudal extremity.

Description.-The worm is threadlike in calibre and white in color; the cephalic extremity is crooked, which gives the worm the appearance of a cane; the mouth is circular and provided with six prominent papillae; the anterior extremity of the worm is provided with a transparent, globe shaped apparatus; this is followed by two lateral wings; the male is provided with a well developed caudal pouch, which gives the worm a cut-off appearance; it is provided with two long spiculae; the tail of the female terminates in a sharp point; the male is about three-fourths of an inch long, the female one inch.

Life Cycle.-The ova find their way to the ground through the feces; the animal becomes infested through the food or water that is contaminated by by the ova or embryo. Upon reaching the intestinal tract the embryos embed themselves in the mucous membrane, forming a cyst, where they proceed with their development; they reach maturity only in the intestinal tract.

Animals Infested.-Cattle.

Parts Infested. - Small and large intestines.

Symptoms. Condition Produced.-Oftentimes cysts in the mucous membrane are so numerous as to thoroughly stud the surface of both small and large intestines; this interferes with digestion and absorption and is a source of irritation; the aduits in the 


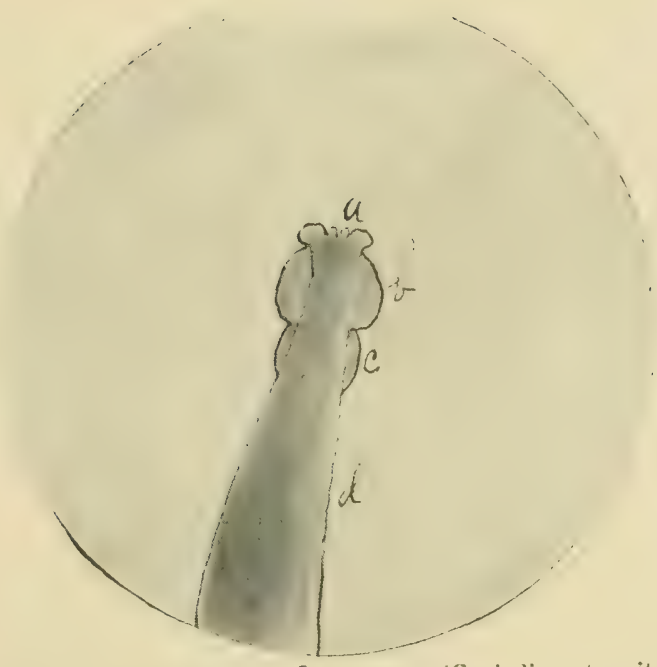

Fig, 43,-Oesophagostoma Inflatum. (Cephalic extremity) Photomicrograph, $1 \times 1 \frac{1}{3}$.

a, Mouth with papillae

c. Lateral membranous wings b. Globe shaped inflation.

d, Anterior part of body.

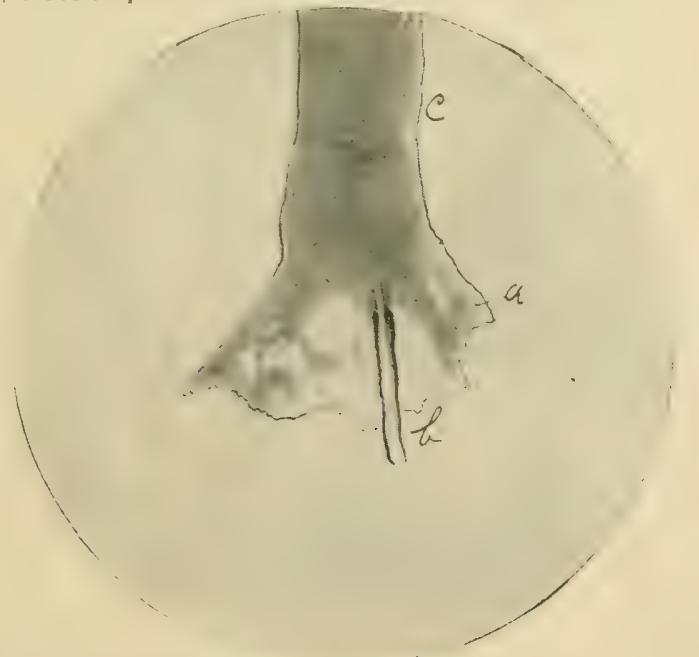

7ig. 44.-Oesophagostoma Inflatum Caudal extremity of male. Photomicrograph, $1 \times 2 / 3$.

a, Caudal pouch. b, Spiculae. c, Posterior part of body, [119 
intestinal tract are blood suckers; they wound the mucous membrane and suck the blood; this adds to the irritation and produces anemia; the symptoms as noted are diarrhoea, thirst, loss of appetite, unthrifty coat, anemia and possibly death.

Treatmont.-Many drugs have been tried with more or less good results; areca nut, santonin, kamala, etc. Good results will be obtained by fasting

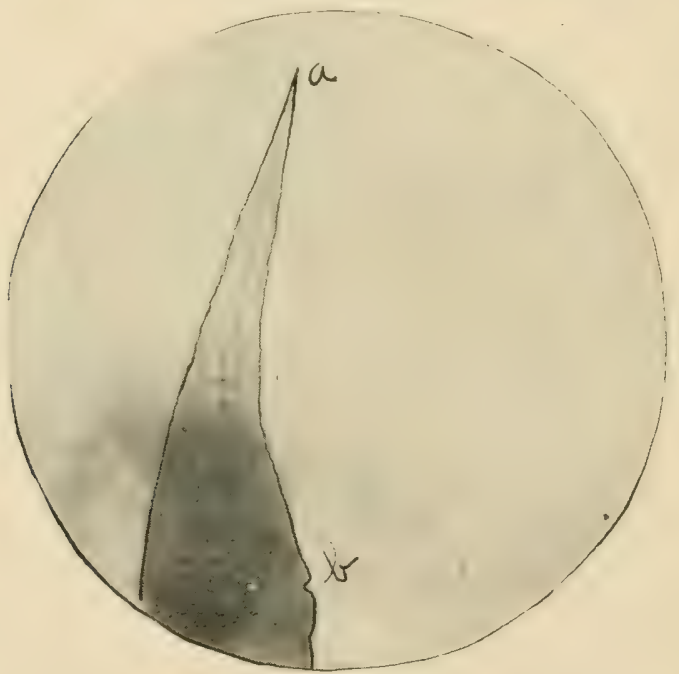

Fig, 45.-Oesophagostoma Inflatum. Caudal extremity, female a, Sharp terminal point. D, Anus.

Photomicrograph, $1 \times 2 / 3$

the animal for 24 hours, then give one and one-haif pounds of salts followed by from two to six ounces of gasoline; calves must receive a proportionately smaller dose; for large bunches of cattle sulphate of iron and salt kept constantly before the animals wil? be effectual in destroying many of the worms. By 


\section{Plate IX.}

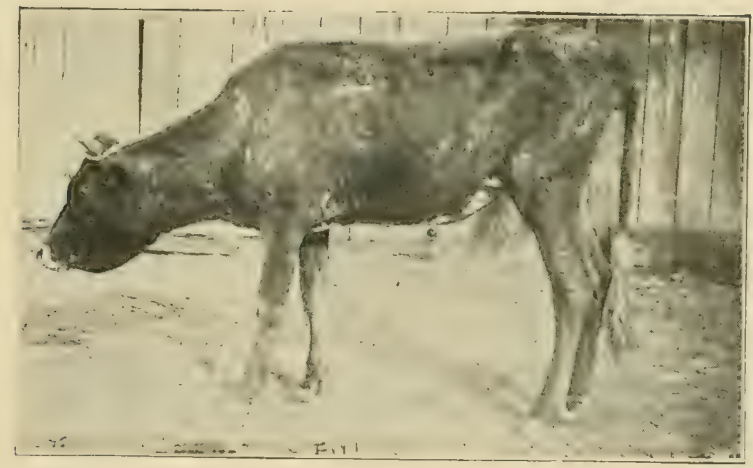

Fig. 1-Heifer infested with lung worms and liver tlukes. Note emaciation and edema.

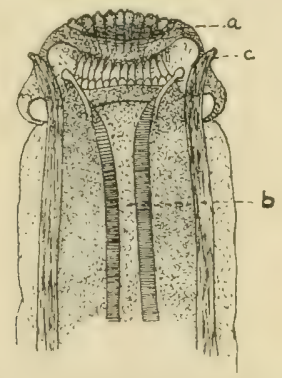

Fign. 2-0esoplatyostoma lumbianum.

Co-

(Cephalic extremity).

a, Oral cavity.

b, Oesophagus.

c, Papillae.
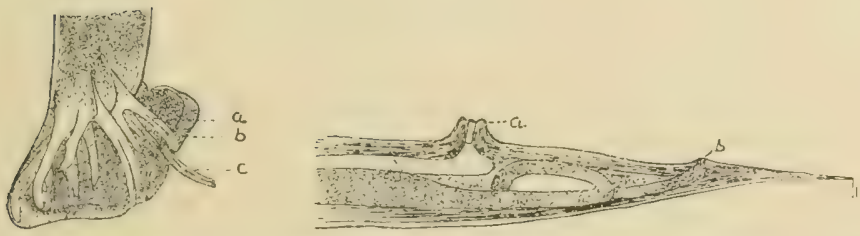

Fig. :-Oesophagostoma Immbianum.

(Caudal extremity of male).

a, Rib of caudal pouch.

b, TVeb.

c, Spiculae.
Fig. 4-Uesophacostoma Co. linmbianum.

(Caudal extremity of females.

a, Vulva.

b, Anus. 

constantly taking the sulphate of iron into the intestinal tract it will create an unfavorable place for the development and life of the worm.

\section{Oesophagostoma Columbianum (Columbia).}

Synonym.-Oesophagostome of Columbia.

Distribution.-Found commonly in the United States. First discovered in the District of Columbia.

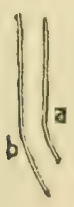

Fig. 46.-

OESOPIAGOSTONA Columbianumi a. Male.

b, Female.

Description.-The worm is threadlike in calibre, white in color, slightly tapering anteriorly; the mouth is circular and provided with a double row of teeth arranged in a crown-like form; the caudal pouch of the male is saucershaped; the tail of the female terminates in a rather sharp point; the male measures about three fourths of an inch in length, the female about one inch.

Life Cycle.-The ovigerous female lays its eggs in the intestinal tract, which find their way to the external world with the feces; the embryos are taken up by the host through the contaminated food and water; upon reaching the intestinal tract they penetrate the mucous membrane and produce nodules which are irregular in outline and vary in size up to a pea; these nodules are found in both small and large intestines; often in badly infested cases embryos are noted to invade the mesentery and mesenteric lymph glands and liver. The tumor, smaller in size than a pin-head, contains a cyst in which is found a growing embryo coiled in a ring-like shape, floating in a colorless fluid; in the second stage the embryo is still in the cyst but a small quantity of 
greenish, cheesy pus has accumulated around it; in nodules larger than a pin-head the entire contents are a cheesy mass; the cyst wall is ruptured and the worm is found free, wandering within the capsule; in the larger nodules the cheesy material is quite hard except at the side where the worm is found. Nearing maturity the worm leaves the nodule and becomes sexually mature only in the intestinal tract; the nodule now gradually shrinks in size until it is quite small and filled with earthy material.

Animals Infested-The sheep, goat and ox.

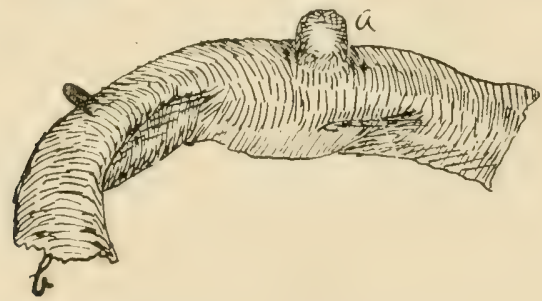

Fig. 47.-Nodular Disease.

a, Nodule caused by larva of Oesophagostome of Columbia.

b, Section of small Intestine.

Parts Infested.-Small and large intestines.

Disease Produced.-Nodular disease.

Condition Produced. - Nodular disease 1s common in native but seldom if ever found in range sheep. In badly infested cases the entire intestinal canal may be thorougly studded with the nodules, which are irregular in outline and push the serous coat out; the nodule lies under the serous covering of the bowel and can be readily told from the tubercle produced by the bacillus of tuberculosis by the fact that the latter is smooth, and that in tuberculosis the lymph glands adjacent to the affected part will be 
tuberculous; in the infested sheep that are slaughtered the gut is rendered unfit for casings, by the disease.

Symptoms. - This form of oesophagostomiasis is not so fatal as that caused by the oesophagostoma inflatum; the fleece may appear dry; it may be the cause of partial loss of the wool crop. There may be diarrhoea, general debility, anemia, sunken eyes, emaciation and death.

In cattle it does not prove serious in the United States. Only a few nodules are found when these animals are infested; these nodules are usually confined to the small intestines.

Treatment.-To destroy the adult worm in the intestinal tract, the same treatment is advised as in the Strongylus Contortus; salt and sulphate of iron constantly before them will also prove beneficial.

Oesophagostoma Dentatum. (Dentis-tooth).

Synonym.-Oesophagostoma Subulatum.

Distribution.- Occasionally found in the United States.

Description. - The body is small in calibre and white or grayish-brown in color; the worm slightly tapering anteriorly; the mouth is circular and provided with six papillae; the head is followed by a constriction. The caudal pouch of the male is short; the tail of the female terminates in a rather sharp point; the male is one-third to one-half inch long; the female is one-half to three-fourths inch.

Animal Infested.-The hog.

Parts Infested. - The caecum and colon; the writer has found them in the kidney once; they have also been reported once in the liver. 
Sy'mptoms. - If only a few worms are found no serious results are noted; if infested in

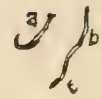

Fig. 48.-

OESOPHAGUSTOMA Dentatum.

a, Male.

b, Female. great numbers they produce gradual anemia as a result of the loss of blood; irregularities in digestion, diarrhoea, unthriftiness, emaciation and finally death. In some cases of infested hogs when the colon is opened the contents are fairly alive with the wriggling myriads of the Oesophagostoma Dentatum; a positive diagnosis is finding the ova and worms in the feces.

Treatment.-Fast the hog for twenty-four hours; then give areca nut and santonin the same as for the Ascaris Suilla.

UNCINARIA RADIATA. (Uncinatus-hooked) (Radiatus-radiate).

Synonym.-Hook worm.

Distribution.-Found in various parts of the United States. Common in certain parts of Texas.

Description.-The worm is the size of a large thread in calibre and white in color; the caudal pouch of the male causes that extremity to appear blunt; the tail of the female terminates in a rather sharp point; the mouth parts are provided with hooklets with which it holds on to the mucous membrane; the male is about three-fourths of an inch long, the female about one inch.

Animal Infested.-The ox.

Parts Infested.-Small intestines.

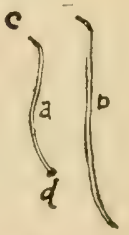

Fig. 49.-

UNCINARIA

RADIATA

a, Male.

b, Female.

d, Caudal extremity.

c, Cephalic extremity.

Conditions Produced.-Causes uncinariosis in cat- 
tle; they are blood suckers of the worst type, and myriads robbing the host of blood cause an unthrifty condition; in calves they cause a stunted growth; later anemia, emaciation and possibly death.

Treatment.-The same as for the Strongylus Contortus.

Uncinaria Cernua. (Cernuus-bent down).

Synonyms.-Hook worm. Dochmius Cernua.

Distribution. - Frequently found in Southern United States.

Description. - A thread-like worm, yellowish white in color; the body is rigid and attenuated at both ends; the mouth is circular and provided with four hook-like teeth; the buccal cavity is ovoid in shape; the male is one-half to three-fourths of an inch long, the female one inch.

Life History. - The ova, reaching water or moist earth, hatch into the embryonic state; if conditions are favorable they moult in three days; in five days they moult the second time; when taken into the intestinal tract at this time they invade the mucous membrane (if not taken in at this stage they will perish in about four weeks); they now fasten themselves to the mucous membrane and develop into the mature worm in about fifteen days; during this time they moult twice.

Animals Infested.-The sheep and goat.

Parts Infested. - Small and frequently the large intestines.

Mode of Infestation. - Like other worms of the family Strongylidae, the pools of water, ponds, pastures and other food become contaminated by feces from infested sheep, laden with the ova; here 
under favorable conditions the larval form develops; thus the sheep become infested through frod and water; the embryo may be carried by small streams of water and thus spread contagion.

Conditions Produced.-Seldom cause serious results, but if found in large numbers they may cause conditions similar to those caused by the Strongylus Contortus, such as unthrifty coat, partial loss in wool crop, diarrhoea, anemia, and if in sufficient numbers emaciation and death.

Treatment. - The same as for the Strongylus Contortus.

UnCiNaria CaniNa (Canis-dog).

Synonyms.-Uncinaria Trigonocephala. Dochmius Trigonocephala. Anchylostoma Trigonocephala.

Distribution.-Common in the United States, also found in Europe.

Description.-It has a thread-like body, white in color; a large buccal cavity; the mouth is provided with six hook-like teeth; by means of these hooklets it holds firmly to the mucous membrane and aided by its strong muscular oesophagus draws blood; they are still found attached to the mucous membrane after death of the dog; the tail of the male has a well developed caudal pouch; the tail of the female terminates in a sharp point; the male is about one-half inch long, the female three-fourths inch.

Life History.-Same as the other species of the Uncinaria. The methods of infestation are the same.

Animals Infested. - The dog, cat, and fox.

Parts Infested.-Small and large intestines.

Symptoms - Uncinariosis among the dogs is very common; it is more fatal among puppies than older 


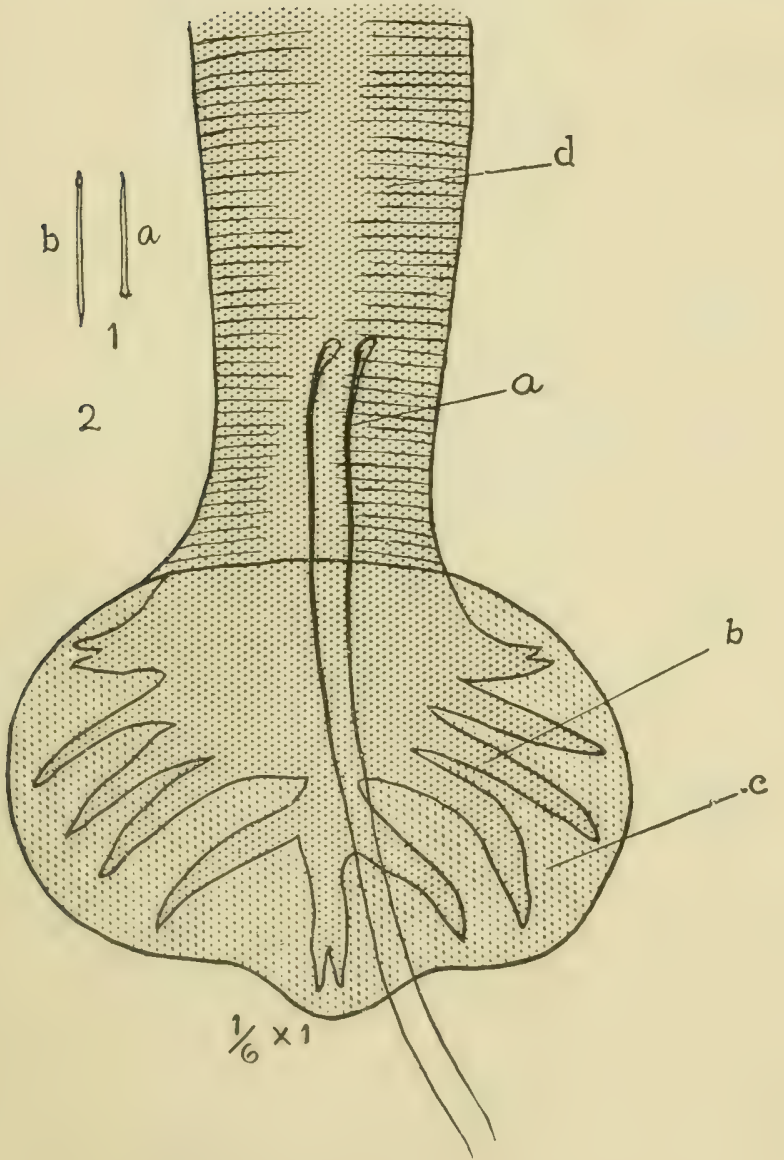

Fig. 50.-UNCINARIA CANINA, natural size.
a, Wale.
b, Female.

Fig. 51.-Caudal extremity of the male, magnified $\mathbf{3 5 0}$ diameters.
a, Spiculae.
b, Ribs of caudal pouch.
c, Web of caudal pouch.
d. Posterior part of body. 


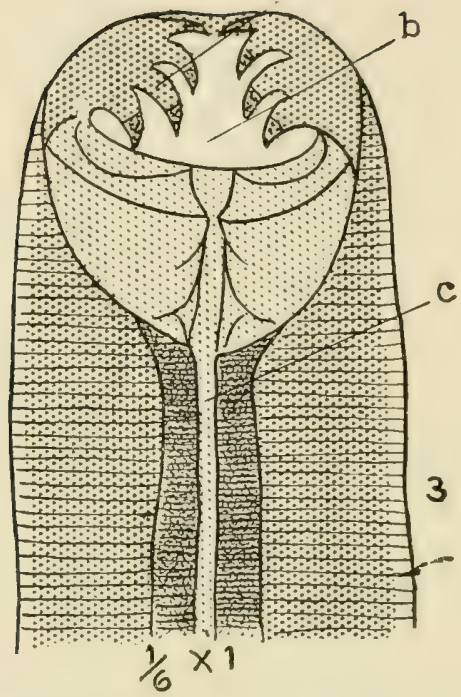

Fig. 52 - UnCINARIA CANina. Cephalic extremityof female, magnified 350 diameters.
a, Hooklets.
b, Mouth cavity.
c, Oesophagu:
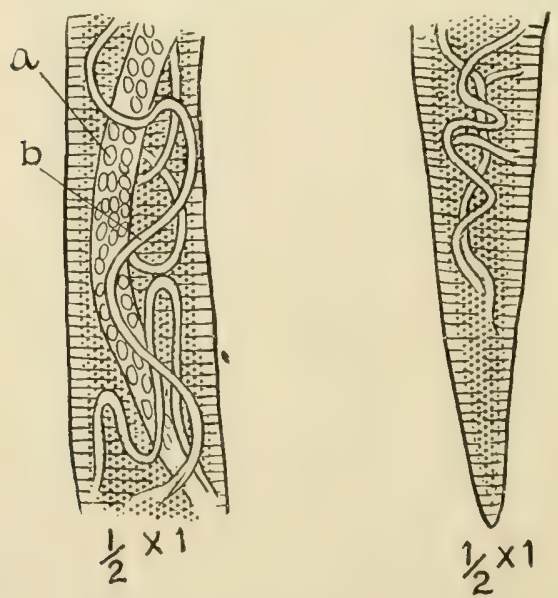

Fig. 53.-Section of body of female, magnified 100 diameters, showing the ova to have formed in worm not to exceed five weeks old.
a, Ovum.
b, Intestine.

Fig. 54.-Caudal extremity of the fernale, magnitied 100 diameters. [128 
dogs ; the worms, when occurring in large numbers, cause derangement of digestion, dullness and indifference; the young pup may whine or cry; tympanites, and in some cases diarrhoea; there is loss of appetite, nervousness and in some cases nausea; later anemia and emaciation is noted and the animal succumbs to the disease.

Treatment. - Santonin and areca nut prove the most effectual parasiticides. The areca nut is an irritant to the bowels and acts as a vermifuge or purge. The following combination gives good results in ridding the bowel of these worms.

R Powdered areca nut _._._._. 5 iii

Crystal santonin _-_____-_ gr xx

Syrup ad. q. s._._.

Mix. Sig.-Give two to three drams at a dose. Repeat dose in five days.

\section{Uncinarta Stenocephala (Stenos-narrow).}

(Cephale-head).

Synonyms.-Dochmius Stenocephala. Anchylos. toma Stenocephala.

Distribution.- Not common in the United States, more common in Europe.

Discription.-The body is thinner than the Uncinaria Canina; the head is narrow; the caudal pouch is trilobate; on each side of the ventral wall of the buccal cavity is a hooklet; the tail of the female terminates in a rather sharp point; the male is about one-third to one inch long; the female three-fourths inch.

The life history, symptoms, and treatment are the same as for the Uncinaria Canina. 


\section{TRICHOTRACHELIDAE.}

The family 'Trichotrachelidae includes a group of blood sucking worms, provided with a nude head; in the adult state they infest the intestinal tract.

$\begin{aligned} & \text { (Trix-a hair) } \\ & \text { Trichocephalus Depressiusculus } \text { (Cephale-head) } \\ & \text { (Depressus depress) }\end{aligned}$

Synonym.-Whip worm.

Distribution. - Found occasionally in the United States, also in Europe.

Description. - This worm in shape resembles the old fashioned "black snake" whip; the posterior part of the body is about the calibre of a thread; the anterior two-thirds is attenuated, resembling a hair ; it is white in color; its mouth is nude; the large part of the body of the male forms a coil ; the corresponding part of the female is straight or slightly curved; the male is provided with a spicula; the vulva of the

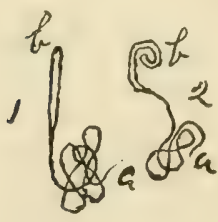

Fig. 55.-

Trichocephalus Depressiusculus.

1, Female.

2, Male,

a, Cephalic extremity.

b, Caudal female is located in the anterior portion of the large part of the body; the male measures from one to one and one-fourth inches in length; the female from one and one-fourth to one and one-half inches.

Life History.-The ova, placed in water and kept at a warm temperature will hatch and develop complete embryos in from four to five months; if these be fed to dogs they develop to the adult stage; drying or desiccation of the eggs or embryos stops their de- 
velopment, but upon again being placed in moist surroundings, they will revivify and complete this phase of their life cycle, providing the desiccation has not been for too long a period.

Animal Infested.-The dog.

Part Infested. - The caecum.

Symptoms. - They hold firmly to the mucous membrane of the caecum and suck blood; specimens of the bowel prepared for the museum still contain the worms, though dead, tightly holding on to the mucous membrane.

Conditions Produccd.-If the animal is infested by large numbers it may show a progressive anemia and gradual emaciation; a derangement of digestion, diarrhoea and possibly death of the host.

Tratment.-The same as for the Uncinaria Canina.

$\begin{array}{ll} & \text { (Affinis-marriage) } \\ \text { Trichocephalus Affinis } & \text { (Trix-hair) } \\ \text { (Cephale-head) }\end{array}$

Distribution.-Found in the United States and Europe.

Discription.-Its body and general appearance resembles the Trichocephalus Depressiusculus; the large part of the body of the male is tightly coiled; the body of the female is straight; the tail terminates very bluntly; the head is provided with two vesicular lobes; the hair-like portion contains the oesophagus and a portion of the intestine; the large portion the intestine and reproductive organs; the male measures from one to two inches in length; the female one and one-half to two and one-half inches. The only difference between those of sheep and those of cattle is the length. 
Animals Infested.-The ox, sheep, and goat.

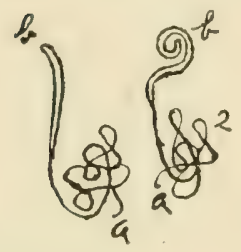

Fig. 56

TRICHOCEPHALES AFFINAS Sheep

1, Female

2, Male.

a. Cephalic extremity. b, Caudal extremity.

Parts Infested. - The colon and caecum.

Condition Produced. - The embryos, upon being taken into the digestive tract of the host, have been observed to reach maturity in two to three weeks; they hold firmly to the mucous membrane and suck blood; only a few have been noted in infested animals and no serious results have been reported in this country.

Trichocephalus Crenatus (Crena-notch).

Synonyms. - Whip worm; Trichocephalus Dispar.

Distribution. - Occasionally found in the United States.

Description. - In shape and appearance the male and female resemble the Trichocephalus Affinis of sheep; the male measures one to one and one-quarter inches long, the female one and one-half inches.

Animals Infested.-The pig.

Parts Infested.-The small intestines.

Conditions Producd. - They are found firmly attached to the mucous membrane. When only a few are present no serious results occur; when myriads are present they cause diarrhoea, indigestion and an unthrifty condition.

Trichina SPIRAlis (Trix-hair; spira-coil).

Distribution-Common in United States and many Furopean countries. Trichina was first discovered by Peacock in 1828, in England. Found in about one 
and one-half percent of the hogs in the United States.

Description. - The adult worm is capillary in size and one-twelfth inch in length; the larva is onetwenty-fifth inch in length; the female is ovoviviparous; the ova undergo complete development in the uterus and hatch in the external genital organs and then escape; the larvae become encysted in lemon shaped cysts which appear as very minute white specks, scarcely visible to the unaided eye; a microscopic examination is necessary to make a diagnosis.

Life History. - When meat containing the live encysted larva is eaten by animals, in from eighteen to twenty hours the meat surrounding the cyst and cyst capsule is digested; the larva thus liberated develops into mature form in from three to four days; frequently on the third day the ovary shows ova in process of segmentation; ovulation commences about the sixth or seventh day; this period lasts five to six weeks, during which time as many as two thousand embryos may be produced by each female; as soon as laid the embryos pass through the stomach or intestinal wall and migrate to various parts of the body; they may burrow directly through the tissues or they may enter the blood and be carried by the blood current, or the lymph vessel and be carried by the $1 y$ mph stream; at the end of eight or ten days the embryo reaches a resting place and coils in a kind of loop, then in a figure three shape, finally in a coil of about one and one-half turns. As a result of the irritation in the elements of the surrounding tissue there is produced a cyst enclosing the embryo; the embryo soon arrives at the fully developed larval state; the cyst is usually lemon shaped, although it 
may appear nearly round; the long axis is parallel with the muscle fiber; the cyst usually contains only one larva although as many as seven have been observed; in this cyst the parasite remains dormant until the animal is killed and the meat is eaten, or if not slaughtered for several months the cyst will undergo degeneration. Two kinds of degeneration are noted, fatty and calcareous; in a few months the cysts are usually observed to commence fatty degeneration; first there are noted a few fat globules at the polls; these gradually increase and the fat is set free and invades the whole cyst; at about the seventh month lime salts (carbonate and phosphate) begin to appear; calcification is usually complete about the twentieth month; during this process the cyst gradually becomes opaque until the outline of the larva can scarcely be seen. Birds prove unfavorable subjects for muscular trichinosis; they, however, develop the intestinal form.

Animals Infested.-Man, hog, dog, rat and, experimentally, other animals.

Parts Infested.-Adults infests the intestine; the larval form infests the muscle structures.

Conditions Produced.-This parasite produces two form of trichinosis; the adult infests the intestinal tract and produces intestinal trichinosis; the worm lives about six weeks ; the larva is found wandering in the tissues and, finally encysted, this form is

\section{muscular trichinosis.}

Symptoms. - Man: - Nausea, vomiting, diarrhoea and vertigo; elevation of temperature with accelerated pulse and respiration; great muscular pain during migration of the embryos; contraction of certain 


\section{Plate X.}

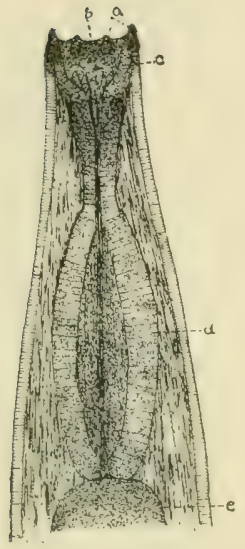

Fig. 1-Srephanurus Deutatus. (Cephalic extremity).

a, Papillae.

b, Mouth

c, Bucal cavity.

d, Oesophagus.

c, Intestines.

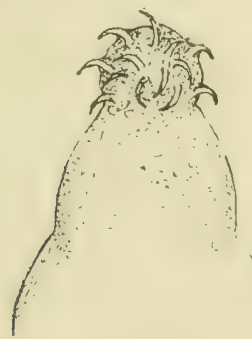

Fiz. T-Echinorlyzuchus Cauis. (Globe shaved proboscis sluwing houliletsi).

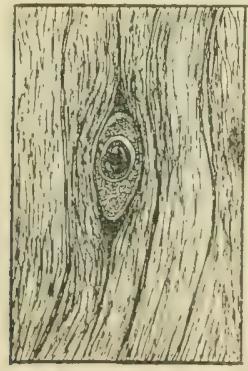

Fiq. dي-Syngramus 'I'racheralix.

(Male and female).

a. Head.

b, Caudal extremity. tus.
Figr. 3-Trichocenhalus Creas?

(1, Female. 2, Male).

a, Cephalic extremity.

b, Caudal extremity.

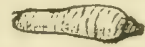

Fig. 4-Echinorhynehus Canis.

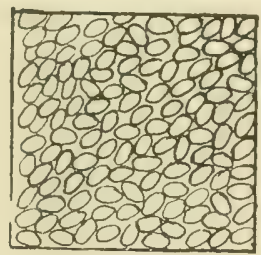

Fig. (3-Echinorhynehus Canis. (Section through uterus showing ova).

a

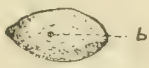

Fig. S-Parggonimus Westermanii.

(Ventral surface).

ralis.

(Encysted, surrounded with muscle fibers). a, Oral sucker.

b) Ventral sucke!: 

groups of muscles; the pain lasts only during the migration of the embryos; atter encystment there is no pain. Hogs:-The intestinal form causes diarrhoea; the migration of the embryos pruritus, rubbing, scratching, stiffness of gait, difficulty in swallowing and mastication, difficult and painful respiration. The disease is usually fatal in man; it is not liable to be fatal in the hog or rat.

Vitality.-Vermifuges and vermicides have little effect upon them. Degeneration usually destroys the larvae in the cysts in from twelve to eighteen months, although cases are on record where their vitality has lasted much longer. They will live one hundred days in decaying meat. Fourteen degrees below zero, Cent., will kill them.

Complete salting kills those that are superficial in a short time, but those in the deeper parts live for a long time. Sausage in pickle 15 days destroys them. Sausage in hot smoke kills them in 24 hours, cold smoke 3 days.

To determine if Trichina are alive two methods can be used. First, feed a small bird the trichinous flesh and kill the bird 8 to 10 hours after; if the trichini are dead they will be digested with the cyst; if they are alive they will be coiled or moving. Second, if a small particle of macerated meat containing the cysts be placed on a platinum plate and heated to a temperature of 100 to 105 degrees Fahrenheit, then noted under the microscope, movement will be seen if they are alive. Thorough cooking destroys them. To destroy the trichina in a ham it should be cooked thirty-five minutes for each two pounds of weight. 


\section{Acanthocephala (Acanthos-thorn) (Cephale-head).}

This order belongs to the class Nemathelmintha and includes a group of parasites that are round in shape but are not provided with a digestive tract as the order Nematoda; they obtain nourishment by absorption of digested nutrients from the intestinal tract of the host; there are complete sexes, male and female ; the cephalic (head) extemity is provided with a globe-shaped proboscis armed with six rows of hooklets by which means it holds on to the mucous membrane; it includes the genus Echinorhynchus, species of which infest the small intestines of the dog, others infest birds and still another, the most important, infests the hog.

(Echinos-spined)

Echinorhynchus GIGAS (Rhynchus-proboscis) (Gigas-giant).

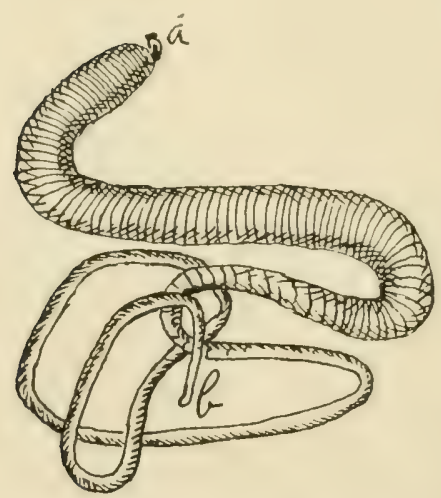

Distribution. - Very common in the United States ; also found in Europe.

Description.-Round in shape, about twothirds the calibre of a lead pencil, with transverse markings. Milk white in color; the cephalic extremity terminates Fig. 57-Fchinorhyches Gigas, Fendie. abruptly and is pro. a. Globe-shaped proboscis, armed with six vided with a globe-
raws of hooklets. b, Caudal extremity. shaped proboscis that is armed with six rows of hooklets irregularly 
arranged, point backwards. The hooklets are very small and resemble, in shape, those of a cat's claw. The posterior half of the female is attenuated until it is no larger than a knitting needle; the female is eight to twelve inches long, the male three to four inches.

Life Cycle.-The female is oviparous; the eggs are oblong and contain fully developed embryos, in a few days after they have passed to the ground with the feces; if they are ingested by the intermediate host, which is the larva of the May bug (white worm or grub worms) they soon hatch in its digestive tract; this embryo is very small and provided with four small hook-

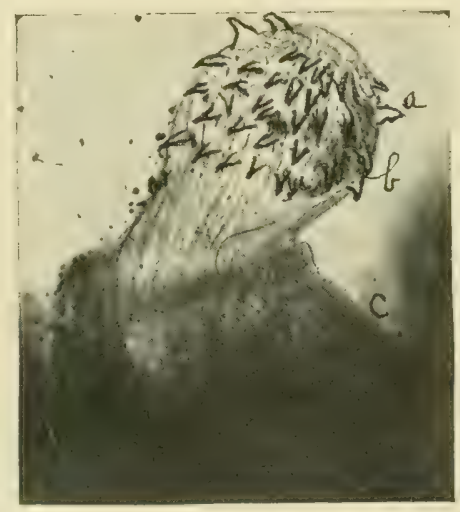

Fig. 58-ECHINORHYאCHUS Gigas. Cephalic extremity showing globeshaped froboscis and six rows of hooklets. lets with which it burrows through the intestinal wall and becomes encysted in the abdominal cavity; when this cyst matures it contains the fully developed larva, which retains its vitality during the existence of the larval worm and has been noted still alive after metamorphosis into the perfect insect; it is possible that other invertebrates may act as an intermediate host; if the pig eats these white worms or May beetles containing the encysted larva, the young echinorhynchus is set free by the process of digestion 
and attaches itself to the mucous membrane of the small intestines by means of its six rows of hooklets and develops into the adult worm.

Animal Infested.-The hog.

Parts Infested. - The small intestines.

Condition Produced. - By the anchorage of the cephalic extremity, by means of its hooked proboscis, there is produced a small tumefaction which pushes the serous covering of the intestine out; from the serous surface of the bowel this nodule resembles a tubercle, and may be mistaken for tuberculosis; upon close examination the head of the echinorhynchus will be found atta ${ }^{-\operatorname{mad}^{2}}$ to the inner part of the nodule.

Symptoms. - When infested by large numbers they may cause a loss of appetite, derangement of digestion, general unthrifty condition and later emaciation and convulsions; they may prove fatal among pigs.

Treatment. - To remove the worms from the intestinal tract the same treatment is used as for the Ascaris Suilla; to prevent the hogs from becoming infested it will be necessary to keep them on a board floor so that it will be impossible for the ova to reach the intermediate host, or to subject the feces laden with ova to an antiseptic solution; as the white worms are found most frequently in manure piles and in very rich earth, these are the most fertile fields for the intermediate host.

\section{TREMATODA (Trematodes-flukes).}

The order Trematoda belongs to the class Plathelmintha and includes a group of worms that are commonly called flukes. They produce a disease 
called Distomiasis or Distomatosis, which is divided into various forms viz.:

Hepatic Distomiasis catsed by the Distoma Hepaticum, Distoma Americanus, Distoma Lanceolata.

Pulmonary Distomiasis caused by the Paragonimus Westermanii.

Gastric Distomiasis caused by the Amphistoma Cervi.

Vascular Distomiasis caused by the Schistosoma Bovis.

\section{FASCIOLIDAE.}

The family Fasciolidae belongs to the order Trematoda and includes the genus Distoma.

THE FLUKES.

(Dis-twice)
Distoma Hepaticum
(Stoma-mouth)
(Hepatic-liver)

Synonyms.-Fasciola Hepaticum. Liver Fluke.

Distribution.-Found in the low-lying lands of the United States where the weather is warm and conditions are favorable for the development of the larval state. Also found in the low-lying land of Scotland and other countries.

Description-The body is flat and leaf-like; it is oblong, larger and rounder in front; at the extreme anterior end it is abruptly contracted in such a way as to present a conical neck; it terminates obtusely behind. The antero-posterior diameter is about one to one and one-fourth inches; the width measures one-third to one-half inch. It is provided 
with two suckers, oral and ventral. At the bottom of the oral sucker is placed the mouth, which communicates with the intestines by means of an oesophagus. The intestines consist of two ramifying branches which permeate the whole body. The ventral sucker lies about one-sixth of an inch behind the oral one. The fluke is brown in color and is a hermaphrodite; the penis projects in front of the ventral sucker, always recurved; the vulva is small and situated at the side or a little behind the male orifice.

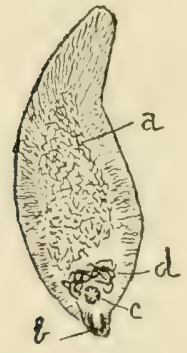

Fig. 59.-Distoma

Hepaticum.

The specimen from which this drawing was made was placed between two glass slides with rubber bands around each end, giving specimen gentle pressure, then kept immersed in alcohol one week, then mounted in Canada balsam.

a, Intestines.

b, Oral sucker.

c, ventral sucker.

d, Uterus.

Life History. - The fluke is oviparous; the eggs are ovoid in shape and brown in color; they are laid in the bile ducts and through the hepatic duct find their way to the intestinal tract, then to the ground through the feces; if the ova fall in dry places they soon perish, if in damp or marshy places they hatch in from five to six weeks; at this stage the whole body of the embryo is covered with cilia, which enables it to move about in the water. At one end is a lancet-like projection which can be thrust out or withdrawn; by means of this apparatus it bores into the second host; if it does not meet one in a day or two it dies; if it meets a water snail it penetrates it and becomes lodged in the respiratory cavity and begins its metamorphosis into the larval 
state. It loses its layer of ciliated epithelial cells and the small mass of round cells forming the interior of the body rapidly grow ; it soon develops into the $\mathbf{S p o}=$ rocyst. From the cells in the sporocyst are formed five to eight redia; each redia in turn develops from fifteen to twenty cercaria; the cercaria is the fully developed larval stage, oval in shape, provided with an oral and ventral sucker, a rudimentary digestive tract and a tail. It now leaves the snail and is enabled to move about in the water by means of its tail and crawls upon a blade of grass or an aquatic plant; it loses its tail at this period and becomes encysted with a gelatinous substance with which it provides itself; this is the fully developed larval stage. The cysts are the most numerous on the part of the grass close to the ground; the larva retains its vitality for a long time if it is in a moist locality; these cysts appear as very small white specks and are eaten by the herbivora grazing upon these infested pastures. The cyst upon reaching the stomach is digested and the larra, set free, soon finds its way to the bile duct, and thence to the liver.

-tuimals Infested.-The ox, sheep, goat, pig, horse, and man.

\section{Part Infested.-The liver.}

Conditions Produced.-The worms invade the bile ducts and here develop into the mature worm; here they live for six months, then die. In autopsy work one's attention is attracted by the enlargement of the large bile duct on the posterior face of the liver; a cut section of this part shows a greatly thickened wall and many worms contained within the duct; the bile may be somewhat thicker than 
normal with a few dark flocculi. As many as a hundred flukes have been taken from the ducts of a single liver. The liver is unfit for food.

Symptoms.-Distomiasis or liver rot appears mostly among cattle in the United States on account of the fact that cattle are grazed on the low lying infested lands; while the sheep come mostly from the high table lands where conditions are not favorable for their development into the larval stage. In England the sheep are most often affected on account of the reversed conditions to what they are in the United States. The symptoms given us by observers in that country are as follows: The malady is divided into four stages or periods.

First period is that of immigration; the flukes are small and do not cause excessive disturbance. This period lasts from four to thirteen weeks.

Second period is that of anemia after the thirteenth week from infestation; the sheep are less lively, the mucous membrane is pale, the appetite good and the sheep show a tendency to fatten ( as a result of the stimulus to the liver which causes an increased flow of bile). In the latter part of this period the appetite diminishes, thirst increases; rumination irregular; mucous membrane yellowish; may show edema; wool is dry and brittle, and the sheep show great weakness. The feces contain the ova of the fluke.

Third Period.-This is a period of loss of flesh; the sheep becomes gradually weaker and emaciated; the temperature is irregular, the respiration feeble and frequent; pregnant ewes abort; the milk of nursing ewes is poor in quality. Oedema is noted 
in dependent parts, as intermaxillary space, along the trachea, under part of the thorax. Pain is noted on pressure on the region over the liver.

Fourth Period,-That of emigration of the flukes, can be considered the period of convalescence. All symptoms grow gradually less. The liver, though infected only once, never entirely recovers.

There is great mortality among sheep. Not such a large percentage of mortality among cattle. The symptoms in cattle are similar to those given above for sheep, though cattle have a greater resisting power to the effects of the invasion.

\section{Distoma Americanus (Americanus-America).}

Synonyms.-Distoma Magna; Fasciola Americanus; Distoma Texicanum; Fasciola Magna; American liver fluke.

Distribution. - Found common in the cattle from the low-1ying lands of the South and Southwest.

Description.- The body is flattened, leat-like and slate colored; it measures one to one and one-quarter inches long and about one inch wide; it is provided with two suckers, oral and ventral, as in the preceding species. The mouth is located at the bottom of the oral sucker. The ramifying intestinal branches permeate the entire worm and can be plainly seen when the worm is placed between two glass slides and pressed. It is a hermaphrodite, the male and female genital organs being placed anterior to and around the ventral sucker. The ventral sucker is located about ne-fourth inch behind the oral one.

Life Cycle.-The life cycle is similar to that of the Distoma Hepaticum. 
Animals Infested.-The ox, sheep, pig, etc.

Parts Infested-Liver, sometimes the lungs. The writer has noted one case of Hepatic Distomiasis in a pig; four specimens of the Distoma Americanus were found.

Conditions Produced.-The larval fluke upon being taken into the stomach on grass is liberated by the dissolving of the gelatinous capsule enclosing it. It finds its way to the liver through the hepatic duct and finally becomes stationary in a small bile duct; or it may penetrate the duct and become lodged in

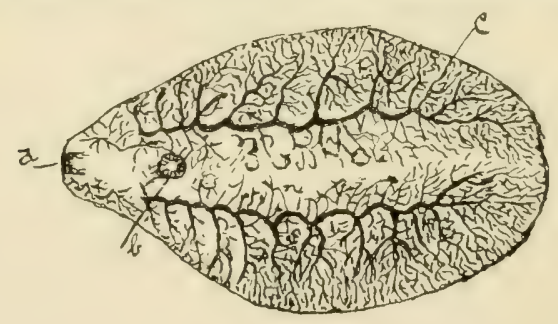

Fig. 60,-Dis roma AMERICANUS.
a, Oral sucker.
b, Ventral sucker.
c, Intestine

the tissue outside. It here forms a cyst which varies in size up to a hen's egg. The outer surface of the liver presents the appearance of black prominent elevations. Upon section of these tumefactions they are found to contain a cavity within, which is filled with a chocolate-colored fluid and some debris, and in the older cysts some earthy material.

One or more flukes are found in each cyst. The portal lymph glands, that lie against the posterior surface of the liver at a point where the portal vein 
enters, are swollen and appear slate colored or black. The serous membrane adjacent to the liver is slate colored. The young flukes may migrate through the diaphragm and become lodged in the posterior lobe of the lung, where they form a cyst as in the liver; the attention is first attracted to the infested part by the interlobular substance being stained dark, oftentimes black; upon closer examination a tumefaction is found which, when sectioned, is found to contain the characteristic cyst. The adult fluke lives about six months. The symptoms and general debilitating conditions are the same as in infestation with the Distoma Hepaticum. Often cattle are infested with both Distoma Hepaticum and Distoma Americanus.

\section{Distoma Lanceolata (Lancea-lance).}

Distribution.-Found in countries and localities where the preceding species are found.

Description. - The body is lancet shaped, brownish in color and semi-transparent; when the uterus is filled with ova the body presents a mottled appearance, on account of the fact that the integument is semi-transparent. The intestinal tract consists of two non-ramifying branches. The adult is from onethird to one-half inch in length and one-tenth inch wide.

Life Cycle.-The life cycle is the same as in the preceding species; the ovum undergoes segmentation and develops embyos in the maternal body, but is not hatched until it has been in water three weeks. The embryo is globular or pyriform in shape, ciliated on the anterior third of the body, and armed with a sharp protractile and retractile cephalic needle. 
Animals Infested.-The ox, sheep, hog, etc.

Parts Infested.-The liver.

Symptoms. - Similar to that caused by infestation with the preceding species.

Paragonimus Westerifanir (Westerman).

Sy'nonyms. - Distoma Ringeri; Distoma Pulmonale; Distoma Westemanii.

Distribution.- - Rare in the United States. Common in China, and other Asiatic countries.

Description. - The body is thick and elongated; bluntly rounded at both extremities; its other anatomical structures are similar to the preceding flukes; the ventral sucker is located about threesixteenths of an inch behind the oral one ; the adult is about one-half inch long; it is reddish brown or slate colored.

Animals Infested.-Man, hog, dog and cat.

Parts Infested.-The lungs.

Conditions Produced.-The fluke invades the lung tissue and produces a cyst; some are located superficially, some deep; the cyst is usually from one-half to one inch in diameter and contains a small quantity of chocolate colored fluid and ustually two flukes.

\section{Amphistoma Cervi (Amphi-both) \\ (Stoma-mouth)}

Synonyms.-Conical Stomach Fluke; Amphistoma Conicum.

Distribution.-Rare in the United States. Have been reported in Canada, Europe, Australia and Egypt.

Description.-It is conical in shape, thin in front 
and gradually thickening toward the posterior part; slightly curved on the ventral surface. It fixes itself to the mucous membrane by means of a sucker on the posterior or large end. It is of a pinkish color and about one-half inch in length.

Animals Infested. - The ox, sheep, goat, and camel. Parts Infested.-The Rumen.

Condition Produced.-They attach themselves to the mucous membrane between the papillae of the rumen; most common near the oesophageal groove. They are not reported as causing serious results.

\section{SCHISTOSOMIDAE.}

The family Schistosomidae includes the blood flukes.

$$
\begin{aligned}
& \text { (Soma-body) } \\
\text { Schistosoma Bovis } & (\text { Bovis-ox) } \\
& \text { (Schistos-cleft). }
\end{aligned}
$$

Synonym.-Blood fluke.

Description.-Small in size, round in shape and provicled with two suckers located on the anterior end. The female is larger than the male. The eggs are elongated and armed with sharp points.

Animals Infested.-The ox and sheep.

Parts Infested.-Blood ressels.

Condition Producid. - The animals presumably become infested through drinking water. The flukes are found principally inhabiting the veins of the abdomen, more especially the venous plexuses of the bladder and rectum. They may cause nephritis, cystitis, and as a result bloody urine or feces. The adjacent lymph glands become hypertrophied. The condition may terminate in death. 


\section{CESTODA.}

The order Cestoda (kestos-girdle, eidos-like) belongs to the class Plathelmintha and includes a large group of worms that are provided with a ribbon shaped body, proceeding from a small head and neck. The head or scolex may be provided with four sucker discs and a rostellum of hooklets. The hooklets are arranged in two circular rows in the center of a square formed by the four sucker discs at the extreme cephalic extremity. This is called an armed taenia (tapeworm). The head may be provicled with only four sucker discs. This is called an unarmed taenia. These constitute its fixation apparatus by which means it fixes itself firmly to the mucous membrane of the intestine and floats back in the intestinal contents. A neck connects the head with the body; in some species it is short, in others long and slender, while in others, as the species found in the horse, the neck is absent. The body is flat, ribbon-shaped and segmented; it is composed of a network of cells with anastomosing prolongations. The integument comprises a homogeneous cuticle lying on a subcuticular layer of longitudinal and transverse fibers. It is provided with a rudimentary nervous system which consists of two longitudinal cords united by a transverse commissure at the head. There is no digestive apparatus; the worm absorbs nourishment through fine canaliculi which traverse the cuticle. There is no circulatory apparatus; the integument serves for the exchange of gases. The excretory canal consists of four tubelike structures which traverse the entire length of 
the worn; two are located dorsaily and two ventraliy and open at the posterior border of the last seg ment through an opening called the caudal foramen. The segments develop from the neck; each new segment pushes the preceding one on, until there is a chain of segments. As the segments grow they become longer and wider so that the strobilus (strobilos-pine cone, meaning adult tapeworm) has an attenuated appearance anteriorly with a narrow neck and a very small head. Each segment is, to a certain extent, an individual within itself. It absorbs nutrients and through its integument exchanges gases. It is a hermaphrodite, possessing both male and female genital organs. The genital pore is located on the side of each segment. In some species there is a genital pore on each side, the segment being a double hermaphrodite. The sexually deve1oped segment is called a mature segment; the segment whose uterus is filled with mature ova is called a ripe segment and is ready to detach itself and produce its kind. The tapeworms of the horse, ox and sheep are all unarmed. The life cycle is unknown; most of the adult tapeworms of man, dog and cat are armed, and the life cycle known. In this life cycle the larval stage is cleveloped in another animal; this stage is called the cystic or hydatic stage.

The condition of an animal harboring tapeworms is called taeniasis.

TAENIDAE.

The family Taenidae belongs to the order Cestoda under which the genus Taenia is placed. 


\section{TAPEWORMS OF MAN.}

Two tapeworms of man find a lower animaí as. an intermediate host, viz.: Taenia Solium and Taenia Saginata.

\section{TAEnia Solium ('Taenia-ribbon) \\ (Sola-alone)}

Synonym.-Taenia Armata.

History. - Adult tapeworms in man and their effect upon the health of the host dates back to the beginning of history; we find the first description of tapeworms in the seventeenth century. The life cycle was worked out about 1850 .

Distribution.-Frequent in the United States; also found in many other countries.

Discription.-The head is scarcely larger than a pin head and is provided with four sucker dises and twenty-four to thirty-two hooklets. The worm may reach the length of forty feet. The latter segments are as long or longer than broad; the genital pores are prominent and irregularly alternate; as soon as the segments are filled with mature ova they detach themselves and pass out to the ground with the feces. From one to half a dozen detach themselves at one time. Each segment contains many hundred ova.

Life Cycle. - The ova become disseminated through the water or food and are through these channels taken in by the intermediate host, which is the hog. In the stomach the ovum hatches into a six-hooked embryo, which, by means of its hooklets finds its way through the stomach or intestinal wall and wanders through the tissues or is carried by the blood stream or lymph current; in nine days the em- 
bryo finds a resting place. From this small mass of protoplasm is developed first an acephalo cyst, which is provided with two membranes, the outer one called the hydatic membrane and the inner one called the germinal membrane; from the germinal membrane there is developed the larva; this constitutes the fully developed larval state. The cyst is oval in shape and about one-half to two-thirds the size of a navy bean; the larva can be seen through the cyst wall as a small white body and consists of the head, provided with four sucker dises and twentyfour to thirty-two hooklets arranged in a double row. This head or larva is attached to the inner or germinal membrane by means of a pedicle and floats in a colorless fluid; each cyst contains but one larva. The cyst is fully developed in sixty days; it infests voluntary, involuntary and heart muscles, and the glands and organs of the body, invading the cancellated portion of bone. After cysts are quite old they undergo degeneration, beginning from without to within; through this degeneration process the cyst wall may rupture and and cyst collapse, or it may become filled with a cheesy or earthy material. Should man eat the meat of the hog infested with the cyst containing the living larva, through digestion the larva is liberated and finds its way to the small intestines and fixes itself to the mucous membrane by means of its hooklets and four sucker discs, and develops into the mature form.

Animals Infested.-Man, hog and dog.

Parts Infested.-Adult infests the small intestines of man. The larval form infest the muscle structure of the hog and sometimes the dog, in cyst formation. 
The condition of the muscle being infested by these cysts is called measly pork; the cyst or larva cysticercus cellulosae.

Symptoms. - In badly infested cases the cysts may be found bulging from the mucous surface of the sides of the tongue or phrenum, or from the conjunctival or rectal murous membrane. When the cysts in the tongue are numerous they may cause partial paralysis, and as a result,di.ficult prehension of food. If the cysts are formed in the brain or spinal cord various nervous disorders, as vertigo, convulsions, etc., may be observed. When generalized the ani-

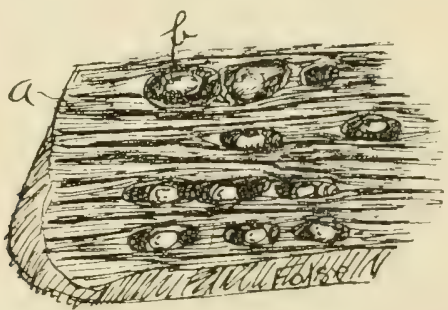

Fig. 61.-Cysticercus Cellulosae of tongue, (measly pork).
a, Muscle fibers.
b, cyst showing larva within.

mal is unthrifty, weak and emaciated. In post mortem work the meat from such infested hogs should be condemned as unwholesome and dangerous. In man the adult worm causes disturbance in digestion, nausea, uncomfortable ferling in the abdominal region, loss of flesh, etc.

Taenia Saginata (Saginatus-to make fat).

Synonym.-Taenia Mediocanellata.

Distribution.-More common in the United States than the preceding species; also common in other countries. 
Discription. - This worm is flat and ribbon shaped, with a narrow neck of medium length joining the head to the body; the head is small and provicled with four sucker discs. It is the unarmed tapeworm of man. The latter segments are a little longer than broad; the terminal segments are about three-sixteenths of an inch wide; the genital pores irregularly alternate. The worm may reach the length of forty feet.

Life Cyclc.-The life cycle is similar to that of the Taenia Solium. The intermediate host is the ox, which becomes infested through water or food contaminated with the infested excrements of man. The ovum upon reaching the stomach of the ox is hatched into a microscopic globular-shaped embryo provided with six hooklets. Like the embryo of the preceding species they penetrate the tissues, through which they gradually work their way to various parts of the body, and in the course of nine days become stationary and they form a cyst through the same transformation as in the preceding, which requires about sixty days. These cysts are about Łwo-thirds the size of a navy bean and contain a single larva which consists of a head and neck. The head is provided with four sucker discs; by examining the cyst the larva appears as a small white mass attached to the mother or germinal membrane, floating in a colorless fluid, and plainly visible through the cyst wall. Should a member of the human family eat meat (beef dried, rare done or raw,) containing the cysts in which is found the living larva, he would become infested with adult tapeworm. In the stomach the larva would be liberated and upon reaching the 
small intestines would attach itself to the mucous membrane by means of its four sucker discs and develop into the adult worm; if the meat is thoroughly cooked the larvae are destroyed. These cysts undergo degeneration as in the preceding species. The writer has observed cysts in the heart of a four year old steer in which many of the cysts had undergone degeneration. The cystic tissues had been replaced with a yellowish cheesy pus. The cystic larva is called cysticercus bovis. The infestation of beef with the cystic form of the Taenia Saginata is called measly beef.

- Inimals Infested.-Man by the adult worm; cattle by the larva.

Parts Infested.-The adult infests the small intestines; the cystic form infests the muscle structures. The most common locations of these cysts are the masseter muscles, then the tongue and heart, and in badly infested cases in all tissues of the body.

Symptoms. - The symptoms of animals and persons infested by this species are the same as that caused by the preceding species.

\section{TAPEWORMS OF HORSES.}

The tapeworms of horses are three. Their life history is unknown, and all are unarmed. They are rare in the United States.

Taenia Perfoliata (Per-through; folium-leaf.)

Description. - The head is large and globular in shape, and is provided with sucker dises; the neck is absent; the segments are very short and at the terminal end are about one-half inch wide. There 
is a slight attenuation toward the posterior extremity. The entire worm measures from two to two and one-half inches long.

Animal Infested.-The horse.

Parts Infested.-The caecum.

Taenia Mamillana (Mammalis-mammal).

Description. - The head is rounded, with the sucker discs located at the side, in the form of slits; the neck is absent, and the posterior border of the segments is wider than the anterior; the worm is much smaller than the preceding one, measuring one to one and one-half inches long.

Animal Infested.-The horse.

Parts Infested.-Small intestines.

Taenia Plicata (Plicatus-to fold).

Description.-The head is thick and wide; it is depressed on either side; the suckers are located at the free end of the head, and are round; the neck is absent; the segments are about one-half inch wide; the worm measures from two to three inches in length.

Animal Infested.-The horse.

Parts Infested.-The intestines and colon.

\section{TAPEWORMS OF CATTLE AND SHEEP.}

The tapeworms of cattle and sheep are unarmed Taenia. The segments are wider than long. The life history outside of the body is unknown.

Taeniasis among cattle and sheep is more common in summer than in winter. During the grass season range cattle are especially prone toward this infestation. 
TaEnia Expansa (Expansus-broad).

Synonym.-Moniesia Planissima.

Distribution.-Common in the United States, especially in range cattle.

Description.-Its head is very small, and is provided with four sucker discs; the head is followed by a long, slender neck; the segments of specimens from cattle often measure an inch in width; these widest segments are only about one-eighth of an
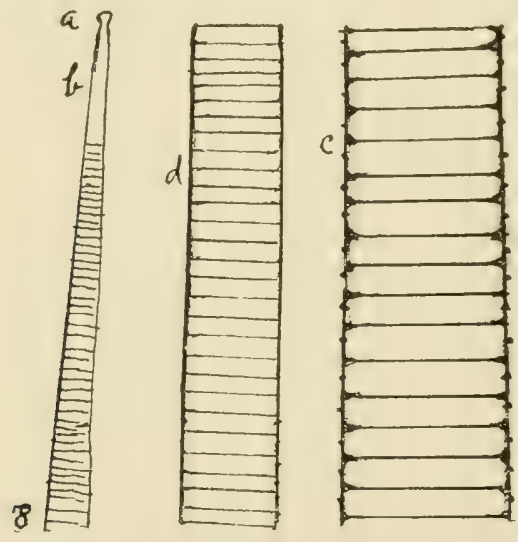

Fig. 62.-Taenia Expansa (from ox).
a, Head.
c. Nature segments.
b, Neck.
d, Partially developed segments.

inch long. The specimens infesting sheep measure only about one-half inch in width. The worm is thin and segments translucent; each segment is provided with two genital pores; one located at each margin. This worm may reach the length of twenty to forty feet.

Life Cycle.-Animals are supposed to become in- 
fested through water or food contaminated by the ova or embryos.

Animals Infested.-The ox and sheep.

Parts Infested. - The small intestines.

Symptoms. - Cattle and sheep infested by only a few worms of this species, do not show any noticeable constitutional effect. Should myriads infest them, the animal may show an unthrifty condition, due to irritation and loss of nutrients.

Treatment. - After the infested animals have been fasted for twenty-four hours, they should be given a physic and parasiticide. Cattle take one to two pounds of Epsom salts, according to the age; this should be accompanied with fluid extract male shield fern from four to six drams, powdered areca nut one-half to one ounce. Sheep take four to six ounces of Epsom

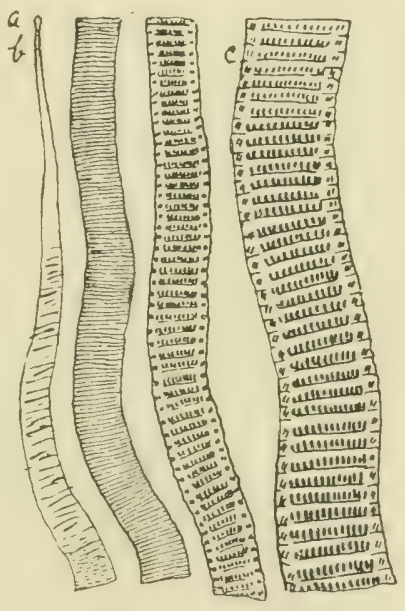

Fig 63.-TAEnia Expansa (from sheep.) a, Head. b, Neck. c, Mature segments. salts according to their age. This should be given in conjunction with one to two drams fluid extract male shield fern, and one to three drams powdered areca nut. 
Taenia Alba (Albus-white).

Synonym.-Moniesia Alba.

Distribution.-Common in native and range cattle and sheep.

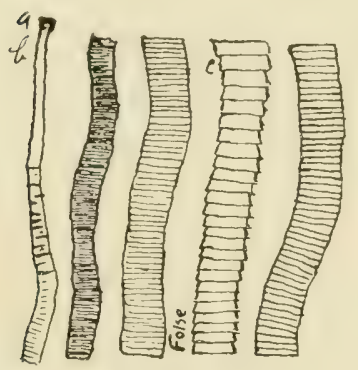

Fig. 64.-TAENIA ALBA (from sheep).
a, Head. b, Neck.
c, Mature segments.

Description. - This worm is whitish in color, the head small and provided with four sucker discs, which constitute the fixation apparatus. The neck is short. The segments are thicker and not so wide as compared to the preceding species. The widest segments reach about one-half inch. The worm, when fully developed, measures from three to seven feet. The ones infesting cattle develop larger and longer than those in sheep.

Life Cycle.-Same as preceding one.

Animals Infested.-The ox and sheep.

Parts Infested.-Small intestines.

Symptoms.-Usually found in small numbers in cattle and no serious results are credited to them. Outbreaks of Taeniasis among lambs have been reported in which the fatality ran fifteen to twenty percent. If in small numbers in sheep they do not cause serious disturbance.

Treatment.-Same as for Taenia Expansa.

Taenia Fimbriata (Fimbria-fringe).

Synonym.-Thysanosoma Actinioides.

Distribution. - The most common species of tapeworm infesting sheep. 
Description.-The head is some larger than that of the two preceding species and is provided with four sucker discs; the neck is short and thick; the segments are wider than long. The terminal segments are narrower than the preceding ones, which gives the worm an attenuated appearance. The posterior borders of the segments are fringed both dorsally and ventrally with finger-like projections; those on the border of the segments close to the head are short but on the lateral segments the fringe covers the succeeding ones. The fully developed worm varies from three to six inches in length.

Life History. - The history outside of the animal is not known. Animals become infested through contaminated food or water.

Animals Infested.-Sheep.

Parts Infested.-Small intestines.

Symptoms. - When the animal is infested by many worms they may interfere with digestion and by robbing the host of nutrients cause an unthrifty condition; they may prove serious to lambs. Many times the worms find their way from the duodenum, through the bile duct to the gall bladder; they

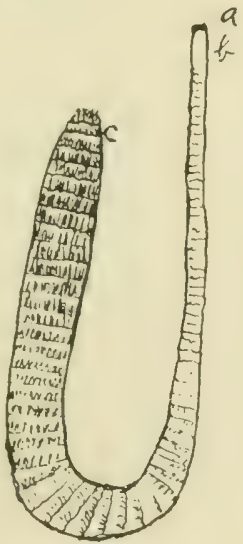

Fig. 65.-

TAENIA FIMBRIATA.

a, Head.

b, neck.

c, Terminal segments with fimbria. may clog the gall duct and cause serious results. Treatment.-Same as for the Taenia Expansa. 


\section{TAPEWORMS OF DOG.}

The tapeworms commonly found in the dog are armed; their life history is known.

TAenia Marginata (Marginatus-margined).

Synonym.-Marginate tapeworm.

Distribution.-One of the common tapeworms of the dog; the shepherd dogs are a common carrier of the worm.

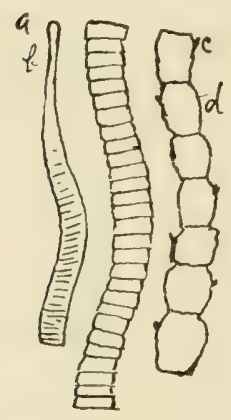

Fig. 66.-

TAENIA MARGINATA.

a, Head.

b. Neck.

c, Genital pore,

d, Ripe segments.

Description.-The head is scarce$1 \mathrm{y}$ wider than the neck and is provided with four sucker discs between which is located a rostellum of hooklets; this rostellum is arranged in a double circular form and consists of from thirty to forty hooklets. The neck is short; the segments as they develop from the neck are shorter than broad. As the distance from the head grows greater the segments become wider and longer; the mature segments are nearly square; the ripe segments are slightly longer than wide; the genital pores irregularly alternate. The worms may develop to a length of five feet.

Life History.-The ripe segments detach themselves and pass out to the ground with the feces; the segments soon decompose and myriads of ova are liberated; these become disseminated by rain. The sheep become infested through the food and water; upon reaching the stomach the ovum hatches into a six hooked embryo which penetrates the stomach 
wall and invades the liver tissues, where it passes part of its life in its transformation into the larva; later it leaves the liver and becomes lodged in the peritoneal cavity; here it forms a cyst which varies in size up to a hen's egg. This cyst is fully developed in 250

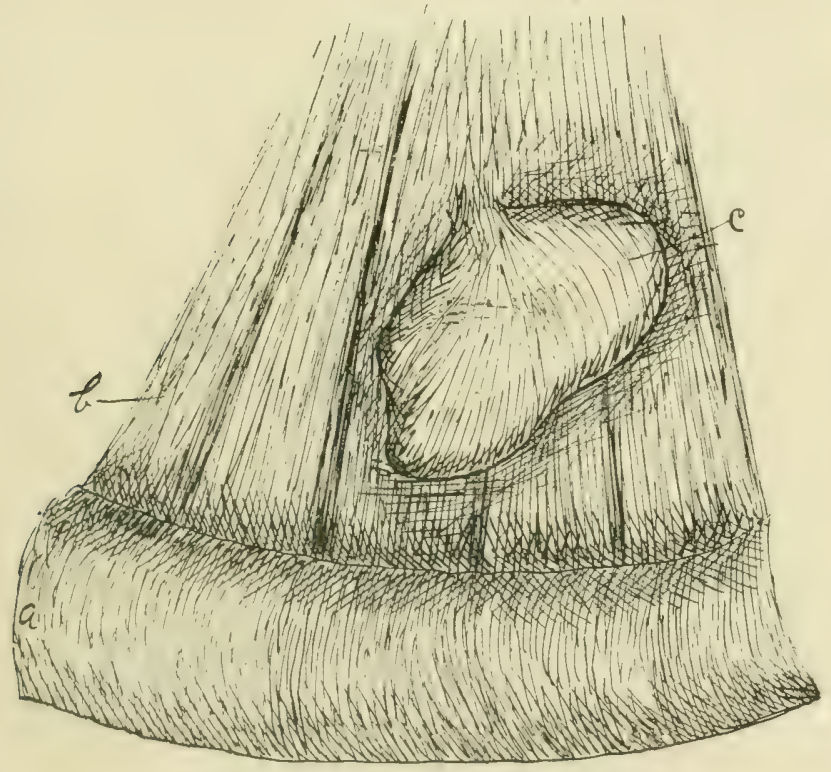

Fig. 67.-Cysticercus Tenuicollis.

a, small intestines.

b, Mesentery.

c. Cyst.

days and is provided with two fibrous walls, an outer thick membrane called the hydatic membrane and a thin inner one called the germinal or mother membrane; from this mother membrane is developed a single larva which is suspended by means of a pedi- 
cle and floats in a colorless fluid; the larva consists of the head and neck, from which is developed the adult worm, when ingested by the dog. The larva can be seen as a small white body through the cyst wall; these cysts are attached to the mesentery, omenta or capsule of the liver. They are called cysticercus tenuicollis. When this cyst is devoured by the dog, the larva is liberated through the digestion of the cyst walls; upon passing out to the small intestines it becomes attached by means. of its fixation apparatus, which consists of four sucker discs and a rostellum of hooklets, and develops into the adult worm in four months.

Animals Infested.-Adult infests dog; larva infests sheep ; also observed in hog and other animals.

Parts Infested.-Adults are found in the small intestines. The cystic or hydatic form in the peritoneal cavity.

Symptoms. - When the dog is infested by large numbers they cause irregularity of digestion, nervousness and loss of condition.

Treatment.-For a dog of twenty-five pounds weight, give the following:

R Fld. ext. male fern

Pulv. areca nut_................

Simple syrup qs. ad._._._. Jiv

M. S. Give at one dose.

This can be repeated in four or five days.

Taenia Echinococcus (Kokkus-berry).

Distribution.-One of the most common tapeworms of dogs in the United States. In autopsy of eighty dogs fifty percent were found to be infested by the 
Taenia Echinococcus; also found in Europe On an average about one percent of hogs harbor the cystic form; rare in sheep; not reported in cattle in this country.

Discription.-The head of the adult worm is globular in shape, provided with four sucker dises and a rostellum of from twenty-eight to fifty hooklets; the neck is long and distinct; the entire worm consists of four segments, including the head; the terminal segment is nearly as long as the balance of the worm. It is four or five times as long as wicle. As soon as the segment is ripe (filled with mature ova) it cletaches itself, and is passed out to the ground with the feces. The entire worm measures from one-fifth to onefourth inch long and is very slender; as a result it may be easily overlooked in holding autopsy.

Lifc History. - The intermediate host is the hog, sheep, ox or man. The detached segment, which passes to the ground, soon decays and liberates myriads of ova, which become disseminated over the ground, pasture and water supply by the rains; thus through contaminated water and food this microscopic egg is taken in by the intermediate host. Upon reaching the stomach a minute six=hooked embryo is liberated which invades the tissues and becomes lodged in some organ, usually the liver or lungs; it here undergoes a metamorphosis into the larval form. First is developed an acephalocyst; this is provided with hydatic and germinal membranes; the hydatic membrane is thick while the germinal membrane is thin. The cyst develops very slowly and arrives at this stage in about five months; on the inner surface of the mother mem- 
brane appears a minute papillary elevation which becomes hollowed in the center and forms another cyst called the daughter cyst (secondary or proligerous cyst). This is attached to the mother membrane by a short pedicle; the bud from the mother membrane may develop a larva or scolex which is attached to it by a short slender pedicle; this development may proceed until fifteen or twenty heads are there attached; on the inner side of the daughter vesicle may be developed five to ten heads or larvae or another vesicle called a grand=daughter vesicle ; the grand-daughter vesicle may develop within it another cyst called a great=grand=daughter vesicle, which is always an acephalocyst. These secondary cysts may develop so as to be practically outside of the mother cyst, thus, multiple cysts result. The cyst contains a colorless poisonous fluid of saline, neutral or slightly acid reaction; this development goes on until the entire organ is filled with multiple cysts; these cysts vary in size up to one and one-half inches in diameter. This condition is called echino= coccus veterinorum, echinococcus polymorphus, or cysticercus echinococcus. Sometimes instead of this form of cyst formation there is formed a cluster of cysts varying in size from a millet seed to a pea ; these are in clusters like a bunch of grapes and are called echinococcus multilocularis or echinococcus alveolaris. These cysts may undergo degeneration; the cyst wall ruptures and the cyst collapses. Cysts have been known to retain their vitality for many years. Dogs consuming these cysts develop the mature worm.

Animals Infested.-The adult Taenia infests the 


\section{Plate XI.}

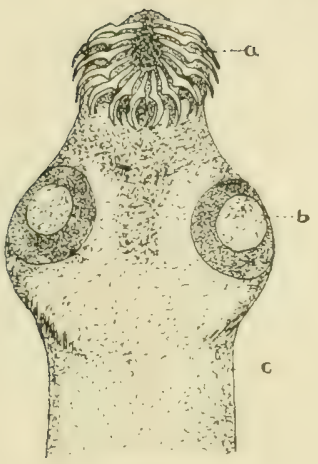

Fig. 1-Tnenin Marminata. (Cephalic extremity).

-a, Hooklets.

b, Sucker.

c, Neck.

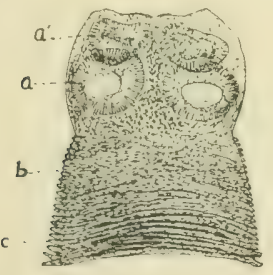

Fig. 3-lvenia Fimbriata.

(Cephalic extremity. Partial front view).

a, Sucker-a partial view of under sucker.

b, Neck.

$\therefore$ First segments of body.

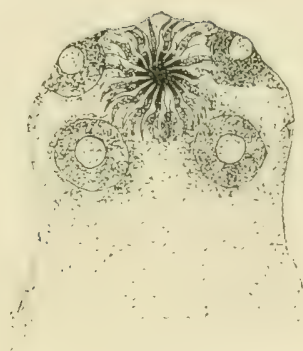

Fir. 2-Cssticerens 'Temuicollis.

(Larra of Tafnia Marginata. Showing four sucker dises and rostellum of hooklets).

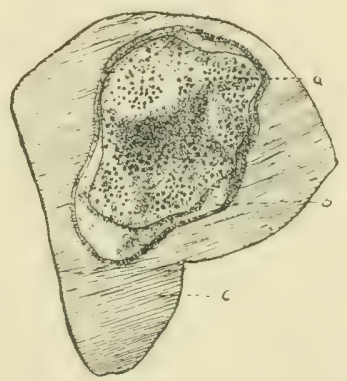

Fig. 4-Section through cyst of Cysticercus wehinocoecus.

Germinal membrane slightiy detached, with larvae.

b, Hydatic membrane.

c, Section of liver.

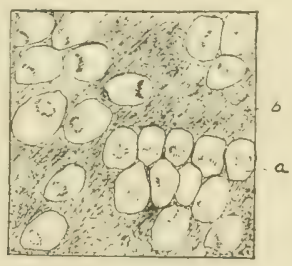

Fig. 5-L a $x$ ze Cysticereus Eehinococeus.

(Magnified).

a, Larvae showing rostellum of hoolilets.

b, Germinal membrane, to which larvae are attached by means of pedicle. 

dog; the larval (cystic or hydatic) form infests the hog, sheep, ox and man.

Parts Infested. - The adult is found in the small intestines; the larval form in the liver, principally; occasionally in the lungs and sometimes in other organs.

Symptoms. - When the cysts invade an organ to a sufficient extent they interfere with the functions of that organ; animals so infested gradually lose condition; there is loss of appetite, jaundice, oedema 11nder breast or neck and jaws; nervous disorders if they should invade the brain.

In dogs, infestation by myriads of adults, produces indigestion, nervousness, nausea and gradual loss of condition.

Taenia Coenurus (Common tail).

Distribution.-Found in European countries; not reported in the United States.

Description. - The head is small and provided with four sucker discs and a rostellum of from twenty-two to thirty-two hooklets; the neck is narrow; the mature segments are as long as wide; the genital pores irregularly alternate; the ripe segments are nearly twice as long as wide. The worm usually attains the length of two to three feet.

Life Cycle.-The ripe segments from the small intestines of the dog pass out to the ground with the feces; these segments soon decompose and myriads of ova are liberated which become desseminated in food and water. The intermediate host is sheep which become infested through contaminated food or water. The ova, upon reaching the stomach, hatch into sixhooked embryos which immeaiately begin to migrate 
through the tissues, or they may penetrate an artery and be carried by the blood current; the embryos will develop only in nerve tissue, and may be carried to these centers through the blood stream; if lodged in tissue, not nerve, they perish, but if lodged in the brain or spinal column they begin their transformation into the hydatic state; in eight or nine days after the ova are ingested the embryos have reached the brain and in twenty days are about one-tenth inch in diameter; development continues and they are fully developed in ninety days. The cysts possess a hydatic and germinal membrane; from this inner or germinal membrane there is developed from one to two hundred heads or larva. The encysted larva is called Coenurus Cerebralis or Cysticercus Coenurus. They may develop in the coverings of the brain or spinal cord or in the brain and cord substance; if the dog eats these cysts, through digestion the larva (which consists of a head provided with four sucker discs and a rostellum of hooklets and a neck) is liberated and fixes itself to the mucous membrane of the small intestines and develops into the mature worm in two months.

Animal Infestcd.-The adult infests the dog; the larva infests sheep, and, rarely, cattle.

Parts Infestcd.-The adult worm infests the small intestines of the dog; the larval or cystic form is found in the brain or spinal cord.

Disease Froduced.-Gid; turnsick; sturdy ; waterbrain.

Symptoms. - A dog infested by the adult worms shows the same symptoms as when infested by any one of the preceding species, and is amenable to the 
same treatment. If many embryos become lodged in the cranial cavity of the sheep the first symptoms will appear about the eighth or tenth day; they cause a cerebral congestion which produces dullness; the head is held in a drooping position, the eyes are red, and the head hot over the affected region; there may be spasms and paralysis. If only a few embryos are present they will not produce the symptoms so quickly; later the sheep keeps apart from the flock, the pupils are dilated, and the animal manifests an unsteady gait; the animal may turn in a circle, to the right or left, depending on which side the cysts are developed; if the cysts are in the right hemisphere it will turn to the right; if in the left hemisphere it will turn to the left. The limbs on the opposite side of the body are stiff or partially paralyzed; if both hemispheres are invaded the sheep may turn to the left, then to the right, depending upon which side the greatest irritation exists; if the cysts are in the center, in the region of the corpus callosum or hippocampus the sheep elevates its nose and goes straight forward; if the cysts are lodged in the cerebellum they produce great incoördination of movements; if in the corpus striatum or optic thalmus the animal will become blind; if the cysts develop in the spinal cord, they produce partial or complete paralysis of the part posterior to this point.

Treatment.-If these cysts are located superficially they may be removed by aid of a trocar or by trephining over the part; as the fluid escapes from the punctured cyst the mother membrane floats out and by aid of a pair of forceps can be removed. 
TAenia Serrata (Serratus-a saw).

Distribution.-Not common in the United States; found in the European countries.

Description.-The head is only a trifle wider than the neck, and is provided with four sucker discs and a rostellum of from thirty-four to thirty-eight hooklets; the first segments, like those in the preceding species, are narrow and shorter than wide; farther down the strobilus the segments are as long as wide and slightly contracted at each end, which gives the worm a serrated appearance. The ripe segments are about one-half inch long.

Life History. - The ripe segments detach themselves, pass out to the ground with the fecal matter of the dog, and thus the ova become desseminated over the ground, and through the food or water the intermediate host becomes infested; the intermediate host is the rabbit. In the stomach of the rabbit the microscopic six-hooked embryo is liberated, which migrates to the peritoneal cavity and forms a cyst called the cysticercus pisiformis; the cyst contains a single larva or scolex (head) attached to the mother membrane by means of a pedicle, and floats in a colorless fluid; the dog becomes infested by eating the viscera containing the encysted larva.

Animals Infested.-The adult infests the dog; the larva infests the rabbit.

Parts Infested.-The adult worm is found in the small intestines of the dog; the larva or cystic form is found in the peritoneal cavity of the rabbit.

Symptoms. - The adult form in the intestines of the dog produces the same symptoms and is amenable to the same treatment as the preceding species; the 
cysticercus pisiformis as a rule do not cause serious results in rabbits.

Taenia Serialis.

Distribution. - Not common; reported more common in European countries.

Description. - The head is wider than the neck and is provided with four sucker discs and a rostellum of from twenty-six to thirty hooklets; the neck is long and slender; the segments, at first shorter than broad, farther down the strobilus are as long as broad; finally the ripe segments are about two and one-half times as long as broad; these latter segments are narrower at the ends than at the middle. The genital pores irregularly alternate.

Life Cy'cle.-The intermediate host is the rabbit and rodent, which become infested through water or food contaminated with the ova from the dog; in the stomach the six-hooked embryos are liberated; they migrate to the connective tissue and develop small cysts which contain a single larva suspended from the mother membrane by means of a pedicle, which floats in a colorless fluid. Dogs become infested by devouring the carcasses of rabbits or rodents harboring the cystic form; the larval or cystic form is called the coenurus serialis.

Animals Infested. - The adult infests the dog; the larval or cystic form infests the rabbits and rodents.

Parts Infested-The adult infests the small intestines; the larval or cystic form the connective tissue.

Symptoms. - The symptoms of a dog infested by the Taenia Serialis are the same as from infestation with other tape worms. The same treatment is indicated. 


\section{Taenia Canina (Canis-dog).}

Synonym.-Taenia Cucumerina.

Distribution. - The most common tapeworm found in the middle West; found in European countries.

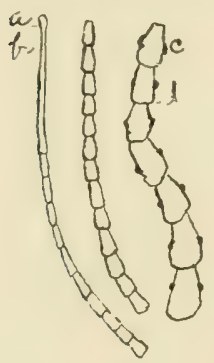

Fig. 68-

Taenia Canina.
a, Head.
b, Neck,
c, Genital pore.
d, Ripe segments.

Description.-The head is succeeded by a narrow, short neck; it is provided with a club-shaped protractile proboscis which is 10cated in the center of the head between four sucker discs; this proboscis is provided with four rows of small hooklets which point backward; by means of this proboscis and the sucker discs it is enabled to hold firmly to the mucous membrane of the small intestines of its host. The termina! segments are about one-sixteenth of an inch in width and one half inch long; each segment is provided with two genital pores, one located in the middle of each lateral side. The adult worm measures from five to twelve inches.

Life History. - The intermediate host of the Taenia Canina is the biting louse (Trichodectes Latus) and the flea (Pulex Serraticeps). These insect parasites become infested while procuring food which is contaminated; the minute embryo is liberated in the digestive tract, migrates to the abdominal cavity and there forms a cyst known as the cryptocystis tricho= dectis (if formed in the louse) or cryptocystis pulecidae (if formed in the flea). The dog, by biting itself to relieve the irritation cansed by these insects, gets them in its mouth; thus the larva, which consists 
of the scolex or head, and neck, after being liberated through digestion finds its way to the small intestines, and attaching itself to the mucous membrane becomes fully developed in about five weeks.

Animals Infested.-The adult infests the dog; the larval or cystic form infests the flea and louse of the dog.

Symptoms. - Treatment.- Same as in the preceding species.

Prophylaxis.-Keep dogs and kennels free from fleas and lice; in this way the chain of the life cycle is broken.

\section{TAPEWORMS OF THE CAT.}

The tapeworms of the cat are armed; the following is the most common.

\section{Taenia Crassicollis.}

Distribution. - Found in the United States.

Description.-The worm may reach the length of five feet; the terminal segments are longer than wide; the head is provided with four sucker dises and a rostellum of from thirty to fifty hooklets; the neck is thick and short.

Life Cycle.-Rats and mice become infested through food and water, in which animals the cystic or hydatic stage develops. The cyst is ovoid in shape, about the size of a pea and contains a single larva; the cystic form is called cysticercus fascio= laris.

Animals Infested. - The cat, rat and mouse.

Parts Infested-The adult infests the intestines of the cat; the larval or cystic form, rats and mice. 
Treatment.-Same as for dogs, with corresponding smaller dosage.

\section{BOTHRIOCEPHALIDAE.}

This family includes a group of worms which are close allies of the tapeworms. The head is oblong and is provided with two suckers arranged on the sides of the head in the form of slits. Each segment is provided with one genital pore, which is located in the center of the ventral surface. There is one genus, viz., Bothriocephalus.

\section{BOTHRIOCEPHALUS LATUS (Bothrida-sucker) \\ (Latus-broad).}

Synonym.-Pit-headed tapeworm.

Distribution. - Found in Japan, Switzerland, Holland and other countries.

Description.-Its head is elongated and followed by a long, slender neck; the head is provided with two suckers in the form of slits, located on the sides of the head; the segments are very short; the widest ones reach one-half inch in width. The genital pore is located in the center of the ventral side of each segment; when the segment is full of mature ova it ruptures and the ova escape; the segment now shrinks, which gives the posterior extremity of the worm an attenuated appearance.

Life Cycle.-The ovum hatches a six-hooked embryo, which is covered with cilia; by means of the cilia it is enabled to move about in the water in quest of an intermediate host, which is a fish; in the fish it develops into the cystic or larval form, called the plerocercoid. Man eating the fish infested with 
the live plerocercoid develops the adult Bothriocephalus Latus.

Animal Infested.-Adult infests man; larva infests fish.

Firts Infested. - The adult infests the smal1 intestines. The larval or eystic form infests the flesh of fish. 


\section{CHAPTER III.}

\section{PROTOZOA.}

\section{CLASSIFICATION OF THE MORE COMMON PARASITIC PROTOZOA.}

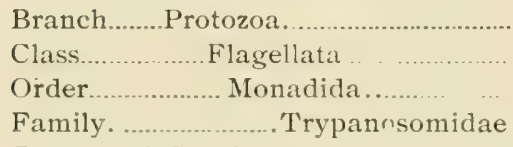

Genus and Species.

Class

Order.

Genus and Species

Order Sarcosporidia

Genus and Species

Order Hemasporidia

Genus and Species

Class Amoeba

Coccidia

Coccidium Oviforme.

Coccidium Bigeminum var. Canis.

Coccidium Perforans.

Trypanosoma Brucii.

Trypanosoma Equiperdum.

Trypanosoma Equinum.

Trypanosoma Lewisi.

Sarcocystis Miescheri.

Balbiania Gigantea.

Piroplasma Bigeminum. Piroplasma Ovis.

Piroplasma Canis.

Piroplasma Equi.

Genus and Species

Amoeba Parasitica.

Amoeba Meleagridis.

$$
\begin{aligned}
\text { ProtozoA } & \text { (Proton-first) } \\
& \text { (Zoon-animal) }
\end{aligned}
$$

The word protozoön is derived from two words, protoön, first and zoön, animal. It is the first or 
lowest form of animal life. The single-cell parasites are classified according to their structure or mode of reproduction. The branch Protozoa includes three classes of interest to us,-viz. Flagellata, Sporozoa and Amoeba.

\section{FLAGELLATA.}

The class Flagellata includes single celled parasites that are provided with one or more flagella; by the aid of the flagella they are enabled to move about in the liquid substances in which they exist. Under this class is rlaced one order, viz., Monadida, and one important family, viz., Trypanosomidae.

\section{THE TRYPANOSOMAS.}

Trypanosoma Evansi (Borer. soma-body)

(Evans).

History.-Discovered in 1880 by Evans.

Distribution.-Found in India, Bombay, Southern China and Indo-China, Philippine Islands.

Description.-The protoplasmic body is elongated, pointed at both ends, and provided with a nucleus in the center. In the posterior end is a small centrosome; from this centrosome there proceeds a threadlike structure which, passing the anterior end, forms a long, projecting flagellum; by this flagellum it is enabled to rapidly move about in the blood. They are twenty-five microns long and one-half micron broad.

Life History.-The Trypanosomas are found free in the blood plasma and obtain their nourishment by osmosis; multiplication occurs by simple cell division; the centrosome, nucleus, flagellum and proto- 
plasm divide into two. The newly formed Trypanosomes develop to full sized organisms and divide again. An insect, - as a blood sucking fly-feasting upon an animal affected with surra, becomes infested, and in turn by piercing the skin of another animal to draw blood, inoculates it.

Animals Infested.-Horse, camel, elephant and dog.

Parts Infested.-The blood.

Disease Produced-Surra; rot.

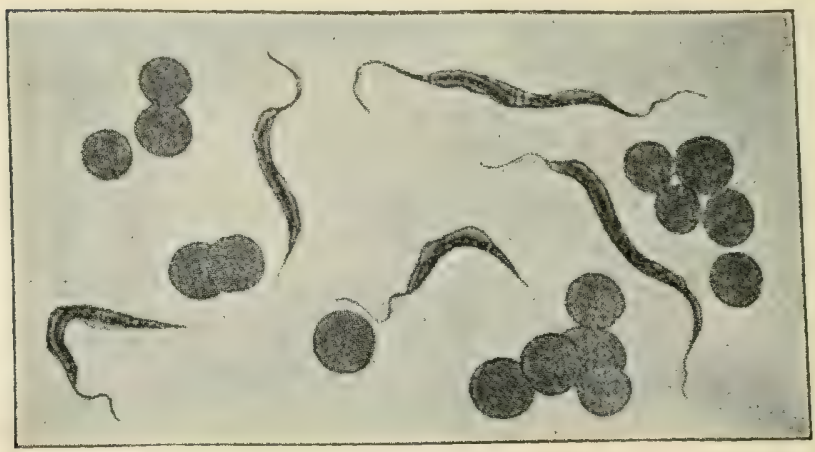

Fig. 70-TRYPanosoma Evansi and blood cells.

Symptoms. - The Trypanosoma invades the blood stream and develops very rapidly; if they be immediately introduced into the blood stream they cause the first symptoms of surra to appear in from six to eight days. Surra is marked by a thermic disturbance; there is noticed a remittent or intermittent fever which lasts for several weeks; eruptions, resembling those of urticaria, may appear; petechia of the mucous membrane of the eyes and 
nose may be observed; there may be a nasal discharge and swelling of the submaxillary lymph glands;

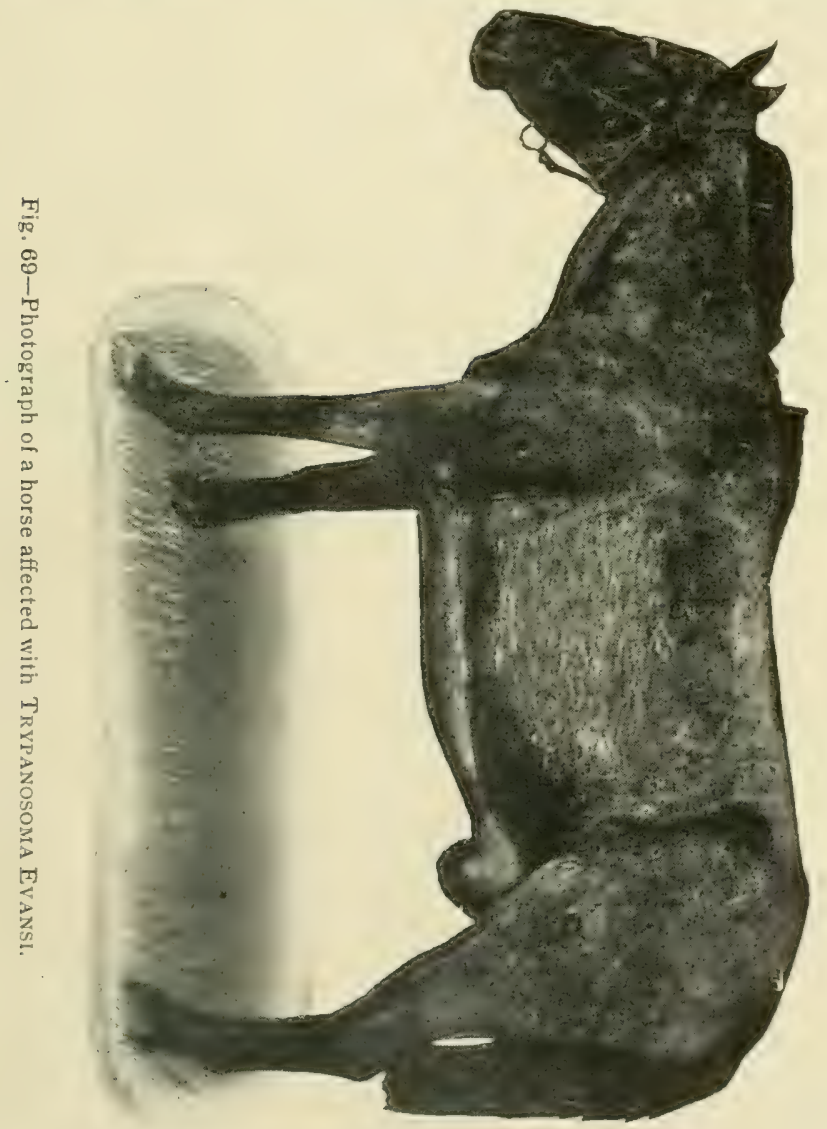

there is a loss of appetite, a stairy coat and the animal gradually becomes emaciated; swellings appear in the region of the chest, abdomen, sheath, etc: 
When these swellings are incised a serum escapes in which the protozoa can be found.

Trypanosoma Brucir (Bruce).

Distribution.-Found in Africa.

Description.-The Trypanosoma Brucii are elongated and more pointed at the flagellated end the body is slightly curved; the nucleus is located in the center, close to the surface; the centrosome is in the blunt end and is clearly separated from the flagellum. The flagellum proceeds from this end, follows the entire length of the body, and projects a distance out from the extremity, forming a hair-like appendage as in the preceding species. The protozoon measures about twenty-eight microns in length by one-half to two microns wide; if a drop of blood be drawn they can be found actively moving about in it.

Life Cycle.-The protozoon divides by simple cell division; the centrosome becomes larger and elongated, then divides into two; the flagellum becomes thickened and divides likewise into two; this is accompanied by a like division of the nucleus. The newly formed centrosome, nucleus and flagellum find their way to their respective sides; then comes the division of the protoplasm lengthwise. The two newly formed parasites now develop to full size and again divide.

Intermediate Host.-The Glossina Morsitans or tsetse fly is the transmitter of the protozoon.

Animals Infested.-The horse, ass, mule, ox and dog.

Parts Infested.-Found free in the blood.

Disease Produced.-Nagana; tsetse fly disease. 
Symptoms. - The period of incubation is about five days; the temperature may reach 106 degrees Fah. Swelling appears in various parts of the body, as the chest, abdomen or head; there is a loss of appetite, anemia and gradual emaciation.

Trypanosoma Equiperdum (Equis-horse).

Distribution.-America and Europe.

Description. - The general appearance and method of cell division does not differ from the description given in the two preceding species; the distinction between the species is largely by the symptoms and lesions produced. The protozoon measures about twenty microns long, one and one-half to two microns broad; it is a trifle shorter than the Trypanosoma Brucii.

Life Cycle.-Its mode of multiplication is the same as in the preceding species; the method of inoculation is by coition; the diseased genital organ conveyes the protozoon; the Trypanosoma is found in the blood and also in the serum from the oedematous and ulcerous parts.

Animals Infested.-The horse, ass and dog.

Parts Infested.-Primarily genital organs; later other parts.

Name of Discase.-Maladie du coit; dourine; equine syphilis.

Symptoms. - In the mare oedematus swellings appear in the vuivar region, which develop in eight to ten days after coition; in the horse, in the sheath, scrotum and penis; the skin over these organs may show eruptions, in the form of vesicles; later, after the vesicles have ruptured, white spots appear. 
The inguinal lymph glands which receive the lymph from these parts become swollen; later, fibrous degeneration may take place both in these glands and the testicles; the testicles may contain cavities of caseous pus; there may develop ulcerous patches on the penis, sheath and vulva. In later stages the nerve tissue, kidneys, lymph glands and other organs become infested.

T'rypanosoma Equinum.

Distribution.-Found in Brazil, Paraguay, Bolivia and Argentine Republic.

Discription.-This protozoon has the same general appearance as the trypanosoma Brucii, and multiplies in like manner. It measures from twenty-two to twenty-four microns long and about one and one-half microns broad.

Life Cy'cle.-It passes through the same changes as the preceding species. The animals probably becume inoculated by blood-sucking flies.

Animals Infested. - The horse and, by experimental inoculation, ox, sheep, pig and dog.

Part Infested. - The blood.

Disease Produced.-Mal de caderas; disease of hind quarters; flagellosis of equidae.

Symptoms. - High elevations of temperature; the animal becomes weak and sluggish. The weakness is greatest in the hind quarters. Later he sways from side to side; scarcely able to move; gradual emaciation; down, unable to rise; death.

Trypanosoma Lewisi (Lewis)

Distribution.-Found in Cuba and other countries. Discription. - It somewhat resembles the other 
trypanosomes and is about twenty-five microns long. and one and one-half microns broad.

Animals Infested.-Rats.

Part Infested.-The blood.

Condition Producel.-The mode of infection is supposed to be by means of lice and fleas. The rats suffer no inconvenience from this infestation, and therefore it must be considered non-pathogenic for this animal.

\section{SPOROZOA (Spore; zoon-animal).}

The class Sporozoa includes a group of singlecelled microörganisms provided with a protoplasmic cell body in which is found a nucleus. It is provided with a limiting membrane. The method of reproduction is by the formation of spore corpuscles, or the division of the nucleus and protoplasm into several parts. Three orders of this class interest us, viz., Coccidia, Sarcosporidia and Hemasporidia.

\section{Coccidium Oviforme (Coccum-a kernel).}

Synonym.-Psorospermia oviforme.

Distribution.-Found in the United States and Europe.

Description.-A single-celled animal organism, ovoid in shape, and forty to fifty microns long by twenty-two to twenty-eight microns thick. It is provided with a double limiting membrane. The nucleus is three times as large as that of an epithelial cell; it readily stains with hematoxylin.

Life Cycli-From the protoplasm of the adult Coccidium there is developed small, rounded, nucleated masses (the spores). At first the diameter measures from nine to ten microns; this body grows 
till it increases to twenty; later there is developed around this spherical mass a limiting membrane; as the development progresses the protoplasm separates from the cell wall; it then divides into two, then into four bodies called sporoblasts; each sporoblast divides into two corpuscles. Each of the corpuscles, under favorable conditions, becomes an amoeboid individual, capable of invading epithelial cells.

Animals Infested.-The ox, sheep, goat, pig, rabbit and man.

Parts Infested.-Epithelial cells of the intestinal mucous membrane and liver cells.

Name of Disease.-Coccidiosis. When the liver cells are invaded it causes coccidian hapatitis. When the intestinal epithelial cells are invaded it causes intestinal coccidiosis.

Condition Produced.-When the intestinal mucosa is infested there is a fetid diarrhoea, an elevation of temperature, loss of appetite, weakness, followed by death. On autopsy there is found a thickened, reddened mucous membrane with ulcerated patches; the mesenteric lymph glands are enlarged. If the liver is infested, sma11, round abscesses, varying in size to a hazel nut, are observed; these abscesses are filled with a thick, creamy or cheesy pus; the wall is thick and the inner surface velvety in appearance; often the liver is several times its normal size, thoroughly studded with small abscesses. The carcass will be in an emaciated condition.

Coccidium Bigeminum, Variety Canis (Bis-twice)

(Canis-dog).

Synonyms.-Tetrasporous Coccidia; Cystospermium Villarum Intestinalium Canis. 
Distribution.-Found in America and Europe.

Description. - These protozoa are elliptical microscopic bodies from twelve to fifteen microns long by seven to ten microns broad, and are found in pairs. In the center is a small granular nucleus.

Life Cycle.-The protoplasm of the parent cell divides into four elongated spores, which are capable of invading new tissues, and which develop into mature form.

Animal Infested.-The dog.

Parts Infested.-Intestines.

Condition Produced.-They are found infesting the intestinal mucosa, lodged immediately beneath the epithelial cells; they are not attributed as causing serious disturbance. They have been found in the intestinal mucosa of healthy dogs.

\section{Coccidium Perforans (Per-through)}

(Forare-to bore).

Distribution.-Reported in European countries; first reported in cattle in 1877.

Description.- Rather ovoid in shape, measuring twenty-five to thirty-five microns long and fourteen to twenty microns broad; the adult produces corpuscles which invade the tissue and develop to full adult size.

Animals Infested.-The ox, dog and rabbit.

Parts Infested.-Air passages and bowels.

Condition Produced. - Catarrhal inflammation of the upper air passage; thickening and inflammation of the mucosa of the stomach and the intestines; the mesenteric lymph glands, liver and spleen are also in a state of inflammation. The lesions all contain the coccidia. 


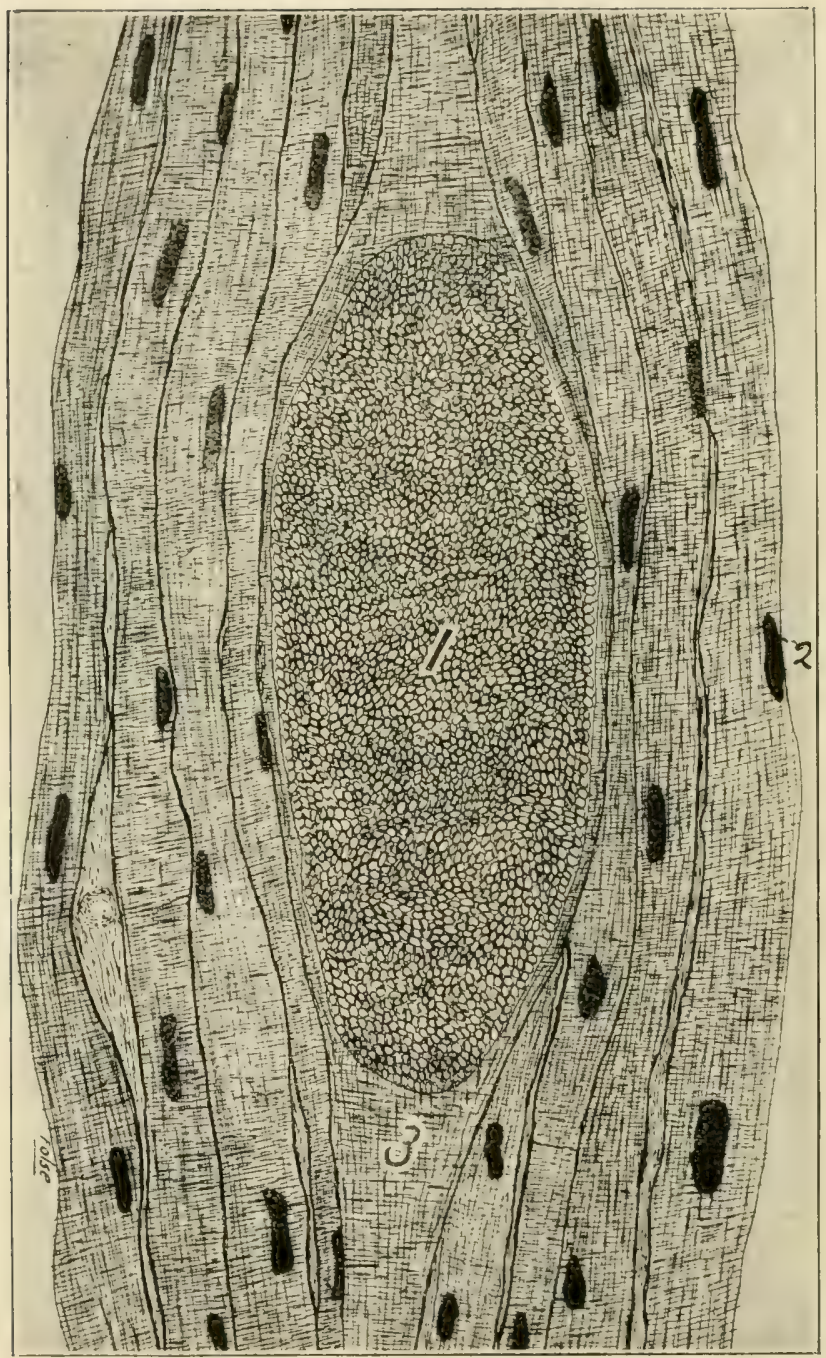

Fig. 71.-SARCocystis Miescheri. Drawing made with Camera Lucida.

1 , Longitudinal section of sarcocyst showing it enclosed in heart muscle cell. (3)

2, Nucleus heart muscle cell.

3. Loneritudinal section heart muscle cell. 


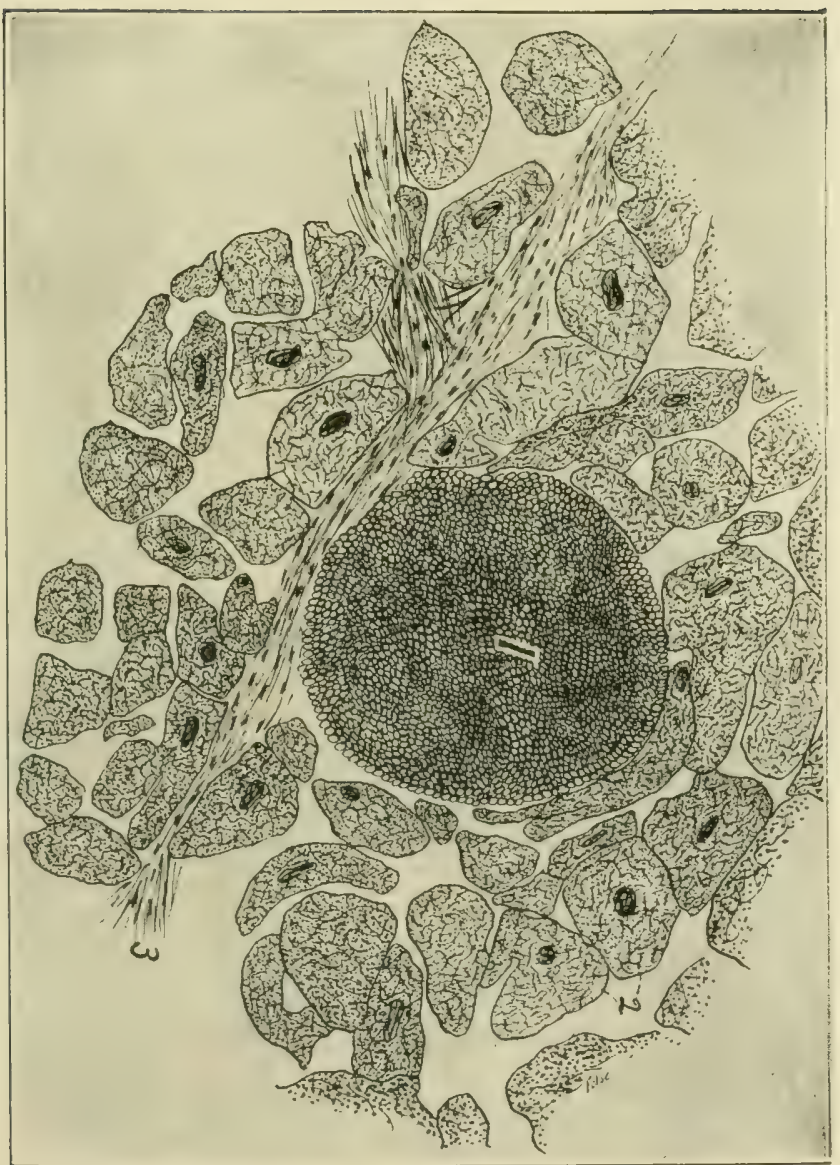

Fig. 72-SARCOCYstis Miescherl, Drawing made with Camera lucida.

1. Cross section sarcocyst. muscle cell enclosing sarcocyst ruptured.

2 , Cross section of heart muscle cell

3 , Fibrous connective tissue. 
Symptoms. - Loss of appetite, elevation of temperature, $102^{\circ}$ to $105^{\circ}$; sunken eyes; grinding of teeth ; later, fetid diarrhoea; feces may be streaked with blood; may prove fatal in one or two days, or patient may live two or three weeks.

Treatment.-Intestinal antiseptics, as eucamphol or kreso solutions.

SARCOSPORIDIA (Sporidum-a spore) (Sarx-flesh).

This order, Sarcosporidia, belongs to the class Sporozoa, and includes single-celled parasites that infest the muscle structures.

\section{Sarcocystis Miescheri (Miescher).}

Synonyms.-Utricles of Miescheri; Rainey's corpuscles.

Distribution.-Common in the United States; discovered in $18+3$ by Miescher. In sections of the oesophagus of the hog and sheep examined in the laboratory of the Kansas City Veterinary College these parasites have been found to be very common.

Description. - The adult is elongated, tapering at both ends; it measures two to three millimeters in length and eighty to two hundred microns wide; it presents a granular appearance, due to spores, and is surrounded by a limiting membrane.

Animals Infested.-The ox, pig, sheep and horse.

Parts Infested.-Muscle structures.

Conditions Produced.-The sarcocyst is located under the sarcolemma, lying longitudinally of the muscle fibre. Pigs whose muscle structures become badly infested are noted to show symptoms of weak. ness, partial paralysis, loss of appetite, unthrifty 
appearance. In a cow which was badly infested there was noted restlessness; constant getting iip and down; she presented an unthrifty appsarance; skin dry and rough; severe diarrhoea; the fecal discharge had a putrid odor; temperature $105.5^{\circ}$ Fahrenheit; pulse 108, soft and compressible; respiration shallow and hurried. She gradually grew weaker and died. Only the liver and heart were saved and studied by aid of the microscope; in these myriads of sarcocysts were found, as illustrated by Figs. 71 and 72 .

\section{Balbiania Gigantea (Balbiana).}

Distribution.-Found in Europe. As yet there is no record of their being found in the United States.

Description.-This sarcospore appears as a whitish spot and varies in size from a rye grain to a hazel nut. It has a thin outer membrane; the interior is filled with cells. In the larger bodies there is located a capsule the size of a pin-head, which contains crescent-shaped non-nucleated bodies.

Animals Infested.-The ox, sheep, pig and goat.

Parts Infested.-Most common in the oesophagus; also found in the muscles of the trunk, head, and heart.

Conditions Produced.-They may cause an effusion into the tissues. If only a few are present no harm comes from the infestation; many may cause conditions similar to that produced by the Coccidia.

\section{HEMASPORIDIA (Hemo-blood)}

(Sporidum-spore).

The order Hemasporidia belongs to the class Sporozoa, and includes the the genus Piroplasma. 


\section{Piroplasma Bigeminum (Bis-twice)}

(Geminus-twin).

Synonyms.-Pirosoma Bigeminum (soma-body), Piroplasma Bovis, Apisoma Bigeminum, Ambosporidies, Portensis Virulentissimus, Babesia Bigeminum Bovis.

Distribution.-Found in the southern part of the United States; also in other warm countries.

Description.-They are pear-shaped protoplasmic bodies three to four microns long.

Life Cycle.-The adult protozoon inhabits the red blood cell. From this pear-shaped adult is formed corpuscles which are capable of invading other cells. The pear-shaped body becomes rounded, then divided into three to five corpuscles; these corpuscles have been noted to possess amoeboid movement, and are capable of invading new red blood cells. These divide into two parts, which develop to the full sized pear-shaped bodies; the pointed ends of these protozoa are usually close together, joined with a fine film. The tick, feasting upon an infested ox, takes the infested blood cells into its intestinal tract; the piroplasma leaves the red blood cell, passes through a change in which new bodies are formed; these new corpuscles leave the intestines and migrate to the ovary; thus the egg becomes infested. These virulent protozoa are contained in the larva, and after it emerges from the egg it is capable of inoculating susceptible cattle.

Parts Infested.-The red blood cells ; may be found free in the plasma.

Name of Discase.-Texas fever; splenic fever; Spanish fever; tick fever; red water; black water; southern cattle fever; Australian tick fever. 
Condition Produced. - The liver is congested, bile thick and granular; fat is icteric (jaundice); the spleen is enormously enlarged and contents consistency of blackberry jam; kidneys congested; urine port-wine colored; cancellated portion of the bone is black. An animal so affected is unfit for food.

Symptoms. - The animal has a loss of appetite; unthrifty appearance; rise in temperature accompanied by an accelerated respiration and pulse. The back is arched; animal stays off to itself; port-wine colored urine, hence the chronic form has been called red water, or bloody murrain.

A condition produced by some species of the genus Piroplasma is called piroplasmosis.

Treatment.-In all forms of piroplasmosis of the blood stream the essential treatment would be quinine in full medicinal doses.

\section{Piroplasma Ovis (Ovis-sheep).}

Distrimution.-Found in Montana and other localities in the United States.

Description.-The protozoa is round or oval in shape and from one-tenth to one-sixth the diameter of a red blood cell. They show amoeboid movement. From one to four are found in a cell. They may also be found free in the serum.

Animals Infested.-The sheep.

Parts Infested. - The red blood cells.

Name of Disease.-Ictero-hematuria.

Condition Produced.-The disease usually runs a rapid and fatal course; the animal does not greatly lose in flesh in these acute attacks. The spleen is enlarged and contents like blackberry jam; the kid- 
neys dark and congested; the urine port-wine colored; the fat icteric; the liver congested. An animal so affected is unfit for food.

Symptoms. - The sheep at first show dullness, loss

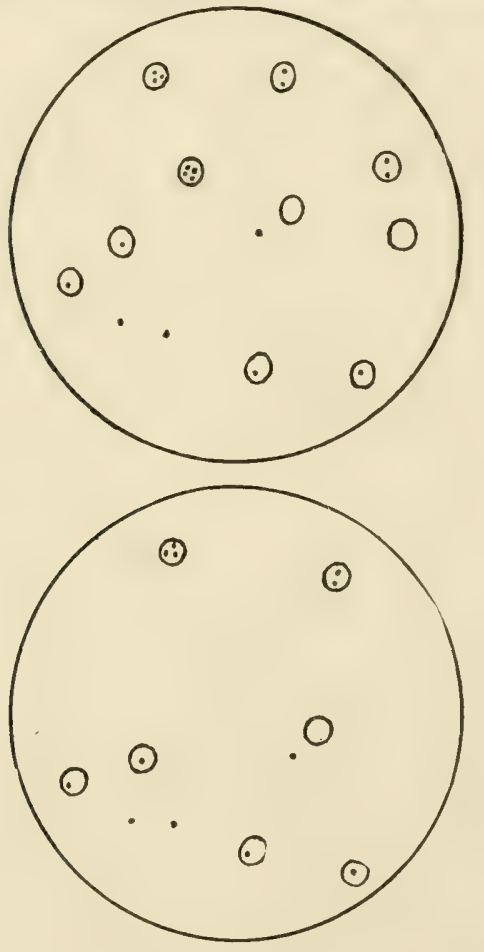

Fig. 73.-PIROPLASMA OVIS.

Showing the protozoa, some in the red blood cells, some free.

of appetite; stay apart from balance of flock; arched back; weak; elevation of temperature, pule and respiration. Swellings may be noted in the head or neck. The duration of the disease is twenty-four hours to four days. 


\section{Piroplasira Canis (Canis-dog).}

Distribution.-Found in Europe and Africa.

Description. - The protozoon is larger than the Piroplasma Bovis, when only one is found in a single red blood cell; as many as ten or twelve have been counted; when many are found they are small, rounded and may be irregular in their outline. Their amoeboid movement has been noted in the blood cells of the fresh specimens. They are noted to clongate their bodies, then contract into spherical masses. The cells present a swollen appearance and are pale in color. After the acute stage of the disease has passed, the parasite apparently ceases its movements, remains stationary and has a rounded contour.

Life Cy'cle.-The parasite multiplies in the red blood cell. The nucleus of the adult becomes elongated, then constricted in the center, finally dividing into two. The newly formed nuclei pass to the side of the cell, opposite each other; now begins the constriction of the protoplasm; finally only a film holds the two newly formed corpuscles together. These corpuscles are at first pear-shaped; later the nucleus passes to the center and the corpuscles become round. This process goes on till as many as sixteen corpuscles may be formed. The great distention of the cell caused by the corpuscles causes it to rupture. These newly formed corpuscles possess amoeboid movement and invade new cells, where they develop to full size.

Animal Infested-The dog.

Part Infested.-The red blood cell. 
Name of Disease.-Canine piroplasmosis; malig. nant malarial jaundice.

Condition Produced.-The spleen is two or three times its normal size, black and soft. The liver is congested; the bile thick and granular; the kidneys are congested and friable; the urine is port-wine colored; medulla of the bone is congested; the fat is yellow.

Symptoms. - Loss of appetite; high elevation of temperature; icteric visible mucous membranes; great prostration and finally death.

Piroplasma Equi (Equus--horse).

Distribution.-Africa, China, and Philippines.

Description. - The parasite is crescent-shaped and takes staining deeply in its center. It varies from one-half to two microns in length.

Animal Infested.-The horse.

Parts Infested. - The red blood cells.

Name of Disease.-Equine piroplasmosis ; paludism in horse.

Condition Produced.-Fat is icteric; mucous and serous membranes may be marked with petechia; the liver is engorged with blood, and yellowish in color; the kidneys are congested and softened; the lungs may be congested. Dropsical swellings may appear in chronic cases.

Symptoms. - Great depression, weakness, unsteady gait; loss of appetite; high elevation of temperature ( $103^{\circ}$ to $105^{\circ}$ Fahrenheit); accelerated respiration. The lungs may become congested and a foamy mucous discharge from the nostrils; in the latter case the respirations would be hurried and 
painful; in later stages port-wine ccioreci urine. Death occurs in acute cases in from a few hours to five or six days. Chronic cases may last two to three months.

\section{AMOEBA (Amoebas-change).}

The class amoeba includes a single-celled group of parasites that are provided with a nucleus and protoplasm and possess amoeboid movement. They infest various parts of the body.

$$
\begin{aligned}
& \text { Amoeba Parasitica (Amoebas-cliange) } \\
& \text { (Parasitus--eating beside). }
\end{aligned}
$$

Synonym.-Amoeba Principes.

Distribution.-Found in Australia; not reported in the United States.

Description.-A single-celled protozoon apparently identical with the Amoeba Principes of fresh water.

Animals Infested.-Sheep.

Parts Infested.-Feet, lips, gums and nostrils.

Symptoms.-Manifests itself as ulcerous patches on lips, gums, nostrils, and involves the sensitive structures of the foot. The granular masses found in the ulcers contain the amoeba.

Treatment.-Copperas solution or any antiseptic as a one-percent solution of kreso or creolin.

Airoeba Meleagridis.

Distribution. - Found in various parts of the United States.

Discription.-They are microscopic granular protoplasmic masses from ten to fiftecin microns in diameter.

Animal Infested.-The turkey.

Parts Infested.-Caecum and liver. 
Symptoms.-Loss of appetite; droopy; head down; diarrhoea; feathers erect; emaciation and death. Most fatal in young birds from one to four months old.

Condition Produced.-Thickening of the walls of the caecum due to inflammation as a result of the in. vasion of the protozoun. The liver is congested or inflamed, has brownish or yellowish areas of degeneration. There is a blackish discoloration of the head.

Name of Disease.-Entero-hepatitis, black head.

Treatment.-Intestinal antiseptics, as teaspoonful doses of listerine, bi-chloride of mercury solution one to a thousand, or carbolic acid one to five bundred. 


\section{CHAPTER IV.}

\section{TO PRESERVE INSECT PARASITES.}

In collecting specimens place them in a bottle containing a piece of gum camphor. After the insect is dead it can be mounted on a block of wood by means of a pin thrust through the thorax. Dark or black parasites should be mounted on a light back-ground. These can be placed in suitable bottles with moth ball or gum camphor, and will keep indefinitely. Another way is to fill the bottle with alcohol. This forms a good preservative and does not rust the pins.

\section{TO MOUNT ECTOZOA.}

1. Wash in alcohol till all dirt is removed from the parasite.

2. Place specimen in xylol for five minutes.

3. Mount in Canada balsam.

By this method lice, gnats, parts of flies, ticks, and scab parasites can be satisfactorily studied. 'Thus preserved the specimen will keep indefinitely. In mounting thick specimens the glass or rubber cells may be used. Keep slide face up, as in the summer the Canada balsam will become soft and the specimen gravitate to one side if the slide be kept edgewise.

\section{TO PRESERVE ENTOZOA.}

1. The Keiserling method may be used.

2. A four percent solution of formalin.

3. Alcohol. 
If alcohol be used then the parasite should be placed in a $25 \%$ solution for one week. Then a $50 \%$ solution for one week. Then a $75 \%$ solution for one week. Then absolute. Alcohol has a tendency to shrivel the tissues of round worms. Formalin has a tendency to expand or swell the tissues, hence some worms, as the Stephanurus Dentatus, have a tendency to rupture at the genital or anal openings, if too strong a solution be used.

For museum purposes the smaller specimens can be placed between two glass slides held together with silk thread tied together at each end and placed in an upright position in the fluid. The back slide should be covered with black shellac and allowed to dry before being used.

\section{TO STAIN AND MOUNT ENTOZOA.}

When collecting worms for laboratory study they :hould be immediately placed in the following solution :

50 parts of $70 \%$ alcohol.

50 parts aqueous solution bichloride of mercury.

A few drops acetic acid.

The parasite thus killed and preserved should then be washed in a gentle stream of water for several hours. Then place in $25 \%$ alcohol for twenty-four hours; then absolute. The parasites stain with either alcoholic eosin or picric acid stains; hematoxylin or methylene blue can be used for secondary stain if desired. After staining the desired shade (the time of which varies with the species of worm) the specimen should be clarified in xylol, oil cedar or 
oil of cloves. The first clearing agent will perhaps give the best results.

\section{PRESERVATION OF MUSEUM SPECIMENS.}

The Keiserling method gives the best results because the tissues retain their normal color. This method consists of three steps as follows :

1. Place in the following solution and leave from one to seven days, depending upon the size of the specimen :

Formalin._._._...... $200 \mathrm{cc}$

Potassium Acetate____ 30 grams

Potassium Nitrate_.... 15 grams

Water...___._._._._. $1000 \mathrm{cc}$

2. Pass the specimen through each of the following solutions, leaving it in each for twenty-four hours. This should restore the normal color:

$40 \%$ Alcohol

$60 \%$ Alcohol

$80 \%$ Alcohol

$95 \%$ Alcohol

3. Place in the following solution permanently :

Glycerine _._._._._._. $4 \mathrm{cc}$

Potassium Acetate_._._-_ 4 grams

Water. $40 \mathrm{cc}$

Mix

\section{PREPARING SPECIMENS TO BE SENT TO} THE LABORATORY.

1. Obtain specimens as fresh as possible.

2. Wash clean in water.

3. The specimen should now be placed in a four 
percent formalin solution. The receptacle for the specimen should be large enough so that it will not be crushed in taking it out.

\section{TO STAIN ANY PROTOZOA IN THE BLOOD CELL.}

1. Make smear by obtaining a drop of blood on a slide then with another slide scrape off the excess. This leaves a thin film.

2. Air dry.

3. Cover with Wright's stain. Leave for one or two minutes.

4. Add distilled water drop by drop and agitate for two minutes.

5. Wash with water until you leave the color you desire.

6. Air dry.

7. Mount in Canada balsam.

\section{TO STAIN THE TRYPANOSOMA.}

1. Obtain blood smear as above.

2. Air dry.

3. Fix by dropping the slide in alcohol for two minutes.

4. Cover with methylene blue or gentian violet one to three minutes.

5. Wash in water.

6. Air dry.

7. Mount in Canada balsam. 


\section{TO STAIN COCCIDIA, SARCOSPORIDIA OR} AMOEBA MELEAGRIDIS IN TISSUES.

THE PREPARATION OF TISSUE.

1. Secure block of tissue one-fourth inch square.

2. Place in four percent formalin solution twentyfour hours.

3. Place in alcohol and ether equal parts twentyfour hours.

4. Place in thin celloidin twenty-four hours.

5. Place in thick celloidin twenty-four hours.

6. Block on tile or wood.

7. Cut eight to ten microns thick.

TO STAIN THE PROTOZOA AND TISSUES.

1. Cover section with Delafield's hematoxylin onehalf to two minutes.

2. Wash in water.

3. Stain two minutes in a one percent aqueous eosin solution.

4. Wash.

5. Dehydrate with alcohol.

6. Clarify with olive oil, xylol or cedar oit.

7. Absorb clarifying fluid with blotting or filter paper.

8. Mount in Canada balsam.

\section{TO STAIN ENCYSTED TRICHINA.}

Prepare the block of tissue and section the same as for coccidia.

The following staining method stains the nuclei 
of the cells violet or deep blue; the cell bodies and intercellular substance red:

1. Immerse the section in hematoxylin three to five minutes.

2. Wash in water.

3. Add a drop of weak hydrochloric acid 1 minute.

4. Wash in water.

5. Aqueous eosin 2 minutes.

6. Wash in water.

7. Dehydrate in alcohol 3 minutes.

8. Clarify in clove oil.

9. Absorb clearing fluid.

10. Mount in Canada balsam. 


\section{ADDENDA.}

\section{THE CHEMISTRY OF ANIMAL PARASITES.}

Some parasites cause harm mechanically and presumably in no other way. In most of them there is more or less evidence of the formation of a poisonous substance. Little, is as yet, known of the chemistry of animal parasites or their excretions. It is known that the cells, at least in part, differ in chemical composition from the cells of the higher animal organisnus. Chitin is one substance that constitutes a large part of the outer coverings of encysted parasites as well as the outer portion of many of the worms.

Protown.-These are the single celled parasites and possess all the chemical characteristics of the celli of the higher animal bodies. These parasitic protozoa contain proteolytic enzymes. They secrete an acid which aids in the digestion. Spontaneous recovery takes place in many of the protozoan infestations which indicates the formation of anti-bodies against these organisms. Is an example:-the piroplasmosis caused by the piroplasma bigeninum.

Sarcosporida. - The body of this protozoon contains a toxic substance. A small quantity of the aqueous extract has proved fatal to rabbits. Its 
toxic property is impaired when heat at $56^{\circ} \mathrm{C}$. is applied for two hours, and is destroyed when subjected to a temperature of $85^{\circ} \mathrm{C}$. for 20 minutes. The fact that it has been found that some of the protozoa are affected by changes in osmotic pressure in. dicates that their outer covering is permeable or semipermeable.

Ncmatodes.-The intestinal parasites without a doubt give off an active antitrypsin which enable: them to live in the intestinal tract. It is also believed by some investigators that they give off a toxic substance which is absorbed from the intestinal tract and produces the constitutional disturbance noted, when in large numbers.

The fluid from these worms have proven toxic for guinea pigs. The intoxication and febrile state noted in infestation with Trichina Spiralis inclicates a toxic substance.

Cestodes.-The fluid in tape worm cysts as the Cysticercus Echinococcus, Cysticercus Tenuicollis. Cysticercus Pisiormis, Cysticercus Cerebralis and the Cysticercus Serialis have been found to be highly toxic. The symptoms this fluid produces are local irritation. inflammation and urticaria. No toxic symptoms are noted till the cyst wall is ruptured and the liberated fluid absorbed. These cysts contain a colorless fluid which has a specific gravity of from 1005 to 1015 , and contains from 1.5 to 2 per cent solids, of which, .25 to .5 per cent is sugar, about one per cent chloride of sodium, cholesterin, succinic 
acid, creatin and traces of lipase and proteids. As the cyst wall contains glycogen it is probable that the sugar comes from this source. The walls also contain chitin.

Eosinophilia.-The chemic substance of the animal parasites produce a positive chemotaxis. This affects particularly the eosinophile leucocytes. There is a local accumulation of the eosins in the tissues nearest the parasite. In some instances there is an increase in the blood. These conditions have, particularly, been noted in parasitism clue to species of the following genera: Taenia, Filaria, Uncinaria, Ascaris, Strongylus, Trichina and certain protozoa. The degree of eosinophilia depends upon the degree of infestation.

In this edition will be found illustrations for three additional parasites, viz.:

Dermacintor Riticulatus. - The parasite is found in some parts of the L'nited States especially in the central part of the rocky mountain region. This tick is about the size of the Dermacentor Electus. Its dorsal shield is large and rusty white in color. The stigmal plate differs in appearance from that of the electus. It is parasitic for cattle.

Echinorhynchus Canis.-This is a worm about onehalf inch in length. The cephalic extremity is provided with a globe shaped proboscis armed with six rows of llooklets, which regularly alternate. Its bodr presents transverse markings. It has been 
found in the small intestines of dogs in Texas. Symptoms: Exhaustion, tucked up abrlomen, muscular inco-ordination, later paralysis, loss of appetite and death.

Heterakis Papillosa.-The male measures from one-third to one-half inch in length, the female onehalf to three-fourths inch. The body is white. The mouth is surrounded by three lips. The caudal extremety of the male is provided with two spiculac of unequal length, a pre-anal sucker surrounded with a vesicular ring. It is provided with a row of papillae. The tail of the female is gradually attenuated. This parasite is found in the intestinal tract of the chicken. Often in company with the Ascaris inflexa. 


\section{N D E X.}

Acanthocephala, 77, 79, 136.

Acari, 42.

Acariasis, 42.

Acaridae, 10, 13, 14.

Acarina, 10, 13, 41.

Acephalocyst, 163, 164.

Achorion Keratophagus, 15, 74.

Achorion Schonleinii, 15, 74.

Actinomyces Bovis, 15, 75.

Actinomycosis, 75 .

Air Sack Mite, 57.

Amblyomma Americanum, 70.

Amblyomma Unapuncta, 70.

Ambosporidies, 188.

American Liver Fluke, 143.

Amoeba, 193.

Amoeta Meleagridis, 174, 193.

Amoeba Parasitica, 174, 193.

Amoeba Principes, 193.

Amplistoma Cervi, 79, 146.

Amphistoma Conicum, 146.

Anchylostoma Canis, 126.

Anchylostoma Stenocephala, 129 .

Anchylostoma Trigonocephala, 126.

Annelida, 76, 77.

Aneurism, Verminous, 111.

Anopheles Punctipennis, 12.

Apiosoma Bigeminum, 188.

Arachnida, 10, 13, 41 .

Argas Americanus, 63.

Argas Miniatus, - 15, 63.

Argasidae, 10, 15, 63.

Armed Sclerostoma, 109.

Armed Taenia, 148.

Arsenical Dip, 58.

A-thropoda, 10, 12.

Ascaridae, 76, 78, 89.

Ascari, Bovis, 91.

Ascaris Inflexa, 78, 95.

Ascaris Lumbricoides, 92.

Ascaris Marginata, 78, 93.
Ascaris Megalocephala, 78, 89.

Ascaris Mystax, 78, 94.

Ascaris Ovis, 78, 91.

Ascaris Suilla, 78, 92.

Ascaris Suis, 92.

Ascaris Vituli, 78, 91.

Auricular Scabies, 56.

Australian Fever Tick, 69.

Australian Tick Fever, 188.

Babesia Bigeminum Bovis, 18.

Balbiania Gigantea, 174, 187.

Beef Measles, 154.

Bird Flea, 31.

Black Head, 194.

Black Water, 68, 188.

Blood Fluke, 147.

Bloody Murrain, 189.

Blow Fly, 21.

Blue Bottle Fly, 21.

Boophilus Ainnulatus, 15, 67.

Boophilus Australis, 15, 67.

Boophilus Bovis, 67.

Bot Fly of Horse, 26, 27.

Bot Fly of $\mathrm{Ox}, 30$.

Bot Fly of Sheep, 28.

Bothriocephalidae, 77, 80, 172.

Bothriocephalus Latus, 80 , 172.

Breeze Fly, 19.

Broad Nosed Ox Louse, 36.

Bronchial Strongylosis, 100.

Buffalo Gnat, 18.

Calliphora Vomitoria, 21.

Canine Piroplasmosis, 192.

Carnivorous Sarcophagus, 22.

Castor Bean Tick, 66.

Cat Flea, 32.

Cayor Fly, 21.

Cephalemyia Ovis, 28.

Cercaria, 141.

Cestoda, 77, 79, 149. 
Chigger, 10, 43, 44.

Chicken Mite, 42.

Chicken Tick, 63.

Circinate Ringworm, 73.

Coccidia, 174.

Coccidia, Staining, 199.

Coccidian Hepatitis, 182.

Coccidiosis, 182.

Coccidium Bigeminum Variety Canis, 174, 181.

Coccidium Oviforme, 174 181.

Coccidium Perforans, 174, 183.

Coenurus Cerebralis, 166.

Coenurus Serialis, 169.

Colic, Thrombo-Embolic, 109.

Compsomyia Macellaria, 21.

Conical Stomach Fluke, 145.

Cryptocystis Pulecidae, 170.

Cryptocystis Trichodectis, 170.

Culex Pipiens, 12.

Culex Pungens, 12.

Culicidae, $10,12$.

Curved Oxyuris, 96.

Cysticercus Bovis, 154.

Cysticercus Cellulosae, 152.

Cysticercus Coenurus, 166.

Cysticercus Echinococcus, 164.

Cysticercu. Fasciolaris, 171.

Cysticercus Pisiformis, 168.

Cysticercus Tenuicollis, 162.

Cystospermium Villarum Intestinalium Canis, 182.

Cytodites Nudus, 14, 57.

Demodecidae, 10, 14, 59.

Demodex Folliculorum Variety Canis, 14, 60 .

Demodex Folliculorum Variety Suis, 14, 61.

Dermacentor Americanum, 15, 69.

Dermacentor Electus, 69.

Dermanyssus Gallinae, 13, 42.

Diptera, 10, 12, 16.

Discophori, 77.

Disease of Hindquarters, 180.

Distoma Americanus, 79, 143.
Distoma Hepaticum, 79, 139.

Distoma Lanceolata, 79, 145.

Distoma Magna, 143.

Distoma Pulmonale, 146.

Distoma Ringeri, 146.

Distoma Texicanum, 143.

Distoma Westermanii, 146.

Distomiasis, 139.

Dochmius Cernua, 125.

Dochmius Stenocephala, 129.

Dochmius Trigonocephala, 126.

Dog Flea, 32.

Dog Louse, 38.

Dog Tick, 69.

Dourine, 179.

Ear Tick, 65.

Echinococcosis, 164.

Echinococcus Alveolaris, 164.

Echinococcus Multilocularis, 164.

Echinococcus Polymorphus, 164.

Echinococcus Veterinorum, 164.

Echinorhynchus Gigas, 79, 136.

Ectozoa, 9.

Ectozoa, Classification, 11.

Entero-Hepatitis, 194.

Entozoa, 9.

Equine Piroplasmosis, 192.

Equine Syphilis, 179.

Fasciola Americanus, 144

Fasciola Hepaticum, 139.

Fasciola Magna, 143.

Fasciolidae, 77, 79, 139.

Fever Tick, 67.

Filaria Cervina, 78, 87.

Filaria Equina, 86.

Filaria Immitis, 78, 87.

Filaria Labiato-Papillosa, 87.

Filaria Oculi, 87.

Filaria Oculi Equina, 87.

Filaria Papillosa, 78, 86.

Filaridae, 67, 77, 82.

Flagellata, 174, 175.

Flagellosis of Equidia, 180. 
Flea, 31.

Flesh Fly, 22.

Flies, 16.

Flukes, 139.

Foot Scab Parasite, 55.

Fungi, 15, 72.

Gad Fly, 26.

Gamasidae, 10, 13.

Gape Worm, 116.

Gapes, 116.

Gastric Distomiasis, 139.

Gastric Strongylosis, 99.

Gastrophilus Equi, 12, 26.

Gastrophilus Hemorrhoidalis, $12,27$.

Gid, 166.

Glossina Morsitans, 12, 23.

Gnathobdellidae, 77.

Goat Louse, 36.

Gongylonema Scutata, 82.

Gray Carnivorous Fly, 22.

Green-Head Horse Fly, 20.

Grub, 28.

Grub Fly, 30.

Grub in Head, 28.

Harvest Bug, 43.

Head Maggot, 28.

Heel Fly, 30.

Hemasporidia, 174, 187.

Hematobia Serrata, 12, 24.

Hematopinus, 33, 35.

Hematopinus Asini, 13, 35

Hematopinus Eurysternus, 13, 36.

Hematopinus Irritans, 36.

Hematopinus Macrocephalus, 35.

Hematopinus Piliferus, 13, 38.

Hematopinus Stenopsis, 13, 38.

Hematopinus Suis, 13, 36 .

Hematopinus Urius, 36.

Hematopinus Tenuirostris, 36 .

Hematopinus Vituli, 13, 36.

Hemiptera, 10, 13.

Haemonchus Contortus, 107.
Haemopis Sanguisuga, 77, 80 .

Hepatic Distomiasis, 139.

Heterakis Inflexa, 95.

Hippoboscidae, 10, 12 .

Hog Louse, 35.

Honey-Comb Ringworm, 74.

Hoose, 104.

Hook Worm, 124, 125, 126.

Horn Fly, 24.

Horse Bot Fly, 26, 27.

Horse Fly, 19, 20.

Horse Leech, 80.

Horse Louse, 35, 36.

House Fly, 20.

Human Flea, 31.

Husk, 104.

Hypoderma Lineata, 12, 30.

Ictero-Hematuria, 189.

Insecta, 10, 12, 15.

Intestinal Coccidiosis, 182

Intestiual Strongylosis, 99.

Intestinal Trichinosis, 134.

Itch Mite, 47.

Ixodes Bovis, 67.

Ixodidae, $10,15,66$

Ixodes Kicinus, 14, 66.

Kidney Worm, 115.

Lard Worm, 115.

Larva in Head, 28.

Leech, 80.

Leptus Irritans, 44

Lice, 33.

Linguatula Rhinaria, 15, 71.

Linguatula Taenoides, 71.

Linguatulidae, $10,15,71$.

Lioatheidae, $10,13,40$.

Liver Fluke, 139.

Liver Rot, 142.

Lone Star Tick, 70.

Long-Nosed Ox Louse. 36

Long-Tailed Oxyuris, 97.

Louse Fly, 25.

Lucilia Macellaria, 12, 21.

Lumbricoid of Horse, 89.

Lung Fluke, 146. 
Naggot, 21.

Maladie Du Coit, 179.

Mal de Caderas, 180.

Malignant Malarial Jaundice in Dog, 192.

Mange, 47.

Mange Mite, 47.

Margaropus Annulatus, 67.

Marginate Tapeworm, 160.

Maw Worm, 93, 96.

Measles in Swine, 152

Measly Beef, 154.

Melophagus Ovinus, 12, 25.

Menopon Biseriatum, 13, 41.

Menopon Pallidum, 13, 41.

Mite, 43.

Monadidae, 174.

Moniesia Alba, 158.

Moniesia Planissima, 156.

Mosquitoes, 16.

Mourning Horse Fly, 19.

Musca Domestica, 11, 20.

Musca Vomitoria, 11, 21.

Muscidae 1012.

Muscular Trichinosis, 134.

Mycotic Stomatitis, 74.

Nagana, 23, 178.

Nemathelmintha, 76, 77.

Nematoda, 76, 77, 81 .

Nodular Disease, 122.

Non-Psoric Acariasis, 42.

Oesophagostoma Columbianum, 78, 121.

Oesophagostoma Dentatum, 79,123 .

Oesophagostoma Inflatum, $78,118$.

Oesophagostoma Subulatum, 123.

Jesophagostome of Columbia. 121.

Oesophagostomiasis, 98 .

Oestridae, 10, 11.

Oestrus Bovis, 29.

Oestrus Equi, 26.

Oestrus Hemorrhoidalis, 27.

Oestrus Lineata، 29.
Oestrus Ovis, 12, 28.

Oidium Albicans, 74.

Urnithodoros Megnini, 15, 64.

Otacariasis, 56.

Ox Gad Fly, 30.

Ox Louse, 35, 38.

Oxyuris Curvula, 78, 96.

Oxyuridae, 76, 78, 95.

Oxyuris Mastigodes, 78, 97.

Palisade Worm, 109.

Paludism in Horse, 192.

Paper Skin, 104.

Paragonimus Westermanii, 79.

Paramphistomidae, 77, 79.

Parasite, 9.

Parasitic Otitis, 56.

Parasitism, 9.

Pediculidae, 10, 13 .

Pentastoma Taenoides, 71.

Plilopteridae, 10, 13.

Phthiriasis, 33.

Pin Worm, 95, 96.

Piroplasma Bigeminum, 68, 174, 188.

Piroplasma Bovis, 188.

Piroplasma Canis, 174, 191.

Piroplasma Equi, 174, 192.

Piroplasma Ovis, 174, 189.

Piroplasmosis, 189.

Pirosoma Bigeminum, 188.

Pit-Headed IVorm, 172.

Plathelmintha, 77, 79.

Plerocercoid, 172.

Pork, Measly, 152.

Portensis Virulentissimus, 188.

Protozoa, 9, 174.

Psoric-Acariasis, 42.

Psorospermosis, 181.

Psoroptes, 45.

Psoroptes Communis Variety Bovis, 14, 52.

Psoroptes Communis Variety Caprae, 14.

Psoroptes Communis Variety Equi, 14, 50.

Psoroptes Communis Variety Ovis, 14, 52.

Psorospermia Oviforme, 181. 
Pulex Avium, 13, 33.

Pulex Irritans, 13, 31.

Pulex Serraticeps, 13, 33.

Pulicidae, 12.

Pulmonary Distomiasis, 139. 146.

Pulmonary Strongylosis, 100.

Rainev's Corpuscles, 186.

Ray Fungus, 75 .

Red Mange, 62.

Red Water, 68, 188.

Red-Tail Bot Fly, 27.

Redia, 141.

Renal Strongylosis, 99, 115.

Rhipicephalus Sanguineus, 15, 66.

Rhyncoprium Spinosum, 65.

Ring IVorm, 73.

Rot, $142,176$.

Round Worm, 81.

Saccharomyces Albicans, 15, 74.

Sarcocystis Miescheri, 174, 186.

Sarcophaga Carnaria, 12, 22.

Sarcoptes, 45.

Sarcoptes Scabei Variety Canis, 13, 48.

Sarcoptes Scabei Variety Caprae, 14, 49.

Sarcoptes Scabei Variety Equi, 13, 47.

Sarcoptes Scabei Variety Ovis, 14, 49.

Sarcoptes Scabei Variety Suis, 14, 49.

Sarcoptes Minor Variety Cati, 14.

Sarcoptes Mutans Variety Gallinae, 14, 50.

Sarcoptidae, 11, 13, 45.

Sarcosporida, 174, 186.

Saw Fly, 24.

Scabies, 47.

Scab Parasites, 11, 47.

Scaly Legs, 50 .
Schistosoma Bovis, 79, 147

Schistosomidae, 77, 79, 147.

Sclerostomá Equinum, 109.

Sclerostoma Hypostomum, 78. 114.

Sclerostoma Pinguicola, 115.

Sclerostoma Tetracanthum, $78,113$.

Sclerostoma Trachealis, $11 \kappa$.

Sclerostomiasis, 98.

Scolex, 148, 168.

screw Worm, 20.

Sheep Bot, 28

Sheep Dip, 58.

Sheep Gad Fly, 28.

Sheep Louse, 36, 38.

Sheep Tick, 25.

Simondsia Paradoxa, 78, 85

Simuliidae, 10, 12.

Simulium Pecuarum, 12, 16.

Siphonaptera, 10, 12 .

Southern Cattle Fever, 68, 188

Spanish Fever, 68, 188.

Splenic Fever, 188.

Spider Tick, 65.

Spinose Tick, 65.

Spiroptera Megastoma, 77,82.

Spiroptera Microstoma, 77, 83 .

Spiroptera Sanguinolenta, 78, 84.

Spiroptera Strongylina, 78, 84.

Spiroptera Scutata, 77, 82.

Sporocyst, 141.

Sporozoa, 174, 181.

Stable Fly, 25.

Stegomia Fasciata, 12

Stephaniasis, 98.

Stephanurus Dentatus, 78, 115.

Stinging Fly, 25.

Stomach Flukes, 146.

Stomoxys Calcitrans, 12, 25.

Stomoxys Stabulans, 25.

Striped Hypoderma, 30.

Strobilus, 149.

Strongylidae, 76, 78, 97.

Strongylosis, 98 
Strongylosis Bronchial, 99, 100.

Strongylosis Gastric, 99.

Strongylosis Intestinal, 99.

Strongylosis Renal, 99.

Strongylosis Vascular, 99.

Strongylus Armatus, 78, 109.

Strongylus Arnfieldi, 78, 101.

Strongylus Contortus, 78, 107.

Strongylus Convolutus, 108.

Strongylus Elongatus, 105.

Strongylus Filaria, 78, 104.

Strongylus Micrurus, 78, 104.

Strongylus Ostertagi, 78, 108.

Strongylus Ovis Pulmonalis, 105.

Strongylus Paradoxıs, 78, 105 .

Strongylus Pulmonalis, 78, 104.

Strongylus Pusillus, 78, 106.

Strongylus Rufescens, 78, 105.

Stronglyus Vasorum, 78, 112.

Sturdy, 166.

Surra, 176.

Symbiotes, 45.

Symbiotes Communis Variety Bovis, 14, 55.

Symbiotes Communis Variety Canis, 14, 56.

Symbiotes Communis Variety Caprae, 14, 56.

Symbiotes Communis Variety Equi, 14, 54.

Symbiotes Communis Variety Ovis, 14, 55.

Syngamosis, 98, 117

Syngamus Bronchialis, 116.

Syngamus Trachealis, 78, 116.

Tabanidae, 10, 12 .

Tabanus Atratus, 12, 19.

Tabanus Lineola, 12, 20.

Taenia Alba, 79, 158.

Taenia Armata, 150.

Taenia Armed, 148.

Taenia Canina, 80, 170.

Taenia Coenurus, 79, 165.

Taenia Crassicollis, 80, 171.
Taenia Cucumerina, 170.

Taenia Denticulata, 79.

Taenia Echinococcus, 79, 162.

Taenia Expansa, 79, 156.

Taenia Fimbriata, 79, 158.

Taenia Mamillana, 79, 155.

Taenia Marginata, 79, 160.

Taenia Mediocanellata, 152.

Taenia Perfoliata, 79, 154.

Taenia Plicata, 79, 154

Taenia Serialis, 80, 169.

Taenia Saginata, 79, 152.

Taenia Serrata, 80, 168.

Taenia Solium, 79, 50.

Taenia Unarmed, 148.

Taeniasis, 148 .

Taenidae, 79, 149.

Tape Worm, 148.

Tetrasporous Coccidia, 182.

Texas Fever, 68, 188.

Texas Fever Tick, 67.

Thrombo-Embolic Colics, 111. Thrush, 74 .

Thysanosoma Actinioides, 158.

Tick Fever, 68, 188.

Tinea Favosa, 74.

Tinea Tonsurans, 73.

Trematoda, 77, 79.

Trichina Spiralis, 79, 132.

Trichina, Staining, 199.

Trichinosis, 134.

Trichocephalus Affinis, 79, 131.

Trichocephalus Crenatus, 79. 132.

Trichocephalus Depressiusculus, 79, 130.

Trichodectes, 33, 38.

Trichodectes Latus, 13, 40.

Trichodectes Pilosus, 13, 38.

Trichodectes Scalaris, 13, 38.

Trichodectes Spherocephalus, 13. 39.

Trichodectes Subrostratus, 13, 40.

Trichophyton Tonsurans, 15, 73 .

Trichotrachelidae, 76, 79, 130.

Trombidiidae, 10, 13. 
Trombidium Holosericeum, Uncinaria Radiata, 79, 128. $13,43$.

Trematoda, 77.

Trypanosoma Brucii, 174, 178. Trypanosoma Equinum, 174, 180.

Trypanosoma Equiperdum, $174,179$.

Trypanosoma Evansi, 174, 175 .

Trypanosoma Lewisi, 174, 180.

Trypanosoma, Staining, 198.

Trypanosomidae, 174.

Trypanosomiasis, 175.

Tse Tse Fly, 23.

Tse Tse Fly Disease, 178.

Turnsick, 166.

Unarmed Taenia, 148.

Uncinaria Canina, 126.

Uncinaria Cernua, 79, 125.

Uncinaria Stenocephala, 79, 129.

Uncinaria Trigonocephala, 126.

Uncinariosis, 98.

Utricles of Miescheri, 186.

Vascular Distomiasis, 139.

Vascular Strongylosis, 99.

Vermes, 76, 77.

Verminous Bronchitis, 100.

Verminous Pneumonia, 100.

Verminous Thrombosis, 111

Warble Fly, 30.

Water Brain, 166.

Whip Worm, 130, 132.

Wire Worm, 107.

Wood Tick, 69. 







\section{LIBRARY OF CONGRESS |||||||||||||||||||||||||||||||| $\mid$
00028407099}

